"SILICOZIRCONATOS DE LITIO: SÍNTESIS, CARACTERIZACIÓN Y EVALUACIÓN DE SUS PROPIEDADES COMO CERÁMICOS GENERADORES DE TRITIO" TESIS QUE PRESENTA: HERIBERTO PFEIFFER PEREA PARA OBTENER EL GRADO DE: DOCTOR EN CIENCIAS

Universidad Autónoma Metropolitana Unidad Iztapalapa División de Ciencias Básicas e Ingeniería Departamento de Química 


\title{
Silicozirconatos de Litio: Síntesis, Caracterización y Evaluación de sus Propiedades como Cerámicos Generadores de Tritio
}

\author{
Tesis que Presenta: \\ Heriberto Pfeiffer Perea
}

Para Obtener el Grado de:

Doctor en Ciencias

Universidad Autónoma Metropolitana

División de Ciencias Básicas e Ingeniería

Iztapalapa, México D. F.

Enero, 2001 
El presente trabajo de tesis se llevó a cabo en las instalaciones de la Universidad Autónoma Metropolitana-Iztapalapa (UAM-I), del Instituto Nacional de Investigaciones Nucleares (ININ) y del Laboratorio de Simulación de Materiales, de la Universidad Nacional Autónoma de México (UNAM), bajo la dirección de los Doctores Pedro Bosch y Silvia Bulbulian. Se contó con apoyo económico del Consejo Nacional de Ciencia y Tecnología (CONACyT) y del ININ. Agradezco a estas instituciones el apoyo y facilidades otorgadas. 


\section{Dedicatorias}

Agradezco a Dios por permitirme

llegar a este momento.
A Claudia, gracias por ayudarme y estar a mi lado siempre.
A mis padres, Heriberto y Ma. del Carmen, porque a ustedes les debo lo que soy.

Arlette, sabes que en todo momento cuentas conmigo. 


\section{Agradecimientos}

Agradezco al Dr. Pedro Bosch y la Dra. Silvia Bulbulian por haber aceptado el asesorarme en este trabajo, pero sobre todo por su amistad, la cual espero conservar por siempre.

A los doctores Patricia Quintana, Armando Domínguez, Juan Méndez y Marcos Solache, por haber formado parte de este trabajo como sinodales y el haber enriquecido al mismo con sus comentarios y sugerencias.

A todo el Departamento de Química del Instituto Nacional de Investigaciones Nucleares (ININ) por su ayuda y amistad.

Al Departamento de Química de la Universidad Autónoma Metropolitana Iztapalapa, por las facilidades para la realización de este trabajo. En especial a Victor $\mathrm{H}$. Lara por su ayuda.

Al Dr. Luis Javier Alvarez y al Dr. Jorge Sanchez, así como a todo el Laboratorio de Simulación de Materiales de la UNAM por el apoyo y ayuda para la realización de la parte de dinámica molecular de este trabajo.

Al Dr. José Antonio Odriozola de la Universidad de Sevilla, por aceptarme en su laboratorio para una estancia doctoral.

A mis amigos, Ernesto, Guillermo, Hugo, Juan Luis y Mauricio. A todos ustedes y sus familias por esos grandes momentos que hemos pasado juntos, y los que faltan. 


\section{ÍNDICE}

Introducción

Capítulo I Generalidades 5

1.1 Fusión nuclear 6

1.2 Producción de tritio $\quad 8$

1.3 Reactor de fusión nuclear 9

1.4 Materiales cerámicos generadores de tritio 11

$\begin{array}{ll}1.5 \text { Silicozirconatos de litio } & 14\end{array}$

$\begin{array}{ll}\text { 1.5.1 } \mathrm{Li}-\mathrm{ZrSiO}_{4} & 14\end{array}$

$\begin{array}{ll}\text { 1.5.2 } \mathrm{Li}_{2} \mathrm{ZrSi}_{6} \mathrm{O}_{15} & 15\end{array}$

$\begin{array}{ll}1.6 \text { Objetivos } & 16\end{array}$

Capítulo II Metodología 17

$\begin{array}{ll}2.1 \text { Reactivos equipos e instalaciones } & 18\end{array}$

2.2 Sintesis $\quad 20$

$\begin{array}{ll}2.2 .1 \mathrm{Li}_{2} \mathrm{ZrO}_{3} & 21\end{array}$

$\begin{array}{ll}2.2 .2 \mathrm{Li}_{-} \mathrm{ZrSiO}_{4} & 23\end{array}$

2.2.3 $\mathrm{Li}_{2} \mathrm{ZrSi}_{6} \mathrm{O}_{15} \quad 24$

2.3 Técnicas de irradiación y conteo de tritio 25

2.4 Cerius $^{2}$ (Modelos numéricos) - 26

$\begin{array}{ll}2.5 \text { Dinámica molecular } & 27\end{array}$

Capítulo III Resultados y Discusión 29

3.1 Efecto del pH en los alcóxidos de zirconio 30

3.1.1 Identificación de los compuestos (XRD) 30

$3.2 \mathrm{Li}-\mathrm{ZrSiO}_{4}$

3.2.1 Características físicas $\quad 34$

3.2.2 Identificación de compuestos (XRD) 34

3.2.3 Composición superficial (XPS) 36

3.2.4 Identificación de litio (EELS) 39 
3.2.5 Comportamiento térmico (TGA) 40

3.2.6 Área superficial (BET) 41

3.2.7 Morfología de los cristales (SEM)

3.2.8 Análisis numérico $\left(\right.$ Cerius $^{2}$ ) 42

$3.3 \mathrm{Li}_{2} \mathrm{ZrSi}_{6} \mathrm{O}_{15}$

3.3.1 Características fisicas $\quad 45$

3.3.2 Identificación de compuestos (XRD) 46

3.3.3 Identificación de compuestos (FTIR) 49

3.3.4 Comportamiento térmico (TGA) 50

3.3.5 Área superficial (BET) 51

3.3.6 Morfología de los cristales (SEM)

3.4 Dinámica molecular del $\mathrm{Li}_{2} \mathrm{O}$

3.4.1 Potencial Li-O

3.4.2 Estructura $\quad 59$

3.4.3 Difusión de litio y de oxígeno 61

3.4.4 Difusión del tritio $\quad 66$

3.5 Irradiación de los silicozirconatos de litio 68

3.5.1 Dosis de radiación $\quad 68$

$\begin{array}{ll}\text { 3.5.2 Daños por radiación } & 69\end{array}$

3.5.2.1 Características físicas $\quad 69$

3.5.2.2 Identificación de compuestos (XRD) 69

3.5.2.3 Área superficial (BET) $\quad 70$

3.5.2.4 Morfología de los cristales (SEM) $\quad 71$

3.5.3 Producción de tritio $\quad 72$

$\begin{array}{ll}\text { Capítulo IV Conclusiones } & 78\end{array}$

$\begin{array}{ll}\text { Bibliografía } & 81\end{array}$ 


\section{Introducción}




\section{Introducción}

La generación de tritio es fundamental para la obtención de energía mediante la fusión nuclear. En efecto, la fusión nuclear del deuterio $\left(\mathrm{H}^{2}\right)$ con el tritio $\left(\mathrm{H}^{3}\right)$, ambos isótopos del hidrógeno, es la más utilizada en los reactores experimentales de fusión termonuclear.

Los generadores de tritio utilizados en los reactores de fusión termonuclear son materiales cerámicos que contienen litio, el cual al ser irradiado con neutrones térmicos se fisiona para producir el tritio. Para que un material cerámico de litio sea considerado útil como cerámico de recubrimiento dentro de los reactores de fusión nuclear, debe cumplir con los siguientes requisitos: ser un buen generador de tritio, no formar otros radioisótopos además del tritio, ser compatible con otro tipo de materiales para formar blindajes sólidos y estables en condiciones de operación extremas, y finalmente, debe ser estable fisica, química y mecánicamente a altas temperaturas.

Aún no se ha encontrado un cerámico de litio que resista las severas condiciones imperantes en los reactores de fusión termonuclear en operación. En la actualidad se estudian como posibles candidatos, entre otros, los aluminatos de litio, los silicatos de litio, los zirconatos de litio y los titanatos de litio. El metasilicato de litio $\left(\mathrm{Li}_{2} \mathrm{SiO}_{3}\right)$ y el metazirconato de litio $\left(\mathrm{Li}_{2} \mathrm{ZrO}_{3}\right)$ presentan las siguientes características: el $\mathrm{Li}_{2} \mathrm{SiO}_{3}$ es el cerámico de litio a través del cual se extrae más fácilmente el tritio, mientras que el $\mathrm{Li}_{2} \mathrm{ZrO}_{3}$ es el cerámico de litio que posee mayor estabilidad térmica (1673 K). La difusión, así como el rendimiento de extracción del tritio generado en los cerámicos de litio, son dos de las características de mayor importancia en este tipo de materiales. En efecto, el tritio al ser parte del combustible del reactor de fusión nuclear, se debe recolectar e inyectar en el plasma del reactor para que se lleve a cabo la reacción de fusión. De igual manera, la estabilidad térmica es de gran importancia por las condiciones mencionadas anteriormente. En este trabajo se pretende encontrar un material cerámico de litio que tenga ambas cualidades; la estabilidad térmica de los zirconatos de litio y la posibilidad de extraer el 
tritio con eficiencia de los silicatos de litio. Por ello se decidió estudiar compuestos que además de litio contengan silicio y zirconio en su estructura.

Por lo tanto, el objetivo de este trabajo es llevar a cabo la síntesis de diferentes silicozirconatos de litio por el método sol-gel, así como la evaluación de sus propiedades para su uso como posibles generadores de tritio. Los cerámicos de litio estudiados en este trabajo son el silicozirconato de litio $\left(\mathrm{Li}_{2} \mathrm{ZrSi}_{6} \mathrm{O}_{15}\right)$ y el zircón dopado con litio ( $\left.\mathrm{Li}-\mathrm{ZrSiO}_{4}\right)$. Para dopar el zircón se usaron diferentes razones molares del Li:Zr.

En el capitulo I se presentan generalidades acerca de los reactores de fusión termonuclear, de los diferentes cerámicos de litio estudiados y finalmente las características y las propiedades del $\mathrm{Li}_{2} \mathrm{ZrSi}_{6} \mathrm{O}_{15}$ y del $\mathrm{Li}-\mathrm{ZrSiO}_{4}$.

En el capítulo II se describen las técnicas utilizadas para la sintesis, la caracterización y la extracción de tritio de los cerámicos en estudio. En este capítulo también se presenta un resumen de los diferentes métodos numéricos empleados en el presente trabajo.

El capítulo III presenta los resultados y la discusión de la síntesis, la caracterización y la extracción de tritio de los cerámicos en estudio. La composición de las muestras puede variar al modificar las condiciones de síntesis. A partir de un estudio previo del efecto del $\mathrm{pH}$ en la sintesis sol-gel del metazirconato de litio $\left(\mathrm{Li}_{2} \mathrm{ZrO}_{3}\right)$, se establecieron las condiciones más adecuadas en la síntesis de dichos cerámicos. También se presenta la caracterización del $\mathrm{Li}_{2} \mathrm{ZrSi}_{6} \mathrm{O}_{15}$ y del $\mathrm{Li}-\mathrm{ZrSiO}_{4}$.

En los reactores de fusión nuclear, los materiales cerámicos estarán expuestos a radiaciones y choques con diversos átomos y partículas subatómicas, lo cual les puede causar daños o cambios estructurales. Por lo anterior, en el capitulo III se estudió la estabilidad de los compuestos ante un campo de radiación mixto de neutrones y radiación $\gamma$. 
Para determinar las condiciones más adecuadas de difusión y de extracción de tritio, previo al estudio de la extracción de tritio, se hizo un estudio de dinámica molecular en un compuesto muy sencillo de litio, el óxido de litio $\left(\mathrm{Li}_{2} \mathrm{O}\right)$. En este capitulo se presentan también los resultados experimentales del estudio de extracción de tritio en los cerámicos de interés. Así mismo se hizo un estudio comparativo de la extracción de tritio con otros cerámicos de litio conocidos.

En el capitulo IV se presentan las conclusiones del trabajo. Se hace una evaluación de la sintesis, de la caracterización y de las propiedades del $\mathrm{Li}_{2} \mathrm{ZrSi}_{6} \mathrm{O}_{15}$ y del $\mathrm{Li}-\mathrm{ZrSiO}_{4}$ como cerámicos de litio generadores de tritio utilizables en los reactores de fusión termonuclear. 


\section{Capítulo I} Generalidades 


\section{Capitulo I Generalidades}

\subsection{Fusión nuclear}

En los próximos años se requerirá en el mundo de una mayor cantidad de energía ambientalmente aceptable y a un costo económico. Aunque probablemente se mejore la eficiencia en el consumo de energía, en el futuro aumentará substancialmente la demanda de energía. Los indicadores actuales muestran que el costo de la electricidad, ambientalmente limpia generada a partir de la fusión nuclear será comparable al costo de la energía de fisión o de la electricidad derivada de los combustibles fósiles. En los próximos años las fuentes tradicionales de energía se volverán más caras, mientras que las nuevas tecnologías, entre las cuales se encuentra la fusión nuclear, se convertirán en tecnologías accesibles de costo razonable [D'Haeseleer, 1999].

Es más, la fusión nuclear libera una gran cantidad de energía y podría ser una posible solución de los problemas energéticos del futuro. En una reacción de fusión nuclear, a partir de dos núcleos ligeros, se forman núcleos más pesados cuya energía de enlace por nucleón es mayor. Las reacciones nucleares más estudiadas que producen una gran cantidad de energía son las siguientes [Murray, 1988]:

$$
\begin{array}{cc}
{ }^{2} \mathrm{H}+{ }^{2} \mathrm{H} \rightarrow{ }^{3} \mathrm{He}+n & Q=-3.25 \mathrm{MeV} \\
{ }^{2} \mathrm{H}+{ }^{2} \mathrm{H} \rightarrow{ }^{3} \mathrm{H}+{ }^{1} \mathrm{H} & Q=-4.02 \mathrm{MeV} \\
{ }^{2} \mathrm{H}+{ }^{3} \mathrm{H} \rightarrow{ }^{4} \mathrm{He}+n & Q=-17.59 \mathrm{MeV} \\
{ }^{2} \mathrm{H}+{ }^{3} \mathrm{He} \rightarrow{ }^{4} \mathrm{He}+{ }^{1} \mathrm{H} & Q=-18.35 \mathrm{MeV}
\end{array}
$$

La reacción entre un átomo de deuterio y un átomo de tritio (reacción 1.3) es la más adecuada para llevarse a cabo dentro de los reactores de fusión nuclear. En efecto, esta reacción posee una sección eficaz de fusión $(\sigma)$ más alta a menor temperatura que el resto de las reacciones (Fig. 1.1), además esta reacción produce una gran cantidad de energía: $17.59 \mathrm{MeV}$ por cada fusión. Solamente la energía producida por la reacción 1.4 es 
ligeramente superior, $-18.35 \mathrm{MeV}$ [Martinell, 1993], pero requiere de temperaturas más elevadas para llevarse a cabo, como se muestra en la figura 1.1.

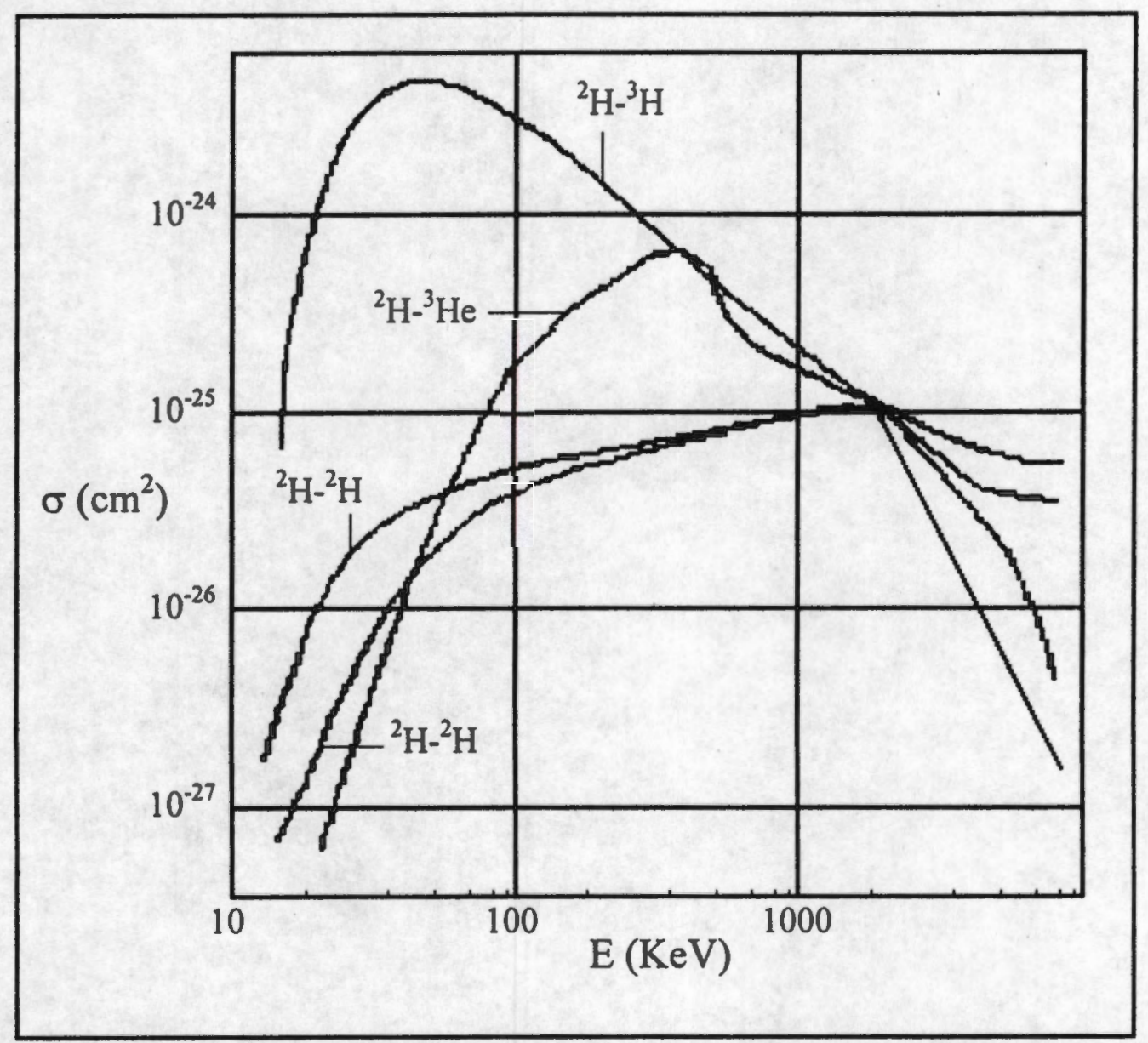

Fig. 1.1, Sección eficaz de fusión de algunas reacciones en función de la energía cinética de los núcleos iniciales.

El deuterio es un isótopo natural, cuya abundancia en la tierra es de una parte por 6500 partes de hidrógeno. Esta cantidad es suficiente para abastecer los reactores de fusión nuclear durante varios miles de años. Por el contrario la abundancia del tritio en la naturaleza es muy baja, aproximadamente una parte por $10^{20}$ partes de hidrógeno, por ello hay que producirlo de manera artificial. 


\subsection{Producción de tritio}

El tritio es un isótopo radiactivo del hidrógeno, y está compuesto por un protón y dos neutrones, lo que le da una masa de 3.006 umas. Se desintegra por emisión de radiación $\beta_{\text {max }}^{-}$con una energía de $0.018619 \mathrm{MeV}$. El tritio tiene una vida media de 12.33 años, y al decaer produce un átomo de ${ }^{3} \mathrm{He}$, el cual es un isótopo natural del helio (Fig. 1.2) [Lederer et al., 1978].

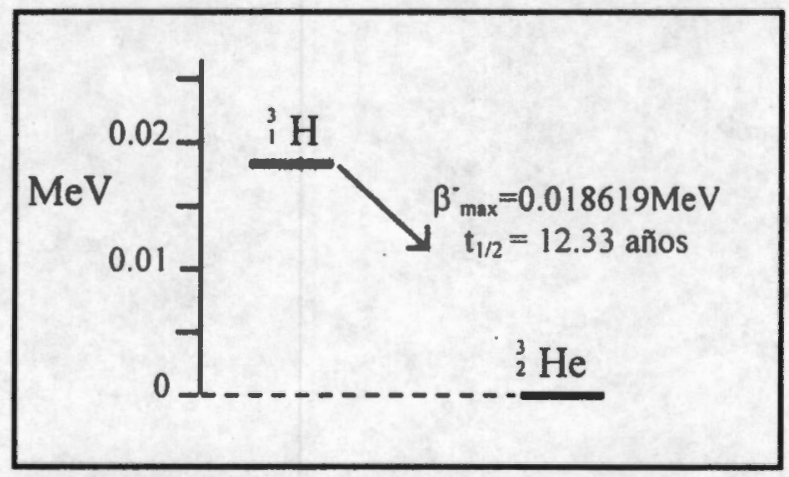

Fig. 1.2, Esquema del decaimiento del tritio.

A partir del litio, el tritio puede producirse mediante las dos reacciones siguientes [Yang et al., 1981; Kummerer et al., 1991]:

$$
\begin{array}{cc}
{ }^{6} \mathrm{Li}+n_{t} \rightarrow{ }^{4} \mathrm{He}+{ }^{3} \mathrm{H} & Q=-4.8 \mathrm{MeV} \\
{ }^{7} \mathrm{Li}+n_{t} \rightarrow{ }^{4} \mathrm{He}+{ }^{3} \mathrm{H}+n_{l} & Q=2.5 \mathrm{MeV}
\end{array}
$$

$\mathrm{El}^{6} \mathrm{Li}$ y el ${ }^{7} \mathrm{Li}$ son los isótopos naturales del litio, y su abundancia es de 7.4 y $92.6 \%$ en masa respectivamente. Ambos producen tritio. Sin embargo, el ${ }^{7} \mathrm{Li}$ tiene una sección eficaz de captura de los neutrones térmicos muy baja ( 0.037 barns), y además la reacción es endotérmica, esto es, absorbe energía. Por el contrario, el ${ }^{6} \mathrm{~L} i$ tiene una sección eficaz de captura de neutrones térmicos mayor (953 barns) y es una reacción exotérmica que genera 4.8 MeV de energía [Kummerer et al., 1991]. 
Resulta entonces razonable pensar que los reactores de fusión nuclear obtengan el tritio a partir de una fuente de litio. Dicha fuente de litio se instalaría dentro del mismo reactor, para aprovechar los neutrones emitidos durante la reacción de fusión nuclear (reacción 1.3).

\subsection{Reactor de fusión nuclear}

Para poder llevar a cabo la reacción de fusión nuclear entre ${ }^{2} \mathrm{H}$ y ${ }^{3} \mathrm{H}$, los gases se confinan por lo general mediante campos magnéticos, se calientan y se les aplica un campo eléctrico además de radiofrecuencia, etc. hasta ionizar las partículas. Como consecuencia, se forma un plasma en el cual se produce la fusión nuclear. Los reactores deben cumplir entonces con dos condiciones fundamentales:

Primero, alcanzar una densidad específica en el plasma de reacción. Se debe calentar el sistema a temperaturas del orden de $10^{8} \mathrm{~K}$, con el objeto de proporcionarle a los átomos suficiente energía cinética como para poder vencer la energía de repulsión culómbica y entonces fusionarse [Bonal, 1987].

El otro factor importante que se deberá controlar dentro de un reactor de fusión nuclear, es el confinamiento del plasma a altas temperaturas durante el tiempo necesario para que la probabilidad de que las partículas colisionen entre sí sea alta. El parámetro de Lawson describe esta situación:

$$
n \tau \geq 10^{14} \mathrm{~s} / \mathrm{cm}^{3}
$$

Este parámetro es el producto de la densidad del plasma $n$, por el tiempo de confinamiento $\tau$. El producto debe ser mayor o igual a $10^{14} \mathrm{~s} / \mathrm{cm}^{3}$ para que la energía producida durante la reacción de fusión nuclear en el plasma sea mucho mayor que la energía perdida por radiación térmica y por la difusión de las partículas hacia el exterior del plasma [Murray, 1988]. 
Uno de los métodos alternativos propuestos actualmente para confinar el plasma, es mediante un sistema inercial. Este sistema consiste en producir el plasma termonuclear utilizando láseres o haces de partículas que se enfocan sobre esferas microscópicas (de aproximadamente $1 \mathrm{~mm}$ de diámetro), que contienen el combustible fusionable. El confinamiento se logra al dirigir diferentes láseres en todas las direcciones alrededor de la esfera. De esta manera se logra producir plasmas de densidad muy alta a altas temperaturas, durante tiempos cortos de aproximadamente $10^{-10} \mathrm{~s}$ [Aboites, 1993].

El método para el confinamiento del plasma, que ha resultado más exitoso en la ruta hacia la producción comercial es el que se conoce como sistema magnético. Este modelo se basa en el hecho de que, en el plasma, todas las partículas son iónicas. Estas partículas cargadas se mueven con dificultad en las direcciones transversales al campo magnético y se ven obligadas a describir trayectorias helicoidales a lo largo de las líneas de fuerza del campo magnético. Queda de esta manera parcialmente confinado el plasma [Llorens et al., 1980]. Uno de los sistemas de confinamiento magnético más comunes es el sistema Tokamak que los rusos propusieron entre 1950 y 1955. Consiste de un sistema toroidal cerrado, en el cual el plasma se confina mediante dos campos magnéticos, uno toroidal dirigido a lo largo del eje de un recipiente en forma de toro, y el otro poloidal, cuyas líneas de fuerza circulares son simétricas respecto al eje toroidal [Llorens et al., 1980; Schiller, 1993].

La estructura de un reactor de fusión nuclear, se puede esquematizar de una manera sencilla (Fig: 1.3). En el núcleo o centro del reactor se encuentra el plasma confinado que se describió anteriormente. El plasma se separa de la primera pared mediante un sistema limitador o diversor. Una pared o capa rica en compuestos de litio cubre el núcleo del reactor. Es en esta capa en donde se genera el tritio como hemos descrito anteriormente. Alrededor de dicha capa hay un blindaje cuya función es la de atenuar las radiaciones emitidas por el plasma, además de aislar térmicamente al resto de los sistemas que se describen a continuación. Todo el calor producido por la reacción nuclear se extrae 
mediante un sistema de refrigeración, que contiene un gas inerte. Este sistema cede el calor en un intercambiador de calor, generando vapor de agua que acciona una turbina. La turbina, a su vez, acciona un generador de corriente alterna, produciendo así corriente eléctrica. Parte de esta energía se utiliza en los mismos sistemas auxiliares del reactor, y el resto es la energía final producida por el reactor de fusión nuclear.

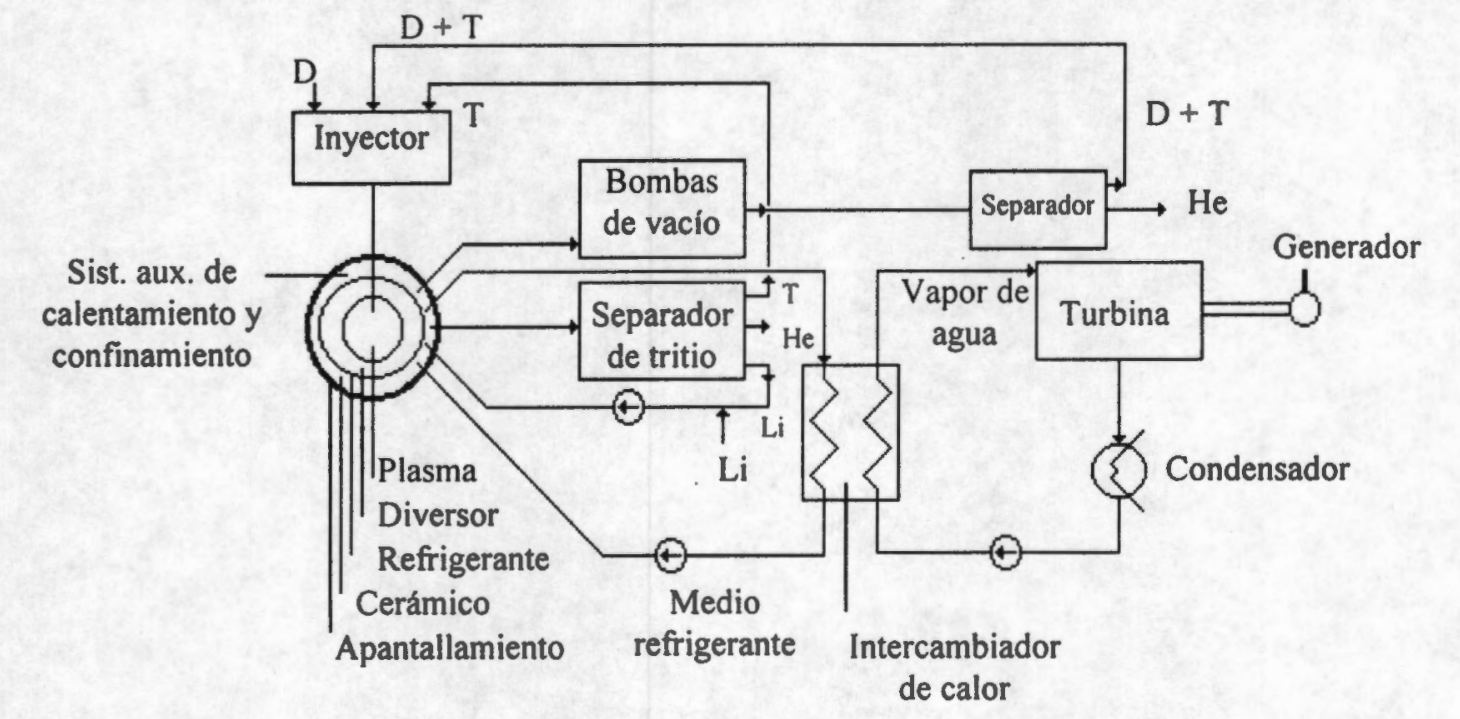

Fig. 1.3, Esquema de la estructura de un reactor de fusión nuclear.

Estos reactores cuentan con un sistema de bombas de vacío para extraer las impurezas, las partículas de plasma difundido y el helio generado en la fusión. Después de extraer en una planta separadora las impurezas, los gases de deuterio y de tritio se vuelven a inyectar en el reactor-[Llorens et al., 1980; Connolly, 1983; Murray, 1988].

\subsection{Materiales cerámicos generadores de tritio}

Un reactor de fusión termonuclear de 3000 MW necesitará para su funcionamiento $500 \mathrm{~g}$ de tritio por hora [Abdou et al., 1984], por lo tanto, los materiales cerámicos de litio productores de tritio deberán ser tan eficientes como sea posible. 
Los primeros estudios sobre materiales generadores de tritio se hicieron entre 1970 y 1979 y se enfocaron al estudio del litio líquido y de sus aleaciones metálicas. Con el tiempo, hubo que descartar este tipo de materiales, debido, en el caso del litio líquido, a su alta reactividad, y en el de las aleaciones metálicas a que presentan altos índices de corrosión [Bonal, 1987]. A partir de 1980, los estudios se enfocaron sólo hacia ciertos materiales cerámicos de litio [Kummerer et al., 1991], ya que además de producir tritio, deben presentar propiedades como estabilidad fisicoquímica a altas temperaturas, compatibilidad con otro tipo de materiales estructurales y una adecuada transferencia de calor [Johnson et al., 1981; Jonson et al., 1988]. Estos cerámicos deben ser, además, estables ante la radiación en un campo mixto de neutrones y de radiación $\gamma$ [Yang et al., 1981; Auvray-Gély et al., 1985; Masabumi et al., 1998]. Algunos de los materiales cerámicos más estudiados son el óxido de litio, los aluminatos de litio, los silicatos de litio y los zirconatos de litio [Johnson et al., 1981; Clemmer et al., 1985; Roux et al., 1992; Pfeiffer et al., 1998]. En la tabla 1.1 se presentan algunas de las propiedades de estos materiales [Johnson et al., 1988].

Tabla 1.1

Propiedades de algunos materiales cerámicos de interés nuclear.

\begin{tabular}{c|cccccc}
\hline \hline Cerámico & $\begin{array}{c}\mathrm{T}_{\mathrm{f}} \\
(\mathrm{K})\end{array}$ & $\begin{array}{c}\rho_{\mathrm{Tot}} \\
\left(\mathrm{gr} / \mathrm{cm}^{3}\right)\end{array}$ & $\begin{array}{c}\rho_{\mathrm{Li}} \\
\left(\mathrm{gr} / \mathrm{cm}^{3}\right)\end{array}$ & $\begin{array}{c}\mathrm{K} \\
(\mathrm{W} / \mathrm{mK})\end{array}$ & $\begin{array}{c}\text { Temp. de } \\
\text { operación }(\mathrm{K})\end{array}$ & $\begin{array}{c}\text { Solubilidad } \\
\text { del tritio }\end{array}$ \\
\hline $\mathrm{Li}_{2} \mathrm{O}$ & 1706 & 2.01 & 0.93 & 3.4 & $673-1073$ & baja \\
$\mathrm{LiAlO}_{2}$ & 1883 & 2.61 & 0.27 & 2.2 & $723-1473$ & baja \\
$\mathrm{Li}_{2} \mathrm{SiO}_{3}$ & 1473 & 2.53 & 0.36 & 1.5 & $683-1073$ & alta \\
$\mathrm{Li}_{4} \mathrm{SiO}_{4}$ & 1523 & 2.35 & 0.54 & 1.5 & $583-1223$ & moderada \\
$\mathrm{Li}_{2} \mathrm{ZrO}_{3}$ & 1888 & 4.15 & 0.33 & 1.3 & $673-1673$ & moderada \\
$\mathrm{Li}_{8} \mathrm{ZrO}_{6}$ & 1568 & 2.99 & 0.68 & 1.5 & $623-1253$ & moderada \\
\hline
\end{tabular}

$\mathrm{T}_{\mathrm{f}}$, temperatura de fusión; $\rho_{\mathrm{Tot}}$, densidad total; $\rho_{\mathrm{Li}}$, densidad de litio; $\mathrm{K}$, conductividad eléctrica, Temp. de operación, intervalo máximo de temperaturas dentro del cual los materiales no presentan cambios estructurales. 
En la tabla anterior se comprueba que el metasilicato de litio $\left(\mathrm{Li}_{2} \mathrm{SiO}_{3}\right)$ presenta como ventaja una mayor solubilidad de tritio, y el metazirconato de litio $\left(\mathrm{Li}_{2} \mathrm{ZrO}_{3}\right)$ es el más estable a altas temperaturas. Existen en la literatura científica diversos estudios sobre los materiales cerámicos de interés nuclear. Con el fin último de proponer el cerámico adecuado para los reactores de fusión termonuclear, en la tabla 1.2 se presenta un resumen de algunos de los estudios realizados a la fecha.

Tabla 1.2

Principales estudios sobre cerámicos generadores de tritio en los últimos 20 años.

\begin{tabular}{|c|c|c|c|}
\hline Autor & Año & Objetivo & Cerámico \\
\hline Baldwin & 1984 & Determinación de las cantidades $\mathrm{de}^{3} \mathrm{H}$ y. & $\mathrm{Li}_{2} \mathrm{SiO}_{3}, \mathrm{Li}_{4} \mathrm{SiO}_{4}$, \\
\hline Clemmer et al. & 1985 & ${ }^{4} \mathrm{He}$ producidas al irradiar con neutrones & $\mathrm{Li}_{2} \mathrm{O}, \mathrm{LiAlO}_{2} \mathrm{y}$ \\
\hline Porter et al. & 1992 & térmicos el cerámico en estudio. & $\mathrm{Li}_{2} \mathrm{ZrO}_{3}$ \\
\hline Hollenberg et al. & 1985 & Determinación de la estabilidad de los & \\
\hline Roth et al. & 1985 & materiales, irradiados con neutrones $y / 0$ & $\mathrm{Li}_{2} \mathrm{SiO}_{3}, \mathrm{Li}_{4} \mathrm{SiO}_{4}$ \\
\hline O'kula et al. & 1985 & radiación gamma. Difusión de tritio. & $\mathrm{Li}_{2} \mathrm{O}$ y $\mathrm{LiAlO}_{2}$ \\
\hline Shah et al. & 1996 & & \\
\hline Johnson et al. & 1981 & & \\
\hline Arons et al. & 1981 & & \\
\hline Vollath et al. & 1985 & & \\
\hline Flipot et al. & 1985 & Estudios sobre la síntesis de los cerámicos & $\mathrm{Li}_{2} \mathrm{SiO}_{3}, \mathrm{Li}_{4} \mathrm{SiO}_{4}$ \\
\hline Johnson et al. & 1988 & y los efectos de la radiación. & $\mathrm{Li}_{2} \mathrm{Si}_{2} \mathrm{O}_{5}, \mathrm{Li}_{2} \mathrm{O}$ \\
\hline Breitung et al. & 1988 & & $\mathrm{LiAlO}_{2}, \mathrm{Li}_{2} \mathrm{ZrO}_{3} \mathrm{y}$ \\
\hline Smaihi et al. & 1991 & & $\mathrm{Li}_{8} \mathrm{ZrO}_{6}$ \\
\hline Dai-Kai & 1994 & & \\
\hline Pfeiffer et al. & 1998 & & \\
\hline De-Vita et al. & 1992 & Estudios teóricos sobre la difusión del & \\
\hline Jacobs et al. & 1996 & $\begin{array}{l}\text { litio y del tritio, en diferentes } \\
\text { cerámicos de litio. }\end{array}$ & $\mathrm{Li}_{2} \mathrm{O}, \mathrm{LiAlO}_{2}$ \\
\hline
\end{tabular}


Los datos experimentales reportados sobre la extracción del tritio varían hasta en seis órdenes de magnitud, debido a factores como la pureza de la muestra, la temperatura a la cual se realiza la extracción, la morfología, el tamaño del cristal y los problemas de límite de grano entre otros [Ohno et al., 1985; Noda et al., 1990; Rasneur, 1990; Johnson, 1999]. Es más, en general la extracción de tritio se hace con un flujo de gas inerte, helio o argón, enriquecido con hidrógeno [Johnson et al., 1997] y la composición del gas es un factor más que puede determinar la cantidad de tritio extraído.

\subsection{Silicozirconatos de litio}

Como se vio en la sección anterior, los diferentes cerámicos de litio que se han estudiado presentan ventajas y desventajas para su empleo en los reactores de fusión. Por un lado, el metasilicato de litio $\left(\mathrm{Li}_{2} \mathrm{SiO}_{3}\right)$ es el cerámico que ofrece mayor solubilidad de tritio, mientras que los zirconatos de litio son los más estables a altas temperaturas. Los compuestos sintetizados en este trabajo, son óxidos mixtos de litio, silicio y zirconio. El propósito fue, el de encontrar un material que posea las diferentes cualidades de los silicatos de litio y de los zirconatos de litio en un solo producto.

El sistema de óxidos mixtos $\mathrm{Li}_{2} \mathrm{O}-\mathrm{ZrO}_{2}-\mathrm{SiO}_{2}$ tiene una amplia gama de aplicaciones en la industria del vidrio, por ejemplo, para producir vidrios cerámicos. Existen también, materiales refractarios a base de zirconia $\left(\mathrm{ZrO}_{2}\right)$ dopada. Hay además, pinturas y esmaltes que contienen estos óxidos [Boilot et al., 1988; Nuñez et al., 1998]. Aquí discutiremos únicamente la sintesis y la estructura del $\mathrm{ZrSiO}_{4}$ y del $\mathrm{Li}_{2} \mathrm{ZrSi}_{6} \mathrm{O}_{15}$ que son el tema de este trabajo.

\subsection{1 $\mathrm{Li}-\mathrm{ZrSiO}_{4}$}

El zircón $\left(\mathrm{ZrSiO}_{4}\right)$ es un compuesto ampliamente usado en la industria por su estabilidad química y por su bajo coeficiente de expansión. Se emplea como material refractario a altas temperaturas [Muller et al., 1974; Hardi et al., 1992; Mori et al., 1993]. 
El $\mathrm{ZrSiO}_{4}$ tiene un punto de fusión de $2773 \mathrm{~K}$ [Weast et al., 1982], su estructura es tetragonal y los parámetros de red son $a_{0}=6.607 \AA$ y $c_{0}=5.982 \AA$. El $\mathrm{ZrSiO}_{4}$ está formado por tetraedros de $\left(\mathrm{SiO}_{4}\right)^{4-}$ que interactúan con átomos de $\mathrm{Zr}$ de coordinación octaédrica. Cuando el $\mathrm{ZrSiO}_{4}$ se sintetiza a altas presiones, se obtiene una estructura de tipo esquelita y, en este caso, los parámetros de red cambian: $a_{0}$ decrece de 6.607 a $4.73 \AA$ mientras que $c_{0}$ aumenta de 5.982 a $10.48 \AA$ [Muller et al., 1974; Hyde et al., 1989]. Además se ha demostrado que el $\mathrm{ZrSiO}_{4}$ puede hidratarse, $\mathrm{ZrSiO}_{4} \cdot \mathrm{xH}_{2} \mathrm{O}$, en donde $\mathrm{x}$ es variable. El agua aparentemente se encuentra en las cavidades internas de la estructura del $\mathrm{ZrSiO}_{4}$ [Muller et al., 1974].

La red cristalina del $\mathrm{ZrSiO}_{4}$ presenta grandes cavidades internas, por las cuales pueden difundirse átomos y/o moléculas, el agua por ejemplo [Muller et al., 1974]. Es por lo tanto probable que el $\mathrm{ZrSiO}_{4}$ se pueda dopar con litio. Las propiedades fisicoquímicas del $\mathrm{ZrSiO}_{4}$ y la posibilidad de doparlo con algún compuesto que contenga litio lo convierten entonces en un cerámico que podría servir para generar tritio en los reactores de fusión nuclear.

\subsection{2 $\mathrm{Li}_{2} \mathrm{ZrSi}_{6} \mathrm{O}_{15}$}

Según la literatura científica el $\mathrm{LiNaZrSi}_{6} \mathrm{O}_{15}$ es un mineral conocido como zekzerita [Dunn et al., 1977] que contiene sodio. Por desgracia, la sección eficaz de adsorción de neutrones del sodio es mucho mayor que la del litio, así que la reacción de fisión del litio en este material se vería altamente desfavorecida [Lederer et al., 1978]. La zekzerita, por lo tanto, no es un cerámico recomendable para generar tritio dentro de los reactores de fusión. Sin embargo, a partir del conocimiento de la zekzerita, Quintana et al., llevaron a cabo la síntesis y la caracterización del silicozirconato de litio, $\mathrm{Li}_{2} \mathrm{ZrSi}_{6} \mathrm{O}_{15}$, en el marco de un estudio de caracterización del sistema $\mathrm{Li}_{2} \mathrm{O}-\mathrm{ZrO}_{2}-\mathrm{SiO}_{2}$ [Quintana (1) et al., 1981; Quintana (2) et al., 1981]. Sintetizaron el $\mathrm{Li}_{2} \mathrm{ZrSi}_{6} \mathrm{O}_{15}$ a partir del método de reacción en estado sólido. Obtuvieron una mezcla de compuestos entre los que se encontraron $\mathrm{Li}_{2} \mathrm{SiO}_{3}, \mathrm{Li}_{2} \mathrm{Si}_{2} \mathrm{O}_{5}, \mathrm{ZrSiO}_{4}$ y vidrio. Sin embargo, no mencionaron los porcentajes de cada 
especie. Desde luego, la presencia de vidrio se debe atribuir al exceso de $\mathrm{SiO}_{2}$ utilizado en todas las síntesis.

$\mathrm{El} \mathrm{Li}_{2} \mathrm{ZrSi}_{6} \mathrm{O}_{15}$ está formado por cadenas dobles de $\left(\mathrm{Si}_{6} \mathrm{O}_{15}\right)^{6-}$. Los átomos de litio y de zirconio son los cationes que balancean la carga del ion silicato. La celda unidad del $\mathrm{Li}_{2} \mathrm{ZrSi}_{6} \mathrm{O}_{15}$ es una celda monoclínica con los siguientes parámetros de red $a_{0}=11.121 \AA$, $b_{0}=10.146 \AA, c_{0}=11.235 \AA$ y $\beta=100.26^{\circ}$.

\subsection{Objetivos}

El objetivo general de este trabajo fue el de realizar la síntesis, caracterización y evaluación de las propiedades como cerámicos generadores de tritio tanto del silicozirconato de litio $\left(\mathrm{Li}_{2} \mathrm{ZrSi}_{6} \mathrm{O}_{15}\right)$ como del zircón dopado con litio $\left(\mathrm{Li}-\mathrm{ZrSiO}_{4}\right)$. A continuación se presentan los objetivos particulares:

Sintetizar el metazirconato de litio $\left(\mathrm{Li}_{2} \mathrm{ZrO}_{3}\right)$, para estudiar el comportamiento de los alcóxidos de zirconio, tanto en medio ácido como en medio básico, con el objeto de determinar las condiciones de síntesis más adecuadas. Este fue el primer paso para sintetizar posteriormente el $\mathrm{Li}_{2} \mathrm{ZrSi}_{6} \mathrm{O}_{15}$ y el $\mathrm{Li}-\mathrm{ZrSiO}_{4}$.

Sintetizar por el método sol-gel el $\mathrm{Li}_{2} \mathrm{ZrSi}_{6} \mathrm{O}_{15}$ y el Li- $\mathrm{ZrSiO}_{4}$ y caracterizarlos.

Realizar un estudio de dinámica molecular de la difusión del litio y tritio dentro de un cerámico de litio $\left(\mathrm{Li}_{2} \mathrm{O}\right)$. Este estudio teórico se realizó para determinar las condiciones más adecuadas para la difusión y extracción del tritio.

Irradiar los cerámicos en un campo de radiación mixto y caracterizarlos para determinar su estabilidad al ser sometidos bajo condiciones de radiación similares a las que serían sometidos en un reactor de fusión termonuclear.

Finalmente, el último objetivo de este trabajo fue evaluar el rendimiento de extracción de tritio de los diferentes cerámicos comparando los resultados con aquellos producidos por otros cerámicos de litio generadores de tritio. 


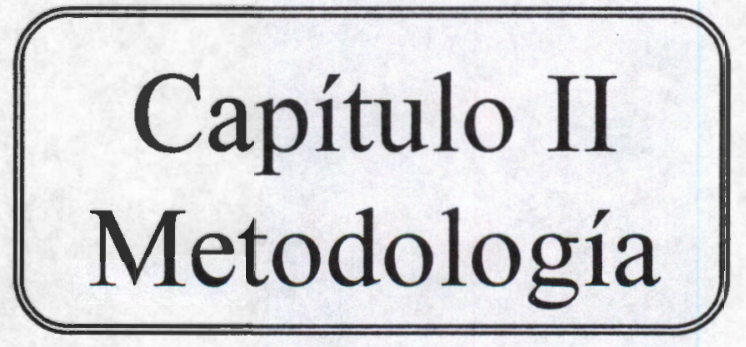




\section{Capítulo II Metodología}

En este trabajo se prepararon el $\mathrm{Li}_{2} \mathrm{ZrSi}_{6} \mathrm{O}_{15}$ y el $\mathrm{Li}_{-} \mathrm{ZrSiO}_{4}$ por el método sol-gel (sección 2.2). Una vez sintetizados los compuestos se caracterizaron mediante diferentes técnicas, las cuales se enumeran en la sección 2.1. Las muestras se irradiaron en el reactor del Instituto Nacional de Investigaciones Nucleares, para estudiar la estabilidad estructural y para determinar la producción de tritio de cada una de las muestras. Además, se efectuó un estudio previo sobre el efecto del $\mathrm{pH}$ en la síntesis sol-gel del metazirconato de litio $\left(\mathrm{Li}_{2} \mathrm{ZrO}_{3}\right)$ para determinar las condiciones optimas de velocidad de polimerización de los alcóxidos de zirconio en la síntesis de los silicozirconatos de litio.

\subsection{Reactivos, equipos e instalaciones}

Los reactivos empleados en la síntesis de los compuestos por el método sol-gel se enlistan en la tabla 2.1. El alcohol isopropílico $\left(\mathrm{CH}_{3}-\mathrm{CH}(\mathrm{OH})-\mathrm{CH}_{3}\right)$ se usó como disolvente de los alcóxidos, y el ácido nítrico $\left(\mathrm{HNO}_{3}\right)$ se empleó para hidrolizar los soles y formar los geles. El grado de pureza de todos los reactivos empleados fue grado analítico.

\section{Tabla 2.1}

Reactivos empleados en la síntesis de los silicozirconatos de litio.

\begin{tabular}{cc}
\hline Reactivo & Fórmula \\
\hline Tetraetil ortosilicato (TEOS) & $\mathrm{Si}\left[\mathrm{OC}_{2} \mathrm{H}_{5}\right]_{4}$ \\
Tetraetóxido de zirconio & $\mathrm{Zr}\left[\mathrm{OC}_{2} \mathrm{H}_{5}\right]_{4}$ \\
Isopropóxido de zirconio & $\mathrm{Zr}\left[\mathrm{OC}_{3} \mathrm{H}_{7}\right]_{4}$ \\
Propóxido de zirconio & $\mathrm{Zr}\left[\mathrm{OC}_{3} \mathrm{H}_{7}\right]_{4}$ \\
Butóxido de zirconio & $\mathrm{Zr}\left[\mathrm{OC}_{4} \mathrm{H}_{9}\right]_{4}$ \\
Metóxido de litio & $\mathrm{LiOCH}_{3}$ \\
Hidróxido de litio & $\mathrm{LiOH}^{2}$ \\
\hline
\end{tabular}


La caracterización de cada uno de los compuestos sintetizados se efectuó antes y después de la irradiación. Para la caracterización de los materiales se emplearon diferentes técnicas, con las cuales se determinaron diferentes parámetros fisicoquímicos necesarios, para la total comprensión de las características de cada una de las muestras. Las técnicas empleadas se presentan a continuación.

Difracción de rayos $\mathbf{X}$ (XRD): Se utilizó un difractómetro Siemens D500 acoplado $\mathrm{a}$ un tubo de rayos $\mathrm{X}$ con ánodo de cobre. La radiación $\mathrm{K} \alpha$ se separó con un monocromador de haz difractado. Los espectros se identificaron convencionalmente utilizando los archivos JCPDS (de las siglas en inglés, Joint Committe of Powder Diffraction Standards). En los casos en los que fue necesario determinar la posición exacta de los picos de difracción se usó corindón $\left(\alpha-\mathrm{Al}_{2} \mathrm{O}_{3}\right)$ y/o cuarzo $\left(\mathrm{SiO}_{2}\right)$ como estándares internos. $\mathrm{El}$ análisis cuantitativo se llevó a cabo suponiendo que el coeficiente de absorción era el mismo en todos los compuestos y que, por lo tanto, el contenido era proporcional a la altura de los picos de difracción.

Espectroscopía infrarroja (FTIR): Los espectros de IR se obtuvieron con un equipo Magna-IR500, Nicolet. Las muestras se prepararon en forma de pastillas, mezclando aproximadamente $5 \%$ de muestra y $95 \%$ de bromuro de potasio $(\mathrm{KBr})$.

Análisis termogravimétrico (TGA): Se empleó un equipo TGA-51 Thermogravimetric Analyzer, TA. Las muestras se analizaron bajo una atmósfera inerte de nitrógeno $(50 \mathrm{ml} / \mathrm{min})$, con un aumento en la temperatura de $5 \mathrm{~K} / \mathrm{min}$, de 298 a $1273 \mathrm{~K}$.

Análisis de área superficial por el método BET: Para el cálculo de las áreas superficiales por el método BET, se empleó un equipo Gemini 2360, Surface Area Analyzer Micromeritics. Las muestras fueron sometidas a un tratamiento previo de calentamiento de $473 \mathrm{~K}$ por 2 horas. El gas empleado para la determinación del área superficial fue nitrógeno. 
Espectroscopía fotoelectrónica de rayos X (XPS): En el estudio de XPS se empleó un espectrofotómetro V. G. Microtech MT500 Fisons Instruments, acoplado a un tubo de rayos $\mathrm{X}$ con ánodo de magnesio.

Espectroscopía de electrones de baja energía (EELS): El microscopio electrónico de transmisión utilizado fue un JEOL 2000FX.

Microscopía electrónica de barrido (SEM): Para este estudio se utilizó un microscopio Phillips, modelo XL-30. Las muestras se recubrieron con oro para hacerlas conductoras, para ello se empleó un equipo Desk II, Denton Vacuum.

Centelleo líquido: Para determinar la cantidad de tritio liberado, así como el contenido total de tritio, se empleó un equipo TRI-CARB 2700TR Liquid Scintillation Analyzer, Packard. El centellador líquido empleado fue un centellador universal Ultima Gold AB, Packard.

Estudio numérico: Para simular los materiales se emplearon computadoras Indy Silicon Graphics. Estas computadoras están conectadas a la red de la supercomputadora CRAY de la Universidad Nacional Autónoma de México.

Reactor nuclear: Las muestras se irradiaron en la posición SIFCA (Sistema de Irradiación Fija en Cápsulas) del reactor TRIGA Mark III del Centro Nuclear de México.

\subsection{Sintesis}

El método de síntesis conocido como sol-gel, es un método que ofrece grandes ventajas sobre los métodos convencionales, ya que presenta entre otras cosas una gran pureza, limpieza e homogeneidad en la reacción, así como la capacidad de controlar el tamaño del poro. A estas ventajas hay que agregar el hecho de que los materiales se pueden obtener a temperaturas más bajas en comparación con los métodos convencionales. Existen 
una gran variedad de materiales que se pueden producir mediante el método sol-gel, tales como películas, fibras, polvos y medios porosos entre otros.

Con base en lo anteriormente descrito sobre el método de síntesis sol-gel, tanto el $\mathrm{Li}_{2} \mathrm{ZrSi}_{6} \mathrm{O}_{15}$ como el $\mathrm{Li}-\mathrm{ZrSiO}_{4}$ se sintetizaron por este método. La sintesis de los materiales se hizo empleando diferentes razones molares de litio, zirconio y silicio ( $\mathrm{Li}: \mathrm{Zr}: \mathrm{Si})$, de acuerdo con la literatura [Quintana (2) et al., 1981; Vollath et al., 1985; Jimenez-Becerril et al., 1991; Hardy et al., 1992; Mori et al., 1993; Pfeiffer et al., 1998].

\subsection{1 $\mathrm{Li}_{2} \mathrm{ZrO}_{3}$}

Primero, se estudió el efecto del $\mathrm{pH}$ en los alcóxidos de zirconio. El objetivo de esta parte del trabajo era conocer las condiciones óptimas de acidez para la síntesis sol-gel de alcóxidos de zirconio. Para ello se realizó la síntesis del metazirconato de litio $\left(\mathrm{Li}_{2} \mathrm{ZrO}_{3}\right)$ por el método de sol-gel [Montanaro et al., 1992]. Se disolvieron los alcóxidos de litio y de zirconio por separado en alcohol isopropílico, posteriormente se mezclaron y el sistema se dejó en reflujo con agitación continua a $343 \mathrm{~K}$, hasta la formación del sol. Los diferentes sistemas se hidrolizaron con $\mathrm{HNO}_{3}, \mathrm{pH}=2$. El proceso de agitación con reflujo se continuó durante un día. Los geles formados se secaron a $383 \mathrm{~K}$ durante un día y posteriormente se calcinaron durante 4 horas a $1073 \mathrm{~K}$. Los alcóxidos de zirconio empleados fueron, el etóxido, el propóxido, el isopropóxido y el butóxido de zirconio, mientras que en el caso del litio se emplearon el metóxido de litio y el hidróxido de litio, con los cuales se definió el ambiente ácido o básico del sistema. Previamente se había hecho un estudio similar con alcóxidos de silicio [ Szu et al., 1990; Pfeiffer et al., 1998].

En la síntesis sol-gel, los alcóxidos de zirconio y de litio presentan una reacción de hidrólisis, reacciones 2.1 y 2.2 respectivamente. En el caso de los alcóxidos de zirconio, después de esta primera reacción de hidrólisis los alcóxidos pueden volver a hidrolizarse en una o más ocasiones (reacción 2.3) [Brinker and Scherer, 1990]. 


$$
\begin{gathered}
\mathrm{Zr}(\mathrm{OR})_{4}+\mathrm{H}_{2} \mathrm{O} \rightarrow \mathrm{Zr}(\mathrm{OH})(\mathrm{OR})_{3}+\mathrm{R}-\mathrm{OH} \\
\mathrm{Li}(\mathrm{OR})+\mathrm{H}_{2} \mathrm{O} \rightarrow \mathrm{LiOH}+\mathrm{R}-\mathrm{OH} \\
\mathrm{Zr}(\mathrm{OH})(\mathrm{OR})_{3}+(x-1) \mathrm{H}_{2} \mathrm{O} \rightarrow \mathrm{Zr}(\mathrm{OH})_{x}(\mathrm{OR})_{4-x}+(x-1) \mathrm{R}-\mathrm{OH}
\end{gathered}
$$

Los alcóxidos de litio y de zirconio, una vez hidrolizados en una o más ocasiones, pueden presentar otro tipo de reacciones como la autocondensación, que se efectúa entre dos moléculas, donde la segunda molécula puede estar hidrolizada o no. En este caso ambas moléculas deben provenir del mismo alcóxido. A continuación se presentan algunos ejemplos de este tipo de reacciones [Brinker and Scherer, 1990].

$$
\begin{gathered}
2 \mathrm{Zr}(\mathrm{OH})(\mathrm{OR})_{3} \rightarrow(\mathrm{OR})_{3} \mathrm{Zr}-\mathrm{O}-\mathrm{Zr}(\mathrm{OR})_{3}+\mathrm{H}_{2} \mathrm{O} \\
\mathrm{Zr}(\mathrm{OH})(\mathrm{OR})_{3}+\mathrm{Zr}(\mathrm{OR})_{4} \rightarrow(\mathrm{OR})_{3} \mathrm{Zr}-\mathrm{O}-\mathrm{Zr}(\mathrm{OR})_{3}+\mathrm{R}-\mathrm{OH} \\
2 \mathrm{LiOH} \rightarrow \mathrm{Li}_{2} \mathrm{O}+\mathrm{H}_{2} \mathrm{O} \\
\mathrm{LiOH}+\mathrm{LiOR} \rightarrow \mathrm{Li}_{2} \mathrm{O}+\mathrm{R}-\mathrm{OH}
\end{gathered}
$$

Otro tipo de reacción que puede presentarse en este sistema es una reacción de heterocondensación, que sucede entre dos moléculas diferentes. En la reacción 2.8 se presenta un ejemplo:

$$
\mathrm{LiOR}+\mathrm{Zr}(\mathrm{OR})_{4-x}(\mathrm{OH})_{x} \rightarrow \mathrm{Li}-\mathrm{O}-\mathrm{Zr}(\mathrm{OR})_{4-x}(\mathrm{OH})_{x-1}+\mathrm{R}-\mathrm{OH}
$$

Los factores que determinan el que se lleve a cabo una reacción u otra son tanto el pH como el tamaño del radical (-R) en el alcóxido. El pH determina la velocidad de hidrólisis de los alcóxidos. En medio ácido, la velocidad de hidrólisis decrece en función del número de hidrólisis por molécula. Esto quiere decir que la velocidad de reacción de la segunda reacción de hidrólisis en una molécula será más lenta que la primera, y así sucesivamente [Brinker and Scherer, 1990; Boilot et al., 1988]. 
En un medio básico cada paso de hidrólisis es más rápido que el anterior. Cuando se usó $\mathrm{LiOH}$ como alcóxido de litio, este mismo reactivo dio a la solución un carácter básico. En efecto, para hidrolizar se usó una relación ácido/alcóxido de 0.2 , por lo tanto:

$$
\begin{gathered}
{\left[\mathrm{H}^{+}\right] /[\text {alcóxido }]_{\text {total }}=0.2} \\
{\left[\mathrm{H}^{+}\right] /[\mathrm{LiOH}]=\left[\mathrm{H}^{+}\right] /[\mathrm{OH}] \approx 0.133} \\
{\left[\mathrm{H}^{+}\right] \approx 0.133[\mathrm{OH}]} \\
{\left[\mathrm{H}^{+}\right] \ll[\mathrm{OH}]}
\end{gathered}
$$

tomando en cuenta las condiciones anteriores ( $\mathrm{LiOH}$ como alcóxido de litio), la síntesis del $\mathrm{Li}_{2} \mathrm{ZrO}_{3}$ se realizó según un régimen de catálisis básico. En este punto cabe hacer mención que el $\mathrm{LiOH}$ no es un alcóxido. Al emplear el $\mathrm{LiOH}$ se idealizó una hidrólisis total del alcóxido de litio.

\subsection{2 $\mathrm{Li}^{-} \mathrm{ZrSiO}_{4}$}

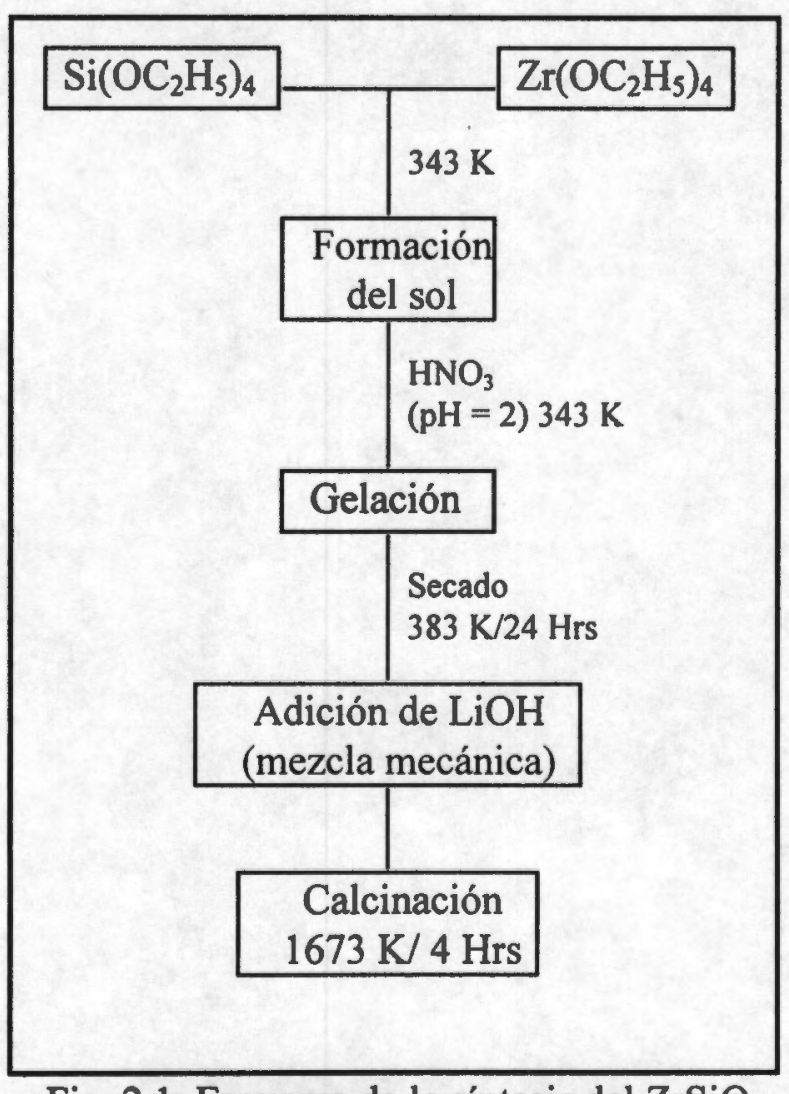

Fig. 2.1, Esquema de la síntesis del $\mathrm{ZrSiO}_{4}$. 
El $\mathrm{ZrSiO}_{4}$ se preparó por el método sol-gel empleando cantidades estequiométricas de TEOS y de $\mathrm{Zr}\left(\mathrm{OC}_{2} \mathrm{H}_{5}\right)_{4}$. Primero se disolvió el $\mathrm{Zr}\left(\mathrm{OC}_{2} \mathrm{H}_{5}\right)_{4}$ en alcohol isopropílico y después se le adicionó el TEOS, la razón molar empleada alcohol:alcóxidoteos fue de 40. La solución se calentó a $343 \mathrm{~K}$ con agitación constante hasta la formación del sol. Una vez obtenido el sol, la solución se hidrolizó mediante la adición de una solución de $\mathrm{HNO}_{3}(\mathrm{pH}$ =2). la agitación se continuó hasta la gelación del material. El gel se secó durante un día a $383 \mathrm{~K}$ y finalmente se calcinó en aire a $1673 \mathrm{~K}$ durante 4 horas. Para incorporar el litio en el $\mathrm{ZrSiO}_{4}$ se agregó $\mathrm{LiOH}$ y se hizo una mezcla mecánica de los polvos. La mezcla se calcinó en las mismas condiciones, a $1673 \mathrm{~K}$ durante 4 horas (Fig. 2.1). Las razones molares de Li:Zr empleadas fueron 1, 3, 5 y 6 [Pfeiffer et al. (1), 2000].

\subsection{3 $\mathrm{Li}_{2} \mathrm{ZrSi}_{6} \mathrm{O}_{15}$}

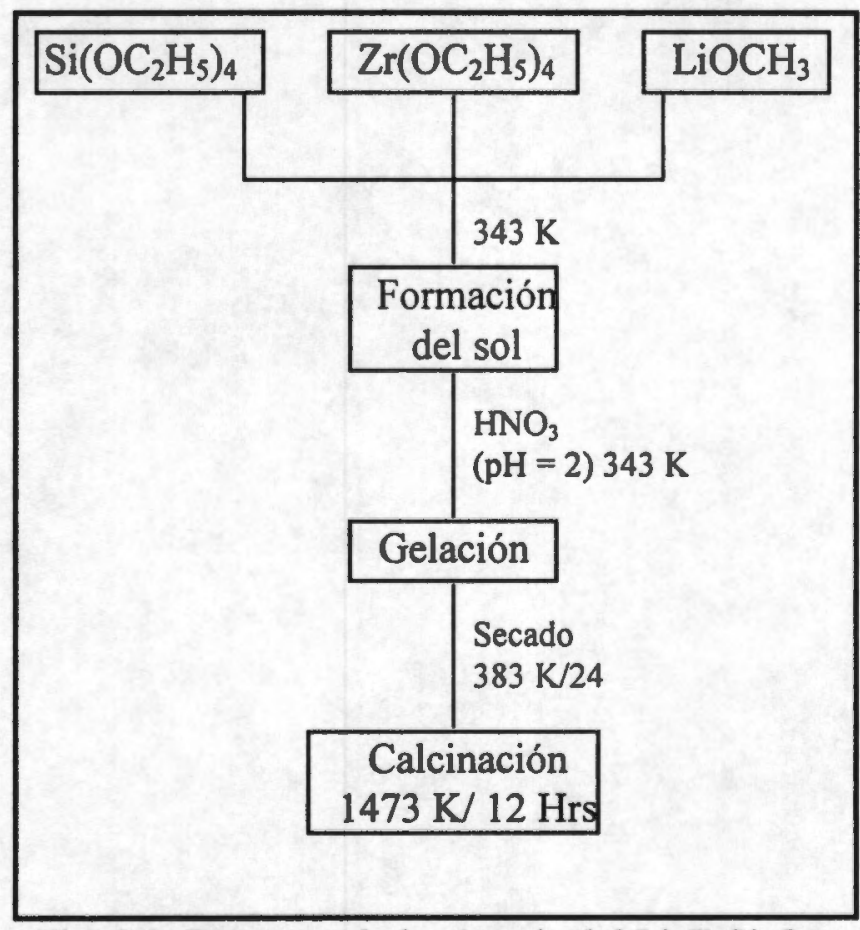

Fig. 2.2, Esquema de la síntesis del $\mathrm{Li}_{2} \mathrm{ZrSi}_{6} \mathrm{O}_{15}$.

El silicozirconato de litio se sintetizó por el método sol-gel como se esquematiza en la figura 2.2. Se disolvieron por separado el TEOS, el $\mathrm{Zr}\left(\mathrm{OC}_{2} \mathrm{H}_{5}\right)_{4}$ y el $\mathrm{LiOCH}_{3}$ en alcohol 
isopropílico. Se mezclaron diferentes razones molares de $\mathrm{Li}: \mathrm{Zr}$ en la síntesis, manteniendo siempre la razón molar de silicio igual a seis de acuerdo con la relación estequiométrica de la fórmula. Así mismo, la razón molar alcohol:alcóxidoteos fue de 40. La solución final se colocó en un sistema de reflujo a $343 \mathrm{~K}$ con agitación continua. Una vez formado, el sol se hidrolizó mediante la adición de una solución de $\mathrm{HNO}_{3}(\mathrm{pH}=2)$ hasta la formación de un gel. El proceso de agitación se mantuvo durante 12 horas a la misma temperatura. Los geles obtenidos se secaron durante un día a $383 \mathrm{~K}$ y posteriormente se calcinaron a $1473 \mathrm{~K}$ durante 12 horas [Pfeiffer et al. (2), 2000].

\subsection{Técnicas de irradiación y conteo de tritio}

Muestras de $100 \mathrm{mg}$ de los cerámicos producidos se irradiaron en el reactor TRIGA Mark III, del Centro Nuclear de México. En el mismo contenedor de la muestra se colocaron 2 muestras de ácido oxálico (120 mg), que se usaron como dosímetros secundarios [Sánchez-Ocampo et al., 1985]. Las muestras se irradiaron durante una hora en la posición SIFCA del reactor, y posteriormente se dejaron en la alberca durante una semana, para asegurarse que los radioisótopos de vida media corta habían decaído.

La figura 2.3 muestra el esquema general del sistema de extracción de tritio montado en el laboratorio de Química del Centro Nuclear de México. Este sistema se construyó de acuerdo con trabajos previos [Baldwin, 1984; Kopasz et al., 1992; Carconi et al., 1992; Alvani et al., 1994]. El gas de arrastre empleado fue argón con $0.5 \%$ en masa de hidrógeno y con un flujo de $200 \mathrm{ml} / \mathrm{min}$. Las muestras irradiadas se compactaron dentro de un tubo de acero inoxidable, que se calentaron a $600 \mathrm{~K}$ dentro de una mufla en forma de tubo. El argón arrastró el tritio fuera del cerámico en forma de HT y/o HTO. El gas de arrastre se hizo pasar por una cama de óxido de cobre ( $\mathrm{CuO})$, la cual se calentó con un mechero, para asegurar la oxidación del tritio a HTO. El tritio en forma de agua se recolectó en una trampa de agua fría $(200 \mathrm{ml})$. Finalmente, el gas de arrastre se hizo pasar por una segunda cama de CuO, la cual también se calentó y otra trampa de agua, para asegurar la total retención del tritio extraído de las muestras. De la trampa número 1 de agua se 
tomaron alícuotas de $1 \mathrm{ml}$ a diferentes tiempos durante lapsos de hasta seis horas. De la segunda trampa de agua se tomo una alícuota a las seis horas, para determinar la cantidad de tritio retenido en dicha trampa. Cada alícuota se colocó en un vial de centelleo con $19 \mathrm{ml}$ de centellador líquido, Ultima Gold AB, Packard, y se determinó el tritio en el equipo de centelleo líquido.

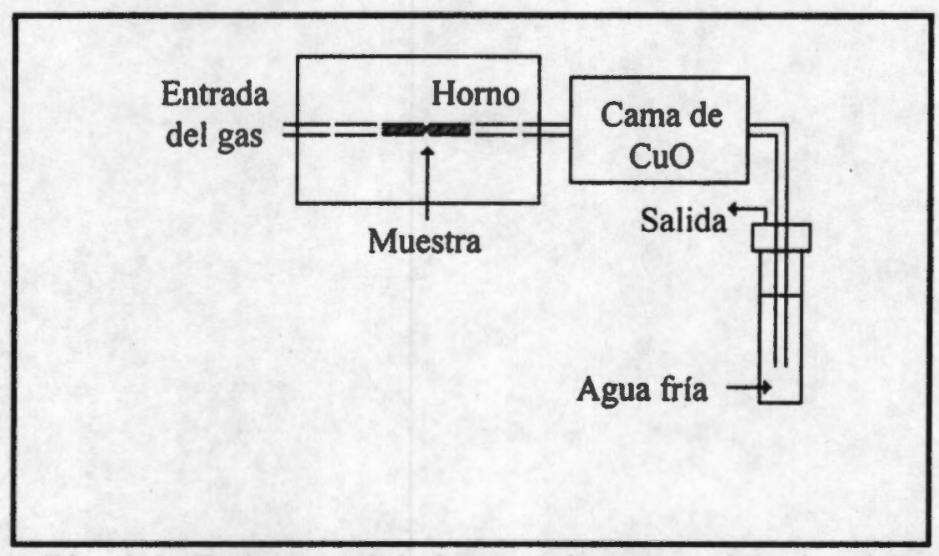

Fig. 2.3, Esquema del sistema de extracción de tritio.

Para conocer el rendimiento de extracción de tritio de los cerámicos se hizo un análisis para estimar la cantidad total de litio transformado a tritio en cada muestra. Se disolvieron $100 \mathrm{mg}$ de muestra irradiada, en una mezcla de ácidos ( $\mathrm{HF}-\mathrm{HCl}, 0.5 \mathrm{~N}-6 \mathrm{~N}$ ). Al ser el proceso de disolución una reacción exotérmica, la disolución se hizo en un baño de hielo para eliminar la posibilidad de que el tritio escapara en forma de vapor. Finalmente alícuotas de $1 \mathrm{ml}$ se colocaron en viales de centelleo con $19 \mathrm{ml}$ de centellador líquido y se determinó el tritio total producido en la forma ya descrita.

\subsection{Cerius ${ }^{2}$ (modelos numéricos)}

Para determinar las posiciones más probables de los átomos de litio dentro de la estructura del $\mathrm{ZrSiO}_{4}$ dopado se hicieron cálculos numéricos. Esta parte del trabajo se realizó con un paquete comercial, Cerius ${ }^{2}$ [Cerius $^{2}$, 1997; Ackland, 1998]. Para refinar el modelo se llevó a cabo un estudio de distribución de cargas, empleando la teoría de funcionales de la densidad (DFT) propuesto por Khon y Sham [Khon et al., 1965]. Este 
método está basado en principios cuánticos, que han demostrado que mediante una teoria de campo medio se puede aplicar cálculos de densidades electrónicas al problema del análisis de las correlaciones entre partículas, átomos y moléculas. De esta manera la densidad electrónica juega un papel sumamente relevante. El principal logro de este método es llegar a determinar la energía de muchos electrones y consecuentemente de un mayor número de átomos. Por lo tanto, se puede aplicar para estudiar tanto moléculas como cristales.

\subsection{Dinámica molecular}

El método de dinámica molecular está basado en la solución de las ecuaciones clásicas del movimiento de $N$ partículas confinadas en un volumen $V$ para determinar el estado dinámico del sistema dado por las $6 \mathrm{~N}$ coordenadas y momentos de las partículas que componen el sistema. Esta metodología es estándar y se encuentra descrita en una serie de referencias ya clásicas [Allen et al., 1987; Demontis et al., 1992; Haile, 1997].

En la simulación de dinámica molecular de materiales con enlaces iónicos como los óxidos metálicos, es posible utilizar potenciales tipo Pauling, mediante el uso de cargas efectivas y de radios adecuados para los diferentes átomos del sistema. El potencial de tipo Pauling está descrito por la ecuación:

$$
V\left(r_{i j}\right)=q_{i} q_{j} / r_{i j}+e^{2} / n\left(\sigma_{i}+\sigma_{j}\right)\left[\left(\sigma_{i}+\sigma_{j}\right) / r_{i j}\right]^{n}
$$

donde $q$ y $\sigma$ son las cargas efectivas y los radios de cada una de las especies, respectivamente. En trabajos previos se ha demostrado que el valor más adecuado para $n$, en sistemas iónicos es 9 [Adams et al., 1975]. Los radios iónicos de los átomos son conocidos, por lo tanto los únicos parámetros a determinar en un sistema iónico de tipo Pauling son las cargas efectivas de los átomos. El empleo efectivo de este tipo de potenciales en compuestos iónicos se justifica en la bibliografia [Alvarez et al., 1994; SanMiguel et al., 1998; Alvarez et al., 1999]. 
Mediante el empleo de los procedimientos anteriormente descritos se realizó el cálculo del potencial de interacción del par de átomos empleados Li-O. En este trabajo se hizo un estudio de dinámica molecular sobre óxido de litio $\left(\mathrm{Li}_{2} \mathrm{O}\right) . \mathrm{El} \mathrm{Li}_{2} \mathrm{O}$ es un cristal iónico, por lo que la interacción $\mathrm{Li}-\mathrm{O}$ puede representarse por un potencial de corto alcance mediante el método de las sumas de Ewald [Pfeiffer et al. (3), 2000]. Las interacciones de corto alcance se generan con la sobreposición de las nubes electrónicas de los átomos. Las fuerzas resultantes presentan dos componentes, uno repulsivo y otro atractivo. El primero se debe a la impenetrabilidad de las nubes electrónicas de cada átomo, mientras que el segundo componente es atractivo debido a las cargas de las partículas. En este trabajo se empleó un potencial tipo Pauling, que se ha usado de manera eficiente en otros sistemas iónicos, como el óxido de itrio y el óxido de cromo [San-Miguel et al., 1998; Álvarez et al., 1999]. 


\section{Capítulo III}

Resultados y discusión 


\section{Capítulo III Resultados y discusión}

\subsection{Efecto del pH en los alcóxidos de zirconio}

Se hizo un estudio del efecto del $\mathrm{pH}$ en la síntesis sol-gel del metazirconato de litio $\left(\mathrm{Li}_{2} \mathrm{ZrO}_{3}\right)$ a partir de diferentes alcóxidos de zirconio, para determinar las condiciones más adecuadas de síntesis del $\mathrm{Li}_{2} \mathrm{ZrO}_{3}$. Este estudio se realizó con el objetivo de elucidar las condiciones de $\mathrm{pH}$ y el alcóxico de zirconio más adecuado para la síntesis del silicozirconato de litio. El estudio se llevó a cabo bajo dos medios de $\mathrm{pH}$, un medio ácido, en el que se empleó metóxido de litio $\left(\mathrm{LiOCH}_{3}\right)$ como alcóxido de litio y un medio básico determinado por el uso de hidróxido de litio ( $\mathrm{LiOH})$. En ambos casos, se hizo reaccionar el alcóxido de litio con cuatro diferentes alcóxidos de zirconio; etóxido de zirconio $\left(\mathrm{Zr}\left(\mathrm{OC}_{2} \mathrm{H}_{5}\right)_{4}\right)$, isopropóxido de zirconio $\left(\mathrm{Zr}\left(\mathrm{OC}_{3} \mathrm{H}_{7}\right)_{4}\right)$, propóxido de zirconio $\left(\mathrm{Zr}\left(\mathrm{OC}_{3} \mathrm{H}_{7}\right)_{4}\right)$ y butóxido de zirconio $\left(\mathrm{Zr}\left(\mathrm{OC}_{4} \mathrm{H}_{9}\right)_{4}\right)$. En todos los casos se usó como disolvente alcohol isopropilico.

\subsubsection{Identificación de los compuestos (XRD)}

Las figura 3.1 y 3.2 presentan los difractogramas de las muestras sintetizadas en medio básico y medio ácido respectivamente. En los difractogramas se identificaron $\mathrm{Li}_{2} \mathrm{ZrO}_{3}$ y $\mathrm{ZrO}_{2}$ en diferentes proporciones. Los picos de difracción son estrechos y están bien definidos, y al estar la línea base bien definida el fondo es mínimo, no existe por lo tanto material amorfo en las muestras. En las preparaciones en las que el contenido de $\mathrm{Li}_{2} \mathrm{ZrO}_{3}$ fue muy bajo o no se detectó, salta a la vista la ausencia de compuestos cristalinos de litio. Como se mencionó anteriormente se descartó la posibilidad de que el litio estuviera presente en forma de materiales amorfos, así mismo, la presencia de microcristales es improbable debido a las temperaturas de calcinación (1073 K). El litio entonces debe de estar presente en vacancias y/o posiciones intersticiales dentro de la red cristalina del $\mathrm{ZrO}_{2}$.

Los resultados obtenidos por XRD en medio básico se resumen en la figura 3.3, en donde se presenta la variación en porcentaje molar de los diferentes compuestos en función del alcóxido de zirconio empleado. Al comparar estos resultados se comprueba que en un 
medio básico los contenidos máximos de $\mathrm{Li}_{2} \mathrm{ZrO}_{3}$ se dieron cuando se usó butóxido de zirconio $(79.1 \%)$. En los casos en los que se usaron propóxido de zirconio e isoprópoxido

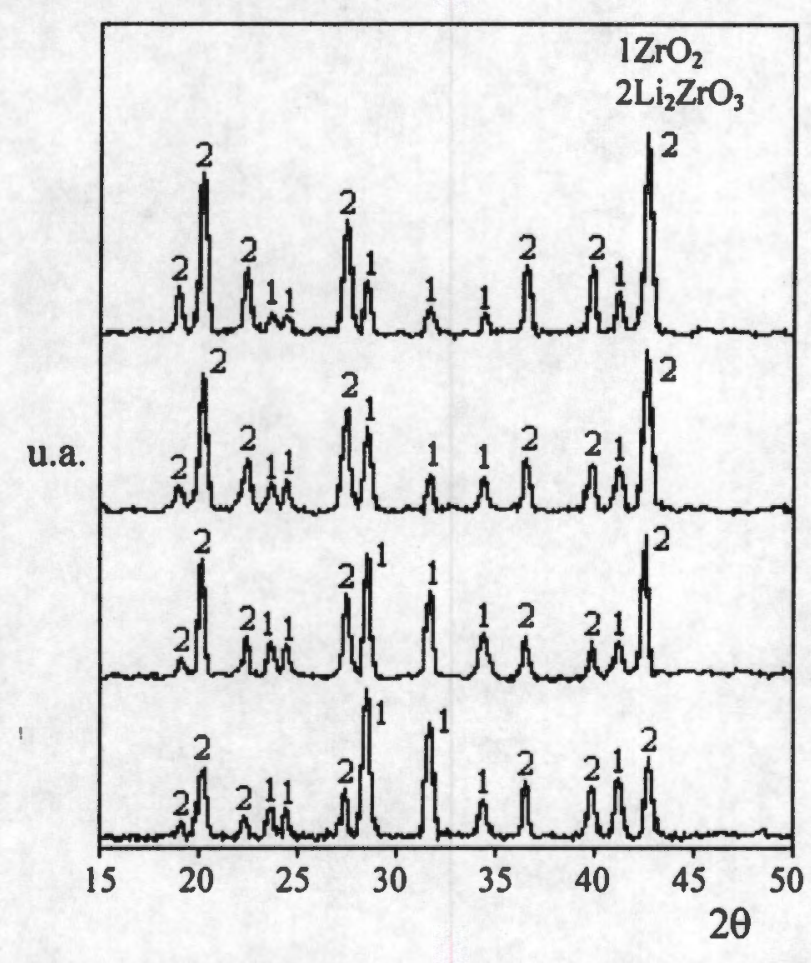

(D)

Fig. 3.1, Difractogramas de las muestras de $\mathrm{Li}_{2} \mathrm{ZrO}_{3}$ sintetizadas en un medio básico. El reactivo de zirconio empleado en cada caso fue: A) Etoxido de zirconio, B) Isopropoxido de zirconio, C) Propoxido de zirconio y D) Butoxido de zirconio.

de zirconio los rendimientos de $\mathrm{Li}_{2} \mathrm{ZrO}_{3}$ disminuyeron a $63.5 \%$ y a $51.4 \%$ respectivamente. Finalmente, en el caso del etóxido de zirconio sólo se obtuvo $35.2 \%$ de $\mathrm{Li}_{2} \mathrm{ZrO}_{3}$ y $64.8 \%$ de $\mathrm{ZrO}_{2}$.

En un medio básico, la reactividad de los alcóxidos metálicos se incrementa, por la presencia de grupos donadores de electrones $\left(\mathrm{OH}^{-}\right)$que tienden a estabilizar el metal, causándole un alto grado de hidrólisis [Brinker and Scherer, 1990]. Bajo estas condiciones, la velocidad de hidrólisis y de homocondensación de ambas especies debe ser mayor que la velocidad de heterocondensación, por lo que se favorece la formación de $\mathrm{ZrO}_{2}$ y $\mathrm{Li}_{2} \mathrm{O}$. Así se explica el alto contenido de $\mathrm{ZrO}_{2}(64.8 \%)$ en la muestra sintetizada a partir del etóxido de zirconio en medio básico. Sin embargo, el contenido de $\mathrm{ZrO}_{2}$ disminuyó conforme se 


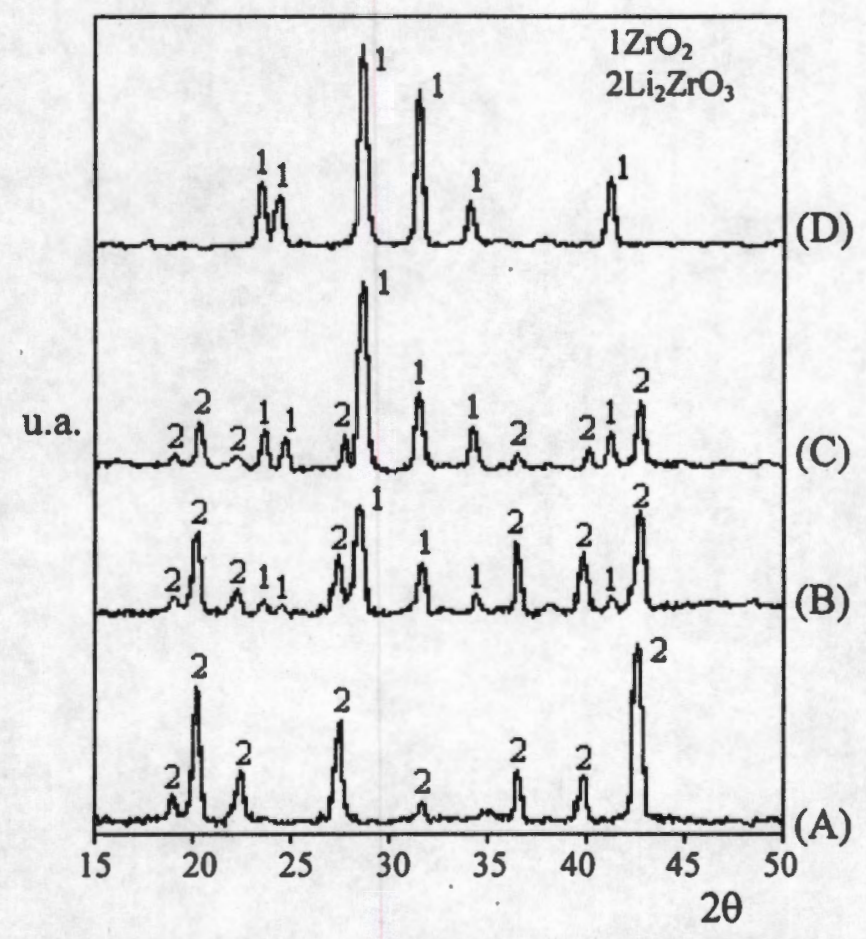

Fig. 3.2, Difractogramas de las muestras de $\mathrm{Li}_{2} \mathrm{ZrO}_{3}$ sintetizadas en un medio ácido. El reactivo de zirconio empleado en cada caso fue: A) Etoxido de zirconio, B) Isopropoxido de zirconio, C) Propoxido de zirconio y D) Butoxido de zirconio.

aumentó el número de átomos de carbono en el alcóxido de zirconio debido a un efecto inductivo de carga en el zirconio. En general, para los alcóxidos de metales de transición, la carga positiva del metal $(\delta(+\mathrm{M}))$ disminuye cuando el número de átomos de carbono en el radical alcoxi aumenta [Livage et al., 1986]. Por lo tanto, las velocidades de hidrólisis de los propóxidos de zirconio y del butóxido de zirconio son menores a la del etóxido de zirconio, lo que provoca una menor homocondensación de los alcóxidos de zirconio y por consecuencia una menor formación de $\mathrm{ZrO}_{2}$. De esta manera al disminuir la velocidad de hidrólisis en función del tamaño del radical alcoxi, la velocidad de homocondensación también se ve disminuida y tiende a igualarse con la velocidad de heterocondensación entre los alcóxidos de zirconio y de litio. 
En medio ácido, el comportamiento fue inverso al del medio básico (Fig. 3.4). Además, se lograron mejores resultados en el sentido de que, cuando se usó etóxido de zirconio se obtuvo un $100 \%$ de $\mathrm{Li}_{2} \mathrm{ZrO}_{3}$. En los casos en los que se usaron isopropóxido de zirconio o propóxido de zirconio los rendimientos de $\mathrm{Li}_{2} \mathrm{ZrO}_{3}$ fueron de $45.2 \%$ y de $27.7 \%$ respectivamente. Finalmente, con el butóxido de zirconio se obtuvo $\mathrm{ZrO}_{2}$ puro.

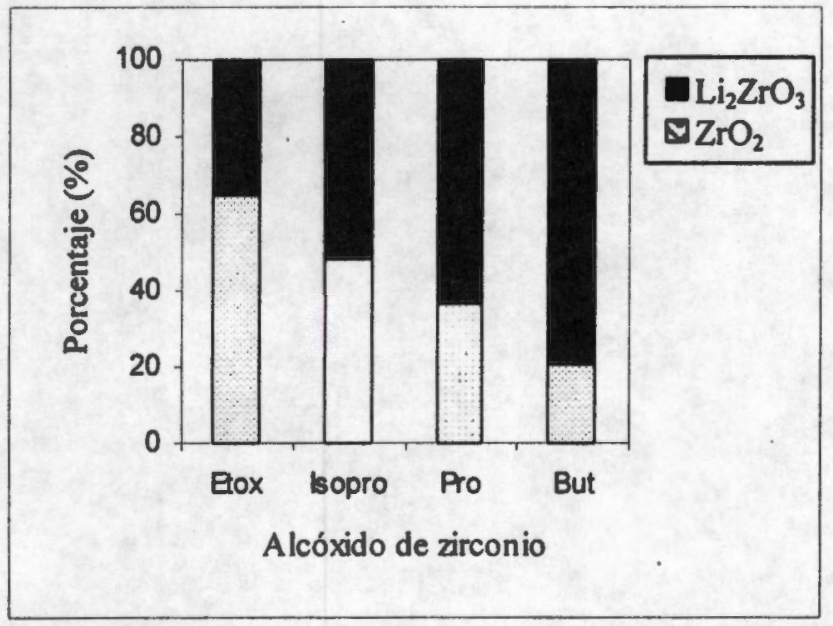

Fig. 3.3 Porcentaje de los compuestos obtenidos en función del alcóxido de zirconio, en un medio básico.

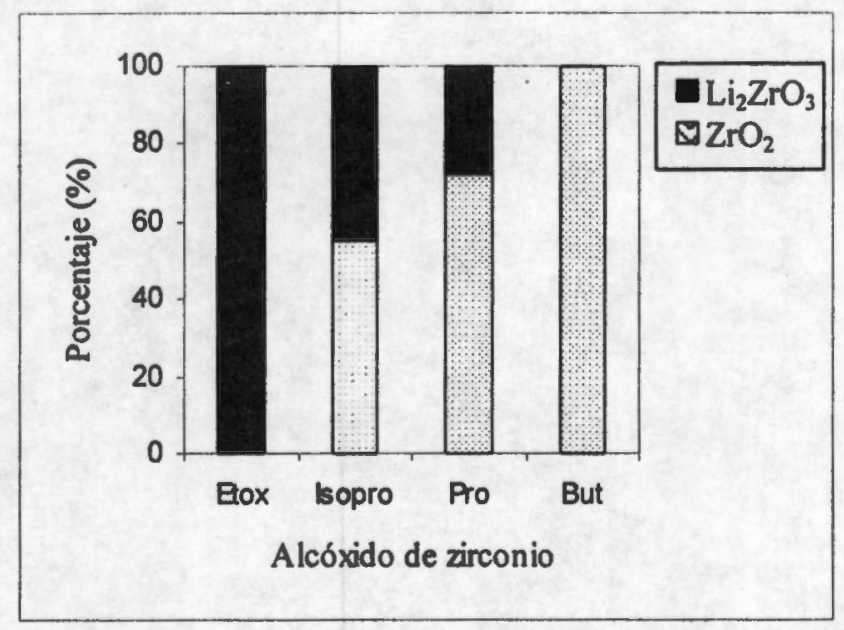

Fig. 3.4 Porcentaje de los compuestos obtenidos en función del alcóxido de zirconio, en un medio ácido. 
Según los resultados de este estudio, el empleo de un medio ácido (empleo de $\mathrm{LiOCH}_{3}$ ) junto con el etóxido de zirconio favorece la síntesis del $\mathrm{Li}_{2} \mathrm{ZrO}_{3}$. Estas condiciones seguramente son adecuadas para la síntesis del silicozirconato de litio.

\section{2 $\mathrm{Li}^{-\mathrm{ZrSiO}_{4}}$}

\subsubsection{Características físicas}

Como se mencionó en el capítulo anterior, se sintetizaron diferentes muestras de zircón $\left(\mathrm{ZrSiO}_{4}\right)$ sin litio y zircón dopado con litio $\left(\mathrm{Li}^{-} \mathrm{ZrSiO}_{4}\right)$ [Pfeiffer et al. (1), 2000]. El zircón se dopó con diferentes cantidades de litio, las razones molares de $\mathrm{Li}: \mathrm{Zr}$ empleadas fueron, $1,3,5$ y 6 . Todas las muestras calcinadas presentaron el mismo aspecto fisico, un polvo fino de color blanco mate.

\subsubsection{Identificación de compuestos (XRD)}

Por difracción de rayos $\mathrm{X}$ se analizaron las muestras de $\mathrm{ZrSiO}_{4}$ tanto sin litio como con litio (razones molares $\mathrm{Li}: \mathrm{Zr}$ de 1, 3, 5 y 6). En la figura 3.5 se muestra el difractograma de la muestra de $\mathrm{Li}-\mathrm{ZrSiO}_{4}$ con una razón molar $\mathrm{Li}: \mathrm{Zr}$ igual a 6 . En ningún difractograma se identificó ninguna fase cristalina o amorfa que no fuese $\mathrm{ZrSiO}_{4}$.

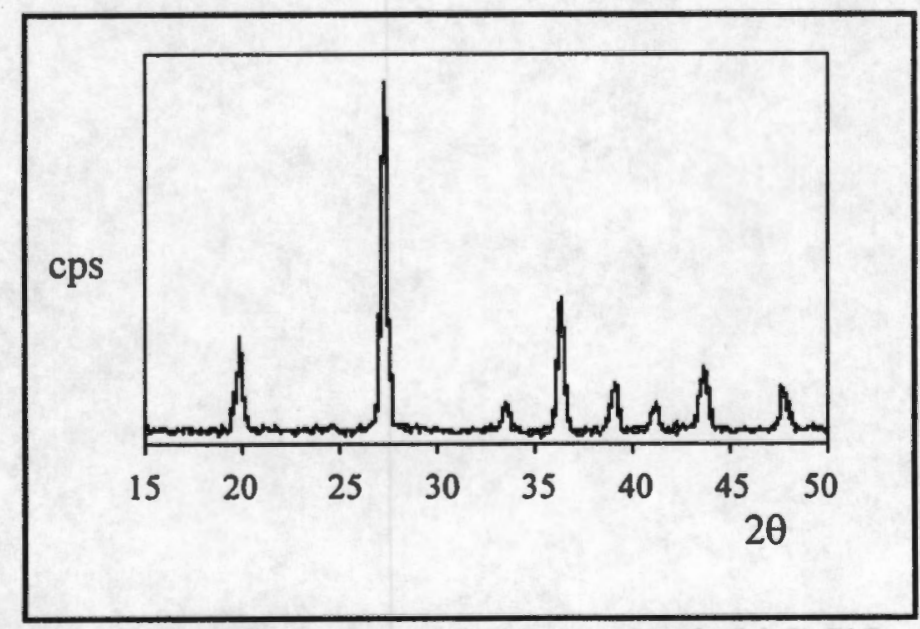

Fig. 3.5, Difractograma de la muestra de $\mathrm{Li}_{-2} \mathrm{ZrSiO}_{4}$ con una razón molar Li:Zr de 6. 
$\mathrm{Al}$ aumentar la cantidad de litio en el $\mathrm{Li}_{-} \mathrm{ZrSiO}_{4}$ las intensidades relativas de los

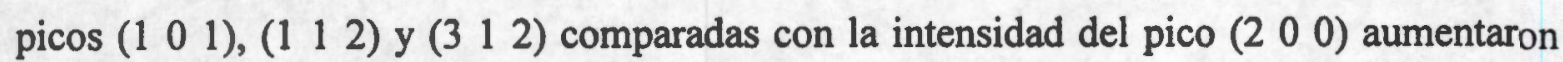
hasta en un $50 \%$. Por lo que, al parecer, el plano (2 00 ) difracta menos rayos X, y por lo tanto la población atómica es menor, es decir que hay un gran número de defectos y de vacancias. Otra posibilidad es que los átomos que están contenidos en el plano $\left(\begin{array}{lll}2 & 0 & 0\end{array}\right)$ tengan menor poder dispersor, es decir, que el litio se encuentre sustituyendo átomos de silicio y/o de zirconio. Ambos postulados son difíciles de aceptar debido a las altas temperaturas de calcinación (1673 K). Por lo tanto, el litio tiene que estar localizado intersticialmente en la estructura cristalina del $\mathrm{ZrSiO}_{4}$, de manera ordenada en los planos ( $\mathrm{k}$ 1) y, si tal conclusión es cierta, los parámetros de la red cristalina deben verse afectados.

Los parámetros de red del $\mathrm{ZrSiO}_{4}$ y de los diferentes $\mathrm{Li}_{-} \mathrm{ZrSiO}_{4}$ se calcularon para comprobar si la introducción del litio en la red había modificado la celda unidad. Para ello se empleó $\alpha-\mathrm{Al}_{2} \mathrm{O}_{3}$ (corindón) como estándar interno y los picos del $\mathrm{Li}-\mathrm{ZrSiO}_{4}$ estudiados fueron el $\left(\begin{array}{lll}2 & 0 & 0\end{array}\right)$ y el $\left(\begin{array}{lll}1 & 1 & 2\end{array}\right)$. Las figuras 3.6 y 3.7 muestran los resultados obtenidos. El parámetro de red $a_{0}$ disminuyó de $6.607 \AA$ a $6.578 \AA$ (Fig. 3.6).

En cambio el parámetro de red $c_{0}$ aumentó de $5.982 \AA$ a $6.027 \AA$ (Fig. 3.7). Los cambios en las dimensiones de la celda unidad concuerdan con la proposición de que los átomos de litio se encuentren en posiciones intersticiales. La variación en los parámetros de red sigue la misma tendencia que las que se obtuvieron para el $\mathrm{ZrSiO}_{4}$ sintetizado a altas presiones (ver capitulo I).

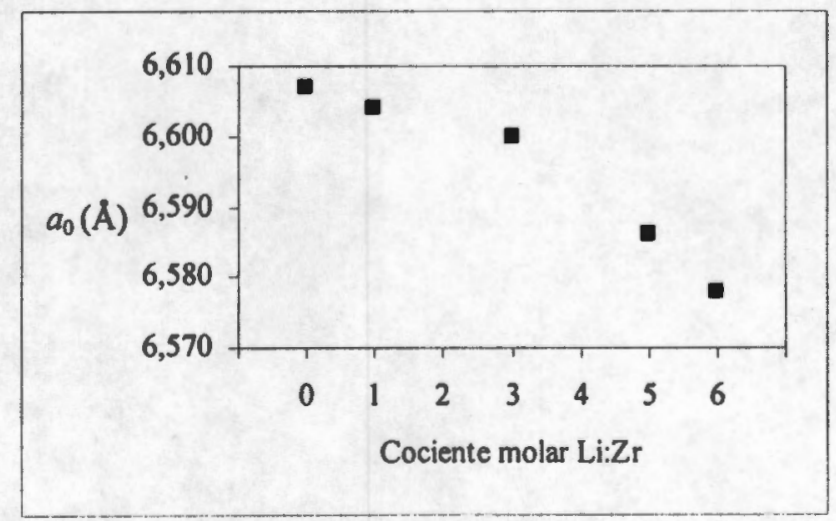

Fig. 3.6, Variación del parámetro $a_{0}$ en función de la razón molar Li:Zr. 


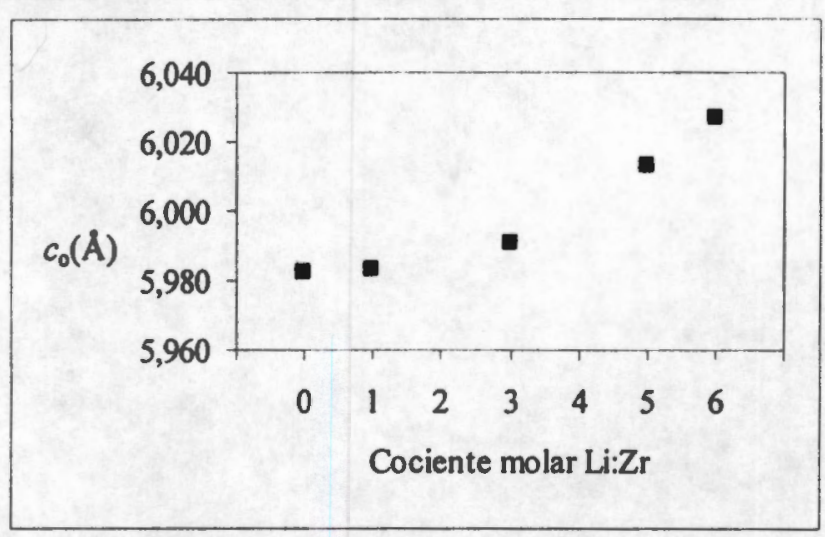

Fig. 3.7, Variación del parámetro $c_{0}$ en función de la razon molar $\mathrm{Li}: \mathrm{Zr}$.

\subsubsection{Composición superficial (XPS)}

La figura 3.8 muestra el espectro completo de la muestra de $\mathrm{ZrSiO}_{4}$. Las bandas de energía de enlace estudiadas fueron las siguientes: $\mathrm{Si}$ (1s), O (1s) y $\mathrm{Zr}$ (3d). Por desgracia, la banda de energía de enlace del $\mathrm{Zr}$ (4s) se traslapa con la banda del $\mathrm{Li}$ (1s), por lo que no

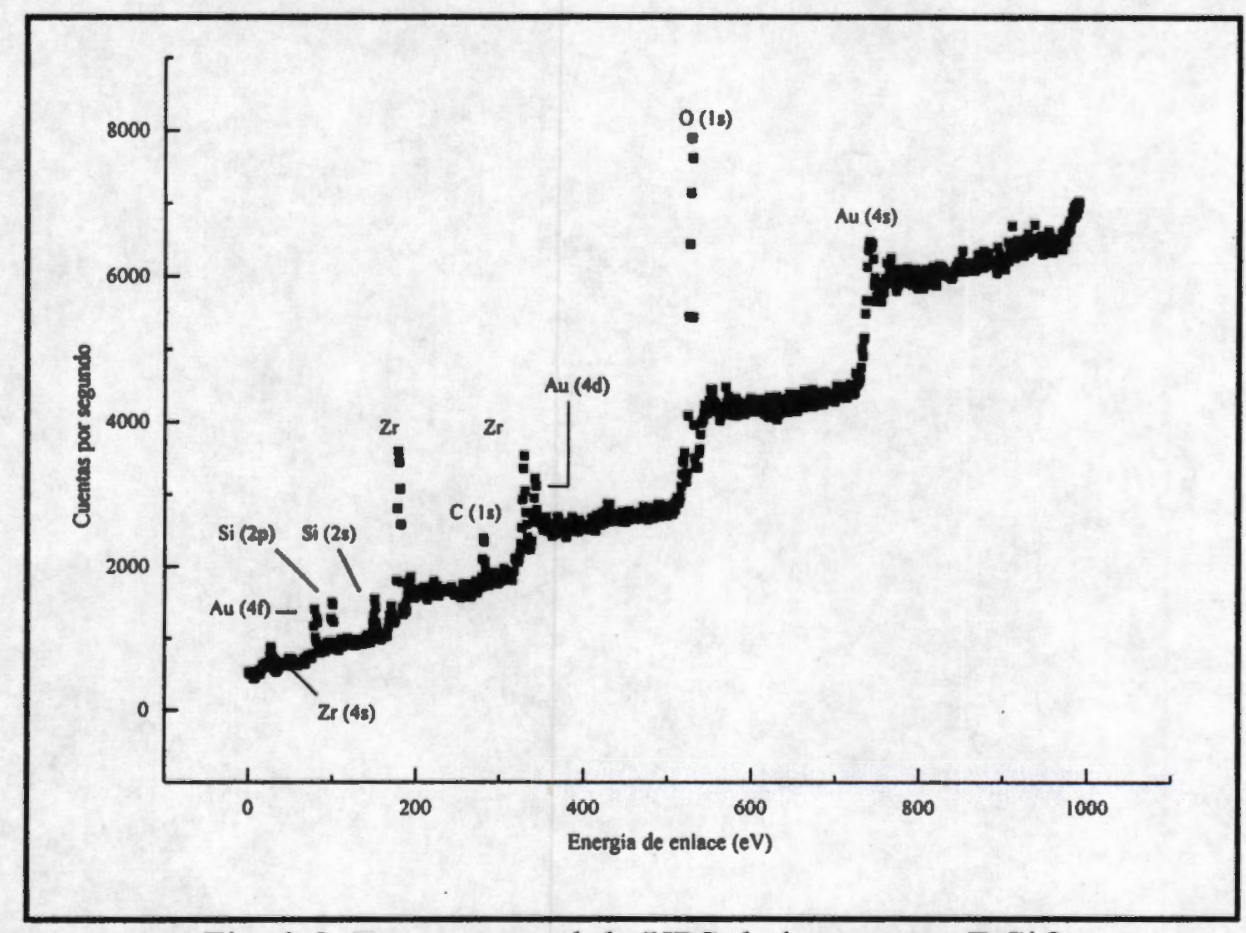

Fig. 3.8, Espectro total de XPS de la muestra $\mathrm{ZrSiO}_{4}$.

fue posible analizar el litio por esta técnica. En este espectro también se detectan bandas de oro y de carbono. Las bandas de oro son debidas a que el soporte de las muestras es de 
dicho material. Mientras que el carbono, al generarse el vacío siempre se deposita en la superficie de los materiales.

La figura 3.9 muestra el espectro de $\mathrm{O}$ (1s) para las muestras de $\mathrm{ZrSiO}_{4}$ (a) y de Li$\mathrm{ZrSiO}_{4}$ con razones molares $\mathrm{Li}: \mathrm{Zr}$ de 1 (b), 5 (c) y 6 (d). En la muestra de $\mathrm{ZrSiO}_{4}$ sin litio, se observó un pico en $531.3 \mathrm{eV}$, que se atribuyó al oxígeno del $\mathrm{ZrSiO}_{4}$. En la muestra Li$\mathrm{ZrSiO}_{4}$ con una razón molar $\mathrm{Li}: \mathrm{Zr}$ de 1 (Fig. 3.9b), se observó la presencia de un segundo pico en $533.8 \mathrm{eV}$, mientras que el primer pico se localizó en $531.6 \mathrm{eV}$. Este segundo pico en el espectro del oxígeno debe corresponder a los oxígenos asociados con el litio presente en la muestra. $\mathrm{La}$ intensidad de este pico $(\mathrm{Li}-\mathrm{O})$ depende de la razón molar $\mathrm{Li}: \mathrm{Zr}$.

La energía de enlace del $\mathrm{Si}$ (1s) en la muestra de $\mathrm{ZrSiO}_{4}$ sin litio aparece en 152.3 $\mathrm{eV}$, pero si se trata de la muestra de $\mathrm{Li}_{-} \mathrm{ZrSiO}_{4}$ con una razón molar $\mathrm{Li}: \mathrm{Zr}$ de 6 este mismo

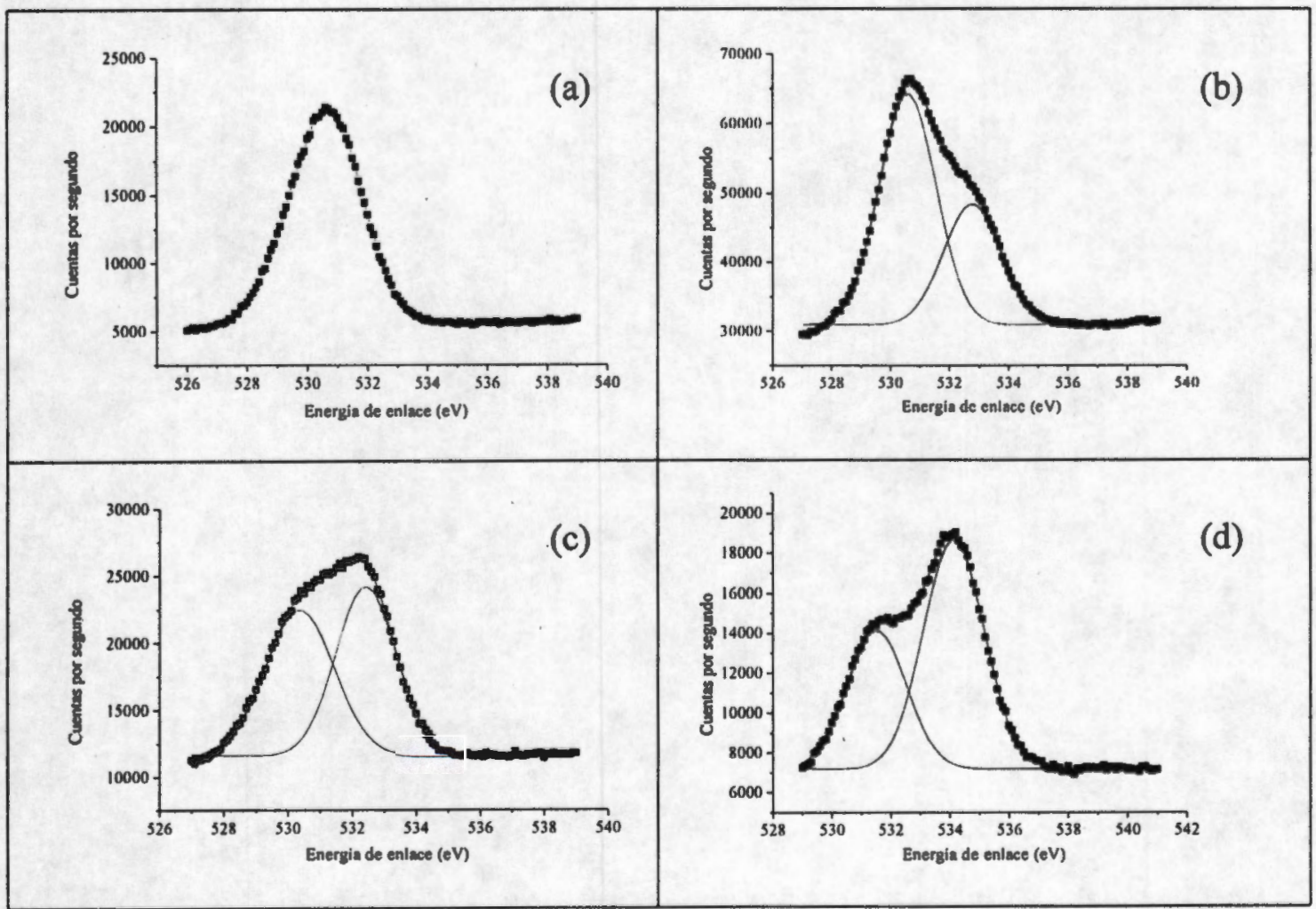

Fig. 3.9, Espectro de la energía de enlace del $\mathrm{O}$ (1s) para las muestras analizadas. (a)

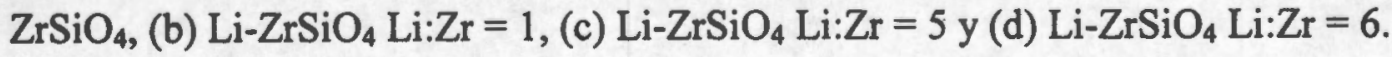


pico aparece en $154.2 \mathrm{eV}$, es decir que se ha desplazado $1.8 \mathrm{eV}$, tabla 3.1. Se encontró el mismo efecto para el $\mathrm{Zr}$ (3d) y el $\mathrm{O}$ (1s). La energía de enlace del $\mathrm{Zr}$ (3d) aumentó $1 \mathrm{eV}$, mientras que las energías de enlace del O (1s) del $\mathrm{ZrSiO}_{4}$ y del Li-O se corrieron 1 y $1.1 \mathrm{eV}$ respectivamente. El cambio en las energías de enlace de los diferentes átomos, indica una mayor energía covalente en los enlaces, probablemente debido a la superposición de los orbitales $\mathrm{Si}-\mathrm{O}, \mathrm{Zr}-\mathrm{O}$ y Li-O. Aparentemente, los átomos de litio se enlazan fuertemente a la red de $\mathrm{ZrSiO}_{4}$. Este resultado está de acuerdo con la variación de los parámetros de red encontrada por $\mathrm{XRD}$.

\section{Tabla 3.1}

Energías de enlace (eV) obtenidas por el análisis de XPS.

\begin{tabular}{ccccc}
\hline Razón molar Li:Zr & $\mathrm{Si}(1 \mathrm{~s})$ & $\mathrm{Zr}(3 \mathrm{~d})$ & $\mathrm{O}(1 \mathrm{~s})$ de $\mathrm{ZrSiO}_{4}$ & $\mathrm{O}(1 \mathrm{~s}) \mathrm{de} \mathrm{Li}-\mathrm{O}$ \\
\hline 0 & 152.3 & 181.9 & 531.3 & $-\cdots$ \\
1 & 153.6 & 182.6 & 531.5 & 533.7 \\
5 & 153.9 & 182.7 & 531.9 & 533.9 \\
6 & 154.2 & 182.9 & 532.3 & 534.9 \\
\hline
\end{tabular}

El análisis elemental de la superficie realizado por XPS se presenta en la tabla 3.2. Los resultados para todas las relaciones atómicas $\mathrm{Si}: \mathrm{Zr}$ fueron similares, aproximadamente 1:1. En la figura 3.10 se muestra cómo la relación atómica $\mathrm{O}: \mathrm{Zr}$ está relacionada con la razón molar $\mathrm{Li}: \mathrm{Zr}$ nominal. En el $\mathrm{ZrSiO}_{4}$ (sin lidio), así como para la muestra con una razón molar Li:Zr igual a 1, la relación O:Zr fue de aproximadamente 4, lo que corresponde a la relación estequiométrica. $\mathrm{Al}$ aumentar el contenido de litio en las muestras, el número de átomos de oxígeno por zirconio aumentó. Por lo tanto, con una razón molar Li:Zr de 1, el contenido de oxígeno en el $\mathrm{ZrSiO}_{4}$ no aumenta: El material es capaz, en efecto, de compensar por sí mismo un pequeño incremento de carga positiva causado por el litio, mediante una redistribución de las cargas. Cuando las cantidades de litio aumentan y, por lo tanto, también aumenta la carga positiva, la estructura del $\mathrm{ZrSiO}_{4}$ ya no tiene la capacidad de redistribuir este exceso de carga, y para balancear la carga se necesita la presencia de más oxígeno. 
Tabla 3.2

Análisis elemental de la superficie (en porcentaje).

\begin{tabular}{ccccc}
\hline Razón molar Li:Zr & Si (1s) & O (1s) & Zr (3d) & Total \\
\hline 0 & 15.4 & 70.4 & 14.2 & 100 \\
1 & 16.5 & 65.8 & 17.7 & 100 \\
5 & 11.6 & 76.0 & 12.4 & 100 \\
6 & 10.9 & 81.1 & 8.0 & 100 \\
\hline
\end{tabular}

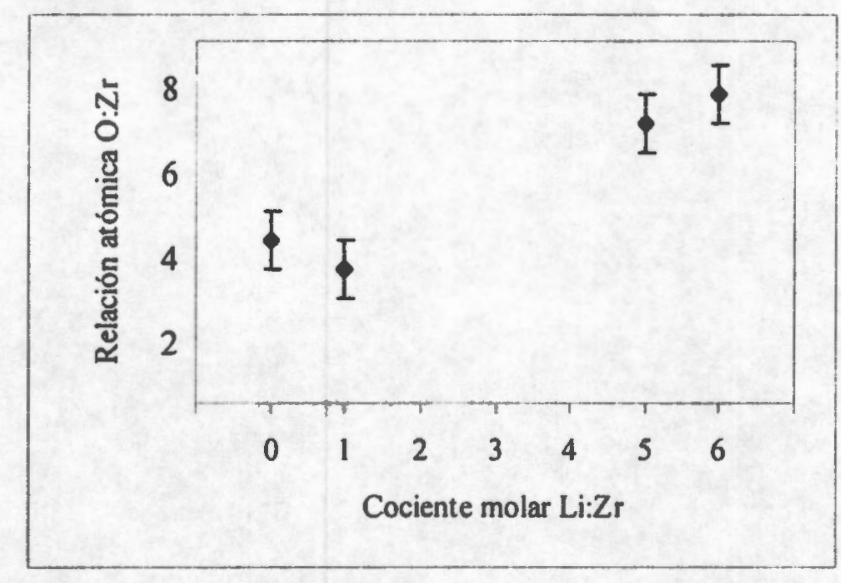

Fig. 3.10, Relación atómica de $\mathrm{O}: \mathrm{Zr}$ en función

de la razón molar Li:Zr.

\subsubsection{Identificación de litio (EELS)}

En los análisis previos se determinaron cambios estructurales (XRD) y de superficie (XPS) en las muestras de $\mathrm{Li}_{-} \mathrm{ZrSiO}_{4}$ que se atribuyeron a la presencia de litio en las muestras, pero por ninguna de estas técnicas se pudo probar directamente la presencia del litio. Con base en lo anterior, se llevó a cabo un análisis EELS con el objetivo de confirmar la existencia de litio en las muestras y de fortalecer la hipótesis de que el litio es el origen de los cambios en la estructura del $\mathrm{ZrSiO}_{4}$.

El litio se detectó sólo en las muestras de $\mathrm{Li}_{-} \mathrm{ZrSiO}_{4}$ con razones molares $\mathrm{Li}: \mathrm{Zr}$ de 5 y de 6. La banda del litio se encuentra aproximadamente en $60 \mathrm{eV}$, y está muy cerca de la banda de electrones elásticos o que no interactúan con la muestra. Así se explica la dificultad de la medida del litio mediante esta técnica. En la figura 3.11 se presenta el 
espectro EELS de la muestra con una razón molar Li:Zr de 6. La banda de electrones elásticos se superpone a la banda del litio, por lo que en este caso tan sólo se observa un pequeño cambio en la pendiente del espectro. Después de eliminar el fondo, se pudo localizar de una manera más evidente la banda del litio, además se logró observar otra banda en $102 \mathrm{eV}$, que corresponde a la energía de la banda M del silicio (Si-M). Se confirmó, entonces, la presencia del litio en las muestras de $\mathrm{Li}_{-} \mathrm{ZrSiO}_{4}$ y se confirma que los cambios estructurales y de superficie discutidos en los puntos previos se deben a la presencia de litio en la red cristalina del $\mathrm{ZrSiO}_{4}$.

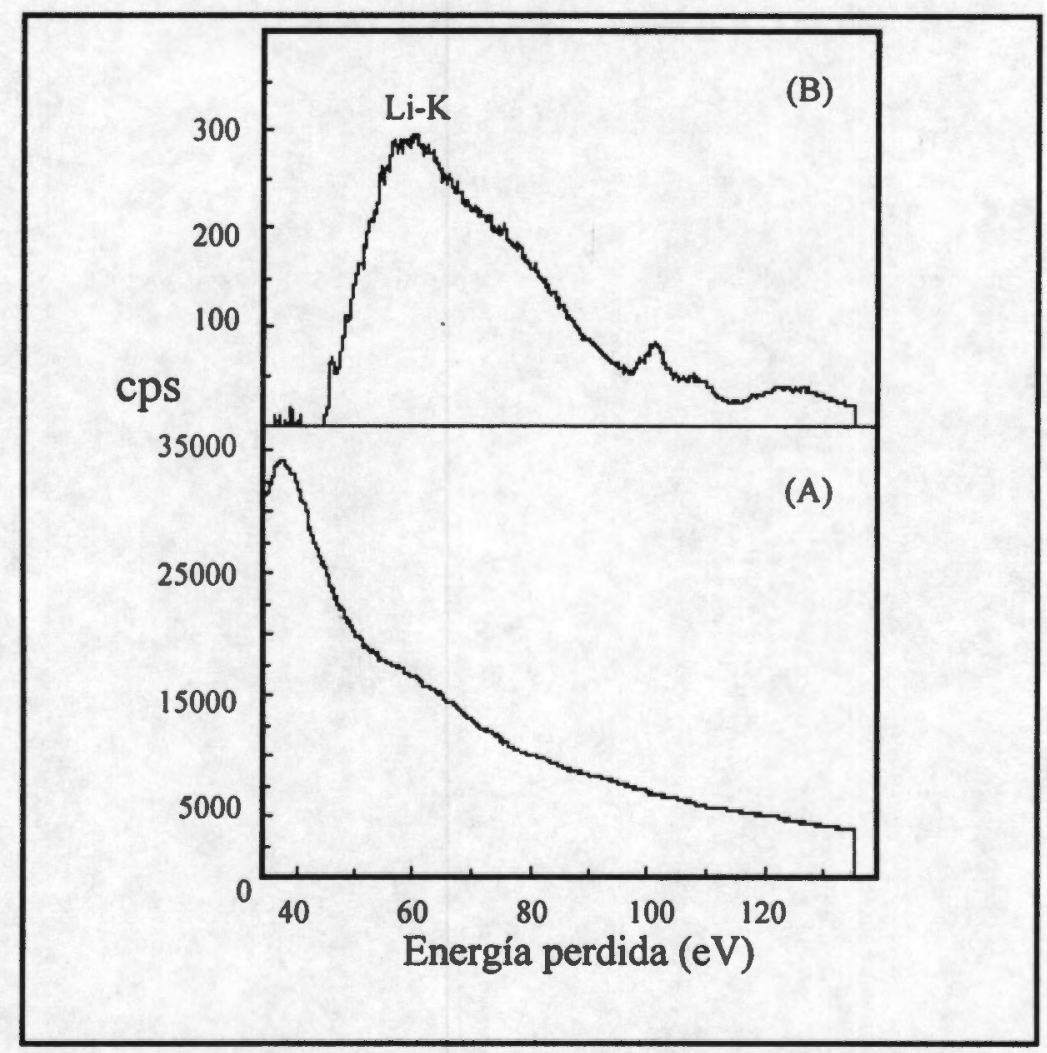

Fig. 3.11, Espectro EELS de la muestra con una razón molar $\mathrm{Li}: \mathrm{Zr}$ de 6, donde (A) es el espectro total y (B) es el espectro después de sustraerle el fondo.

\subsubsection{Comportamiento térmico (TGA)}

El $\mathrm{ZrSiO}_{4}$ es un compuesto muy estable a altas temperaturas, por lo que sólo se observaron pérdidas de masa de aproximadamente $1 \%$ en masa, tabla 3.3. La pérdida de 
masa en todas las muestras se dio en un intervalo de temperatura de 473 a $523 \mathrm{~K}$, lo cual se debe a un proceso de deshidratación [Brown, 1988; Valenzuela et al., 1996], quedando claro que el grado de hidratación es independiente de la razón molar Li:Zr, es decir, del contenido de litio.

\section{Tabla 3.3}

Porciento en masa perdida por las muestras de $\mathrm{Li}_{-} \mathrm{ZrSiO}_{4}$.

\begin{tabular}{cc}
\hline Razón molar Li:Zr & Masa perdida (\%) \\
\hline 0 & 0.8 \\
1 & 1.0 \\
3 & 0.8 \\
5 & 1.1 \\
6 & 0.9 \\
\hline
\end{tabular}

\subsection{6 Área superficial (BET)}

Así como en el análisis TGA se observaron bajos porcentajes de pérdida de masa, en el caso del área superficial por el método BET se obtuvieron también áreas pequeñas. La tabla 3.4 presenta los resultados.

Tabla 3.4

Área superficial calculada por el método BET.

\begin{tabular}{cc}
\hline Razón molar Li:Zr & Área $\left(\mathrm{m}^{2} / \mathrm{g}\right)$ \\
\hline 0 & 14.2 \\
1 & 15.0 \\
3 & 14.7 \\
5 & 15.8 \\
6 & 14.9 \\
\hline
\end{tabular}


Las áreas superficiales obtenidas fueron bajas y prácticamente iguales considerando el factor de error, $5 \%$. Las muestras presentaron áreas alrededor de $15 \mathrm{~m}^{2} / \mathrm{g}$, como era de esperarse debido a las altas temperaturas de calcinación. Además, la variación en la razón molar Li:Zr no afectó el valor del área superficial que permaneció constante.

\subsubsection{Morfología de los cristales (SEM)}

Las partículas de $\mathrm{ZrSiO}_{4}$ presentaron formas poliédricas con superficies planas y no se observó variación alguna debida al dopaje con litio. El tamaño promedio de estas partículas fue de $40-50 \times 10^{4} \AA$. La figura 3.12 presenta una micrografia del $\mathrm{Li}_{-} \mathrm{ZrSiO}_{4}$ con una razón molar $\mathrm{Li}: \mathrm{Zr}$ de 1 . Aunque la composición de la superficie varíe en función de la razón molar Li:Zr (XPS), la morfología de las partículas no se ve afectada. El litio, está distribuido de una manera homogénea en el volumen y en la superficie del $\mathrm{ZrSiO}_{4}$ y no altera los parámetros morfológicos macroscópicos del material.

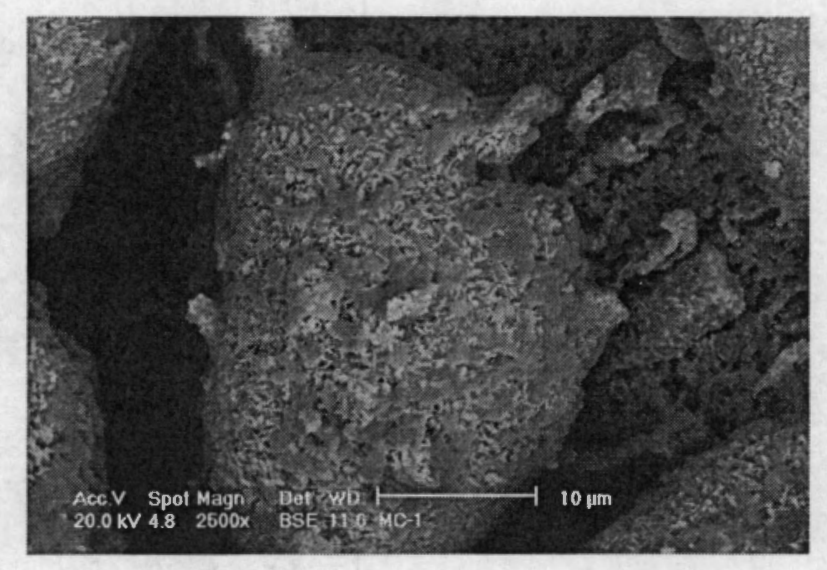

Fig. 3.12, Análisis SEM de la muestra de

$\mathrm{Li}-\mathrm{ZrSiO}_{4}$ con una razón molar $\mathrm{Li}: \mathrm{Zr}$ igual a 6.

\subsubsection{Análisis numérico (Cerius ${ }^{2}$ )}

$\mathrm{El}$ modelo de $\mathrm{ZrSiO}_{4}$ se construyó a partir de los valores reportados por Hyde et al. [Hyde et al., 1989]. Para refinar el modelo se realizó un estudio de distribución de cargas, empleando la teoría de funcionales de la densidad (DFT) propuesto por Khon y Sham 
[Khon et al., 1965], y mediante el software Cerius ${ }^{2}$, el cual esta basado en principios cuánticos (ver sección 2.4) [Cerius ${ }^{2}, 1997$; Ackland, 1998]. Para estudiar la estructura del Li- $\mathrm{ZrSiO}_{4}$ con una razón molar $\mathrm{Li}: \mathrm{Zr}$ de 6 , se hizo un análisis DFT, mediante el empleo de CASTEP, determinando los estados electrónicos iniciales y finales de los sistemas con litio y $\sin$ litio.

La figura 3.13 muestra las celdas unidad de $\mathrm{ZrSiO}_{4}$ con y sin átomos de litio, en el plano cristalográfico $\left(\begin{array}{lll}1 & 1 & 1\end{array}\right)$. Como lo sugieren los resultados de XPS y para balancear la carga total del sistema, se agregaron átomos de oxígeno a la configuración que contiene átomos de litio.

Al minimizar la energía en ambos sistemas, el $\mathrm{ZrSiO}_{4}$ sin litio, como era de esperarse, no presentó ningún cambio estructural. En cambio en el sistema $\mathrm{Li}_{-} \mathrm{ZrSiO}_{4}$, los átomos de litio ocuparon posiciones intersticiales en la red del $\mathrm{ZrSiO}_{4}$. Además, los parámetros de red se vieron modificados, el parámetro $a_{0}$ decreció de $6.607 \AA$ a $6.572 \AA$, mientras que $c_{0}$ aumentó de $5.982 \AA$ a $6.039 \AA$. Estos resultados concuerdan con los resultados experimentales obtenidos por XRD y corroboran las hipótesis que se propusieron entonces.


Fig. 3.13, Esquema de la estructura del $\mathrm{ZrSiO}_{4}$ (a) sin átomos de litio y (b) con átomos de litio, plano (llll). 
Para localizar la posición de los átomos de litio dentro de la red de $\mathrm{ZrSiO}_{4}$ se calculó la distribución de cargas, figura 3.14. La densidad de carga electrónica es baja en los canales de la red que siguen la dirección $\left[\begin{array}{lll}0 & 0 & 1\end{array}\right]$. Estos canales de baja densidad electrónica están rodeados, principalmente, por átomos de oxígeno y algunos de silicio que determinan su forma. Estos conductos son cavidades abiertas que seguramente favorecen la difusión.

La figura 3.15 muestra la celda unidad del $\mathrm{ZrSiO}_{4}$ con litio y sin litio en la

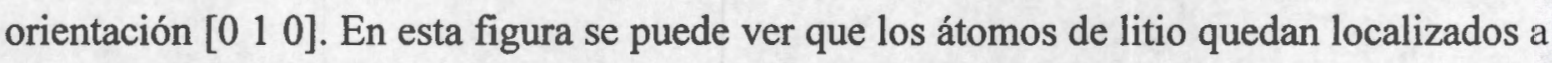
$1 / 4$ y $3 / 4$ del parámetro $c_{0}$ de la celda unidad. Es importante hacer notar que la presencia de los átomos de litio sólo altera la disposición de los oxígenos, es más, los átomos de litio ocupan posiciones regulares periódicas y definidas dentro de la red del $\mathrm{ZrSiO}_{4}$ como se muestra en los diagramas isosuperficiales de densidad de carga de la figura 3.16. Aquí cabe recalcar el hecho de que los átomos de litio están localizados antisimétricamente a lo largo del eje X.

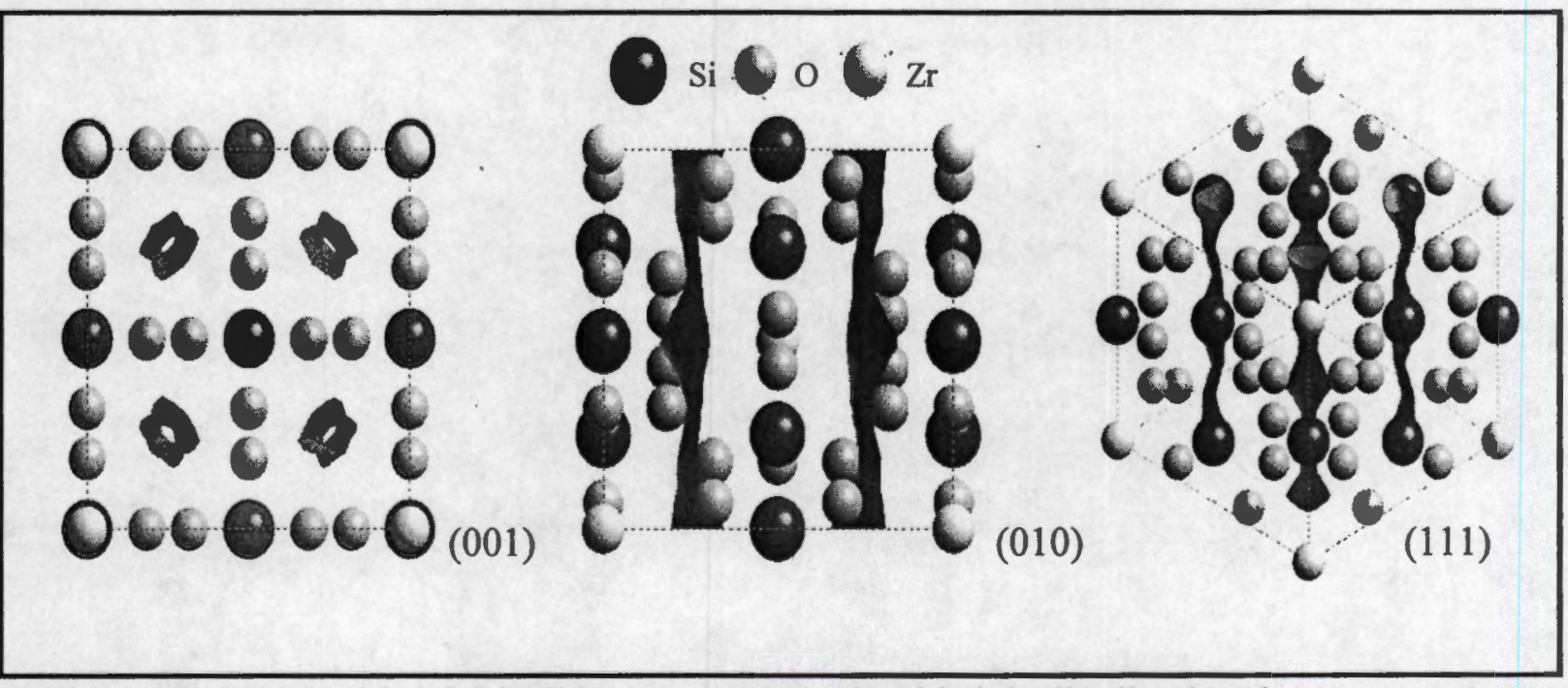

Fig. 3.14, Celda unidad del $\mathrm{ZrSiO}_{4}$ mostrando la densidad de distribución de carga, según



Los resultados obtenidos con los modelos del sistema $\mathrm{Li}_{-} \mathrm{ZrSiO}_{4}$ concuerdan con los resultados experimentales, por lo tanto se confirma que los átomos de litio están colocados en posiciones intersticiales dentro de la red del $\mathrm{ZrSiO}_{4}$, y que la presencia de los átomos de litio modifica los parámetros de la red. 


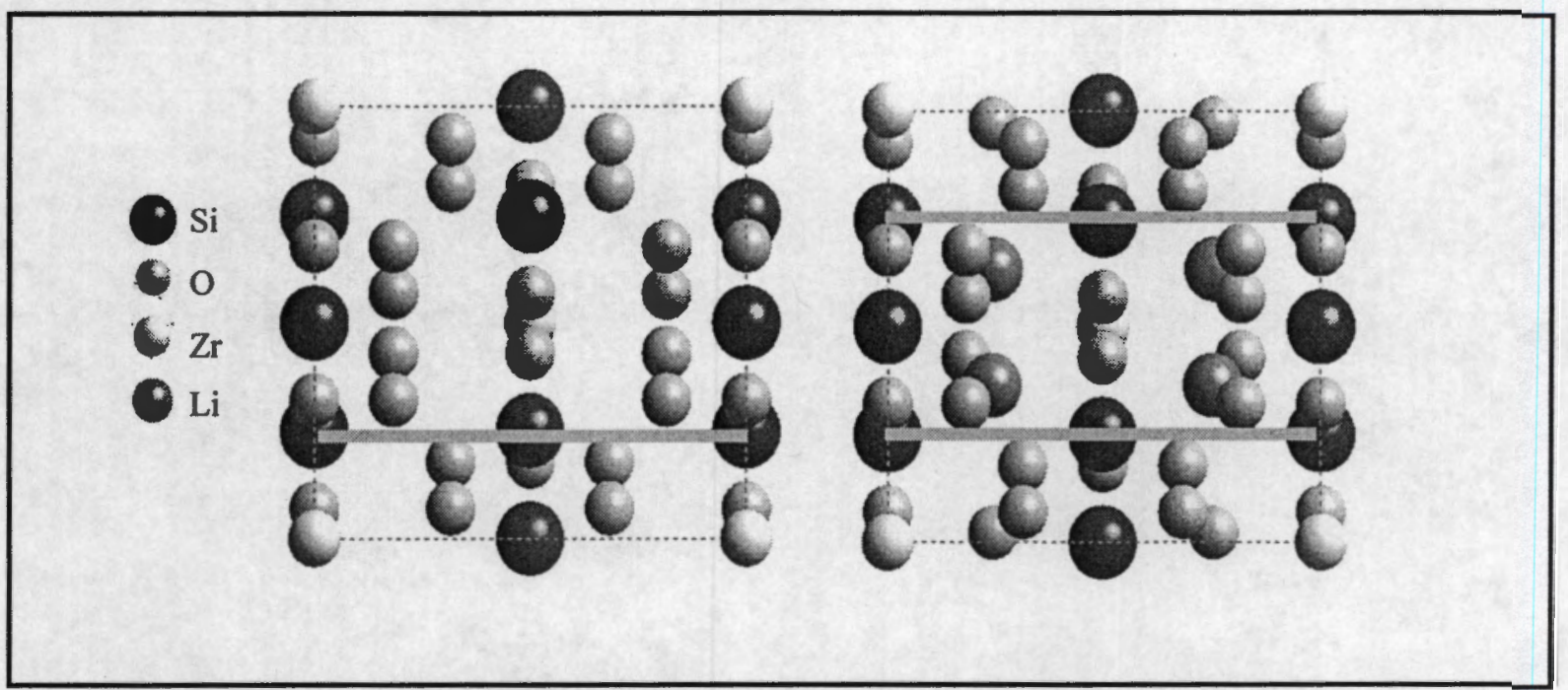

Fig. 3.15, Celda unidad del $\mathrm{ZrSiO}_{4}$, (a) sin litio y (b) con litio en la orientación [ $\left[\begin{array}{lll}0 & 1 & 0\end{array}\right]$ donde se muestran los cortes seleccionados.

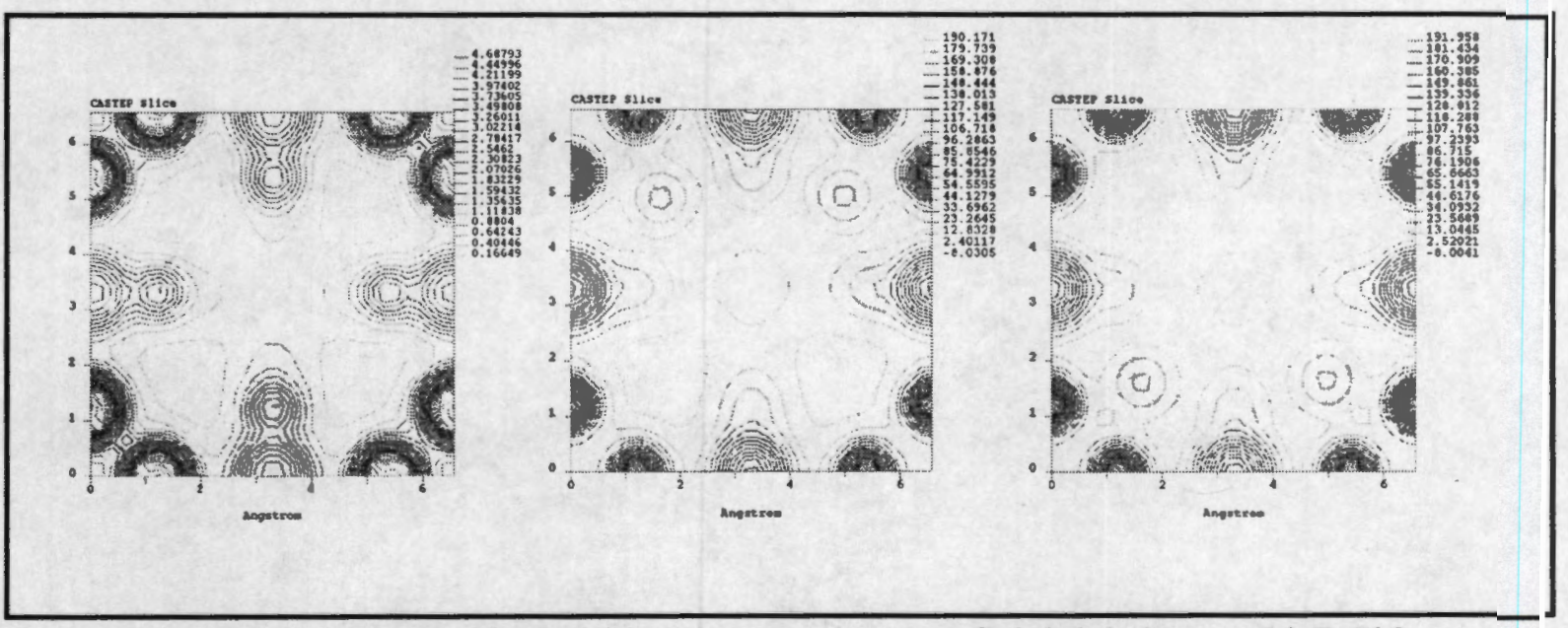

Fig. 3.16, Diagramas de densidad de carga isosuperficial del sistema $\mathrm{Li}^{-} \mathrm{ZrSiO}_{4}$.

\section{3 $\mathrm{Li}_{2} \mathrm{ZrSi}_{6} \mathrm{O}_{15}$}

\subsubsection{Características físicas}

En la síntesis del silicozirconato de litio $\left(\mathrm{Li}_{2} \mathrm{ZrSi}_{6} \mathrm{O}_{15}\right)$ se estudió el efecto de la variación de la razón molar $\mathrm{Li}: \mathrm{Zr}: \mathrm{Si}$ para obtener el mejor rendimiento de $\mathrm{Li}_{2} \mathrm{ZrSi}_{6} \mathrm{O}_{15}$ [Pfeiffer et al. (2), 2000]. En todos los casos la razón molar de silicio en los reactivos fue de seis, de acuerdo con la fórmula estequiométrica del $\mathrm{Li}_{2} \mathrm{ZrSi}_{6} \mathrm{O}_{15}$, las razones molares que se 
variaron fueron las de litio y las de zirconio. Después de calcinar las muestras, todos los polvos presentaron el mismo aspecto físico, un polvo muy fino de color blanco opaco.

\subsubsection{Identificación de compuestos (XRD)}

Las muestras sintetizadas resultaron ser mezclas de los siguientes compuestos: óxido de zirconio $\left(\mathrm{ZrO}_{2}\right.$, badelellita), óxido de silicio $\left(\mathrm{SiO}_{2}\right.$, cuarzo), metazirconato de litio $\left(\mathrm{Li}_{2} \mathrm{ZrO}_{3}\right)$, metasilicato de litio $\left(\mathrm{Li}_{2} \mathrm{SiO}_{3}\right)$ y silicozirconato de litio $\left(\mathrm{Li}_{2} \mathrm{ZrSi}_{6} \mathrm{O}_{15}\right)$. En las figuras $3.17,3.18$ y 3.19 se resumen los resultados obtenidos, en porcentajes molares.

Cuando el contenido de litio fue de $1 \mathrm{~mol}$ y la razón Li:Zr de 1:1, figura 3.17, sólo se obtuvo $\mathrm{SiO}_{2}$ (47\%) y ZrO $(53 \%)$. En cambio cuando la razón molar $\mathrm{Li}: \mathrm{Zr}$ se disminuyó a 1:2 se obtuvo el $\mathrm{Li}_{2} \mathrm{ZrSi}_{6} \mathrm{O}_{15}$ en un porcentaje de $28 \%$, también se formaron; $\mathrm{ZrO}_{2}(65 \%)$ y $\mathrm{SiO}_{2}$ en cuyo caso el rendimiento decreció a tan sólo un $7 \%$. Cuando se empleó una razón molar de $\mathrm{Li}: \mathrm{Zr}$ igual a 1:3, no se obtuvo el $\mathrm{Li}_{2} \mathrm{ZrSi}_{6} \mathrm{O}_{15}$, en este caso los productos fueron $\mathrm{ZrO}_{2}(35 \%), \mathrm{SiO}_{2}(58 \%)$, y además $\mathrm{Li}_{2} \mathrm{ZrO}_{3}(7 \%)$. La presencia de esta nueva fase se debe atribuir al exceso de $\mathrm{Zr}$ empleado en la reacción. Finalmente, la razón molar $\mathrm{Li}: \mathrm{Zr}$ igual a 1:4 arrojó resultados muy parecidos a la razón molar anterior $(\mathrm{Li}: \mathrm{Zr}=1: 3)$. Es evidente que bajo estas condiciones experimentales se obtienen altos porcentajes tanto de $\mathrm{SiO}_{2}$ como de $\mathrm{ZrO}_{2}$, en el caso de la razón molar de $\mathrm{Li}: \mathrm{Zr}$ igual a $1: 2$ se obtuvo además $\mathrm{Li}_{2} \mathrm{ZrSi}_{6} \mathrm{O}_{15}$ en muy bajas proporciones $28 \%$.

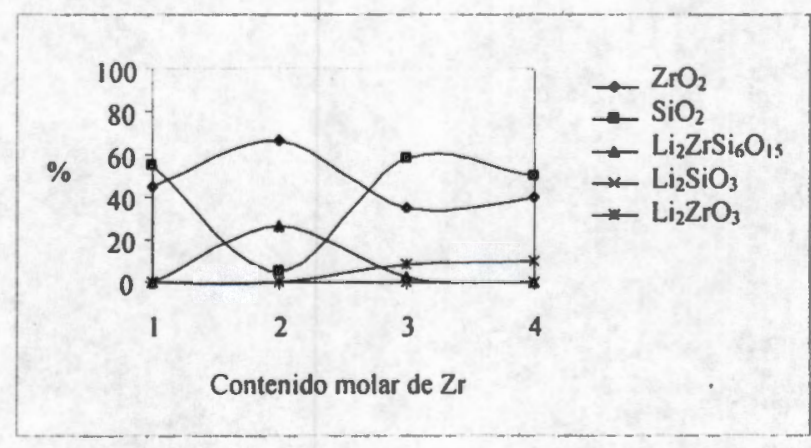

Fig. 3.17, Porcentaje de cada compuesto en función del contenido molar de $\mathrm{Zr}$, donde [Li] $=1$. 
Los resultados obtenidos para la razón molar litio igual a 2, se presentan en la figura 3.18. Para una razón molar $\mathrm{Li}: \mathrm{Zr}$ de $2: 1$, sólo se obtuvieron $\mathrm{SiO}_{2}$ y $\mathrm{ZrO}_{2}$ en proporciones similares, $46 \%$ y $54 \%$ respectivamente. En el caso de una razón molar de Li:Zr igual a 2:2 se formaron nuevamente $\mathrm{SiO}_{2}$ y $\mathrm{ZrO}_{2}$, pero sus porcentajes decrecieron a tan sólo 5 y $6 \%$ respectivamente, en este caso el producto mayoritario fue el $\mathrm{Li}_{2} \mathrm{ZrSi}_{6} \mathrm{O}_{15}$, con un rendimiento del $89 \%$. Sin embargo, cuando la razón molar Li:Zr se fijó en $2: 3$ el rendimiento de $\mathrm{Li}_{2} \mathrm{ZrSi}_{6} \mathrm{O}_{15}$ decreció a $6 \%$ y uno de los productos principales fue el $\mathrm{ZrO}_{2}$ (43\%), se formaron además $\mathrm{Li}_{2} \mathrm{SiO}_{3}$ y $\mathrm{Li}_{2} \mathrm{ZrO}_{3}, 40$ y $11 \%$ respectivamente. Finalmente, para la razón molar $\mathrm{Li}: \mathrm{Zr}$ de 2:4, ya no se obtuvo $\mathrm{Li}_{2} \mathrm{ZrSi}_{6} \mathrm{O}_{15}$ y el resto de los productos se obtuvieron en proporciones similares a la razón molar anterior. En resumen, en este sistema las relaciones extremas de $\operatorname{Zr}(1$ y 4 ) presentaron mezclas de óxidos, mientras que con la razón molar $\mathrm{Li}: \mathrm{Zr}$ de 2:2 se produjo $89 \%$ de $\mathrm{Li}_{2} \mathrm{ZrSi}_{6} \mathrm{O}_{15}$.

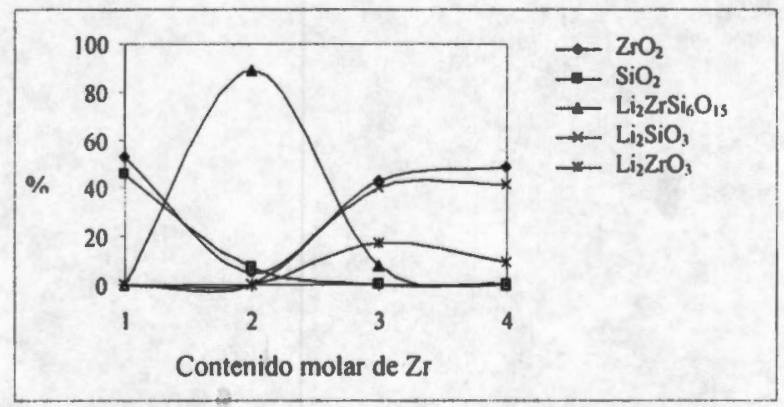

Fig. 3.18, Porcentaje de cada compuesto en función del contenido molar de $\mathrm{Zr}$, donde $[\mathrm{Li}]=2$.

Los resultados obtenidos al variar la razón molar Li:Zr, fijando la cantidad de litio en 3 moles, se presentan en la figura 3.19. Para la razón molar Li: $\mathrm{Zr}$ de 3:1 se encontraron solamente $\mathrm{SiO}_{2}(60 \%)$ y $\mathrm{ZrO}_{2}(40 \%)$. Cuando la razón molar $\mathrm{Li}: \mathrm{Zr}$ se aumentó a $3: 2$ el producto principal fue $\mathrm{Li}_{2} \mathrm{ZrSi}_{6} \mathrm{O}_{15}(55 \%)$, obteniéndose también $\mathrm{ZrO}_{2}(45 \%)$ mientras que no se formó $\mathrm{SiO}_{2}$. En el caso de una razón molar $\mathrm{Li}: \mathrm{Zr}$ de 3:3, los contenidos de $\mathrm{SiO}_{2}$ y $\mathrm{ZrO}_{2}$ fueron de 30 y $35 \%$ respectivamente, y también aparecieron $\mathrm{Li}_{2} \mathrm{SiO}_{3}$ y $\mathrm{Li}_{2} \mathrm{ZrO}_{3}$ en proporciones de 15 y $20 \%$. Finalmente, para la razón molar Li:Zr igual a 3:4, se identificaron los mismos compuestos que con la razón molar anterior, manteniéndose proporciones muy similares entre ellos. 


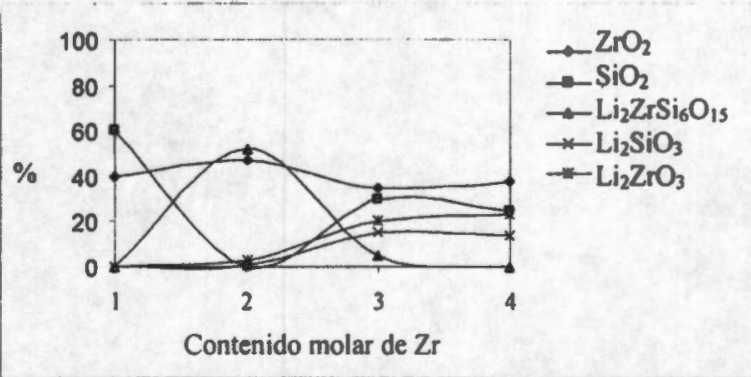

Fig. 3.19, Porcentaje de cada compuesto en función del contenido molar de $\mathrm{Zr}$, donde $[\mathrm{Li}]=3$.

En la figura 3.20 se presenta el difractograma de la muestra con una razón molar $\mathrm{Li}: \mathrm{Zr}: S i$ de 2:2:6, en este caso el producto principal fue el $\mathrm{Li}_{2} \mathrm{ZrSi}_{6} \mathrm{O}_{15}(89 \%)$, además de $\mathrm{ZrO}_{2}$ y $\mathrm{SiO}_{2}$. En este difractograma se puede apreciar el alto grado de cristalinidad de los compuestos, así como la ausencia de orientaciones preferenciales. Todas las muestras sintetizadas presentaron el mismo comportamiento.

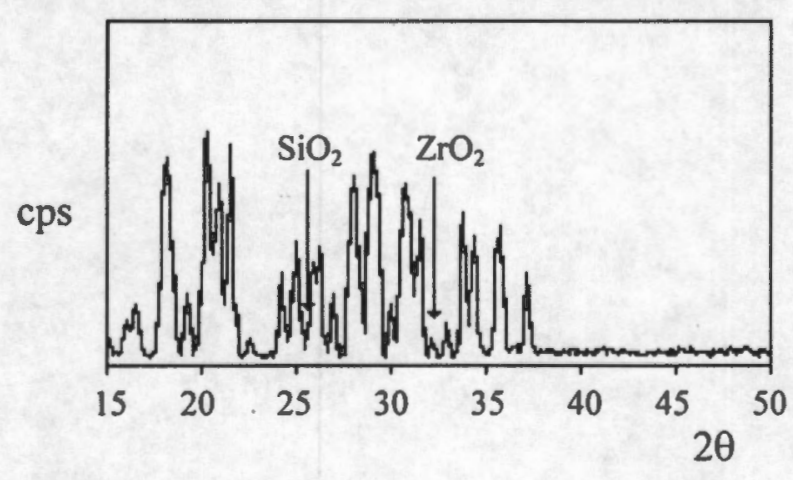

Fig. 3.20, Difractograma de la muestra de silicozirconato de litio sintetizada a partir de una razón molar Li:Zr:Si igual a 2:2:6.

En los tres casos $(\mathrm{Li}=1,2$ y 3$)$ el mayor rendimiento de $\mathrm{Li}_{2} \mathrm{ZrSi}_{6} \mathrm{O}_{15}$ se logró cuando la razón molar de $\mathrm{Li}: \mathrm{Zr}$ fue 2:2. Se alcanzó un $89 \%$ de $\mathrm{Li}_{2} \mathrm{ZrSi}_{6} \mathrm{O}_{15}$ para una razón molar $\mathrm{Li}: \mathrm{Zr}: \mathrm{Si}=2: 2: 6$. Como en las muestras de $\mathrm{Li}_{-} \mathrm{ZrSiO}_{4}$ y según la misma argumentación, sugerimos que el litio ocupa posiciones intersticiales en la red de $\mathrm{Li}_{2} \mathrm{ZrSi}_{6} \mathrm{O}_{15}$ ó de $\mathrm{ZrO}_{2}$. 
Con base en los resultados obtenidos mediante la técnica de $\mathrm{XRD}$, quedó claro que sólo las muestras con mayor contenido de $\mathrm{Li}_{2} \mathrm{ZrSi}_{6} \mathrm{O}_{15}$ son interesantes en este estudio. Estas muestras son las que presentan una razón molar Li:Zr:Si igual a 1:2:6, 2:2:6 y 3:2:6 y son por lo tanto las únicas que se estudian en las siguientes secciones.

\subsubsection{Identificación de compuestos (FTIR)}

En la figura 3.21 se presenta el espectro infrarrojo de la muestra cuya razón molar Li:Zr:Si es 2:2:6. El primer pico localizado entre 1100 y $1040 \mathrm{~cm}^{-1}$ se atribuye a la vibración O-Si-O ( $\delta$ ) [Nakamoto, 1986]. El pico en $986 \mathrm{~cm}^{-1}$ corresponde a la vibración Si$\mathrm{O}$ en el ion $\left(\mathrm{Si}_{2} \mathrm{O}_{5}\right)^{2-}$ que es la fórmula mínima del $\left(\mathrm{Si}_{6} \mathrm{O}_{15}\right)^{6-}$ [Anderson et al., 1969]. Los dos picos siguientes pueden interpretarse como vibraciones $\mathrm{Zr}-\mathrm{O}\left(943\right.$ y $852 \mathrm{~cm}^{-1}$ ) [Ross, 1972]. Se encontraron otras vibraciones de Si-O (v) y Si-O-Si ( $\delta$ ) en 730 y $624 \mathrm{~cm}^{-1}$ respectivamente [Ross, 1972; Robinson, 1994]. La vibración Li-O aparece en $533 \mathrm{~cm}^{-1}$ [Robinson, 1994], seguida de una vibración $\mathrm{Zr}-\mathrm{O}$ en $502 \mathrm{~cm}^{-1}$ [Ross, 1972; Nakamoto, 1986].



Fig. 3.21, Espectro IR de la muestra sintetizada

con una razón molar Li:Zr:Si de 2:2:6. 
Las otras dos muestras analizadas por espectroscopía IR ( $\mathrm{Li}: \mathrm{Zr}: \mathrm{Si}=1: 2: 6$ y $3: 2: 6$ ) presentaron espectros de IR similares, variando únicamente algunas de sus intensidades. En todos los casos el espectro IR presentó una serie de vibraciones conocidas entre átomos de silicio y oxígeno como $\mathrm{Si}-\mathrm{O}(v)$, Si-O-Si $(\delta)$ y O-Si-O $(\delta)$. Además, se identificó la vibración del sistema $\left(\mathrm{Si}_{2} \mathrm{O}_{5}\right)^{2-}$, que como se mencionó anteriormente, es la formula mínima del $\left(\mathrm{Si}_{2} \mathrm{O}_{15}\right)^{6-}$. Este resultado confirma lo obtenido por XRD en cuanto a que el único silicato presente en estas muestras es el $\left(\mathrm{Si}_{2} \mathrm{O}_{5}\right)^{2-}$. Finalmente, los espectros mostraron una banda ancha en $3300 \mathrm{~cm}^{-1}$, que se atribuyó a la vibración $\mathrm{O}-\mathrm{H}$.

\subsubsection{Comportamiento térmico (TGA)}

Los resultados de las muestras cuya razón molar $\mathrm{Li}: \mathrm{Zr}: \mathrm{Si}$ es $1: 2: 6,2: 2: 6$ y 3:2:6 se resumen en la tabla 3.5. En todos los casos la primera pérdida de masa ocurre justo antes de $573 \mathrm{~K}$, lo cual se atribuye a una deshidratación de las muestras. Debido a esta deshidratación cada una de las muestras perdió aproximadamente $4 \%$ en masa. La segunda y última pérdida de masa ocurrió entre 773 y $923 \mathrm{~K}$, la pérdida de masa en este intervalo de temperaturas se debe atribuir a un proceso de deshidroxilación de las muestras, así como a la combustión de compuestos orgánicos aun existentes dentro de la muestra [Brown, 1988; Valenzuela et al., 1996].

Tabla 3.5

Porciento en masa perdida por las muestras de $\mathrm{Li}_{2} \mathrm{ZrSi}_{6} \mathrm{O}_{15}$.

\begin{tabular}{cccc}
\hline $\begin{array}{c}\text { Razón molar } \\
\text { Li:Zr:Si }\end{array}$ & $\begin{array}{c}\text { Masa perdida (\%) entre } \\
473 \text { y } 573 \mathrm{~K}\end{array}$ & $\begin{array}{c}\text { Masa perdida (\%) entre } \\
823 \text { y } 923 \mathrm{~K}\end{array}$ & $\begin{array}{c}\text { Masa perdida } \\
\text { total (\%) }\end{array}$ \\
\hline $1: 2: 6$ & 3.8 & 4.0 & 7.8 \\
$2: 2: 6$ & 4.0 & 8.2 & 12.2 \\
$3: 2: 6$ & 3.9 & 3.8 & 7.7 \\
\hline
\end{tabular}

La muestra con una razón molar $\mathrm{Li}: \mathrm{Zr}: \mathrm{Si}$ de 2:2:6 perdió más masa que el resto de las muestras (Tabla 3.5). Es justamente la muestra que presenta el mayor contenido de $\mathrm{Li}_{2} \mathrm{ZrSi}_{6} \mathrm{O}_{15}$. Residuos de alcoholes y/o alcóxidos quizá estén retenidos dentro de la 
estructura laminar del $\mathrm{Li}_{2} \mathrm{ZrSi}_{6} \mathrm{O}_{15}$, ya que es durante el proceso de deshidroxilación cuando hay diferencias. El termograma correspondiente a esta última muestra se presenta en la figura 3.22 .

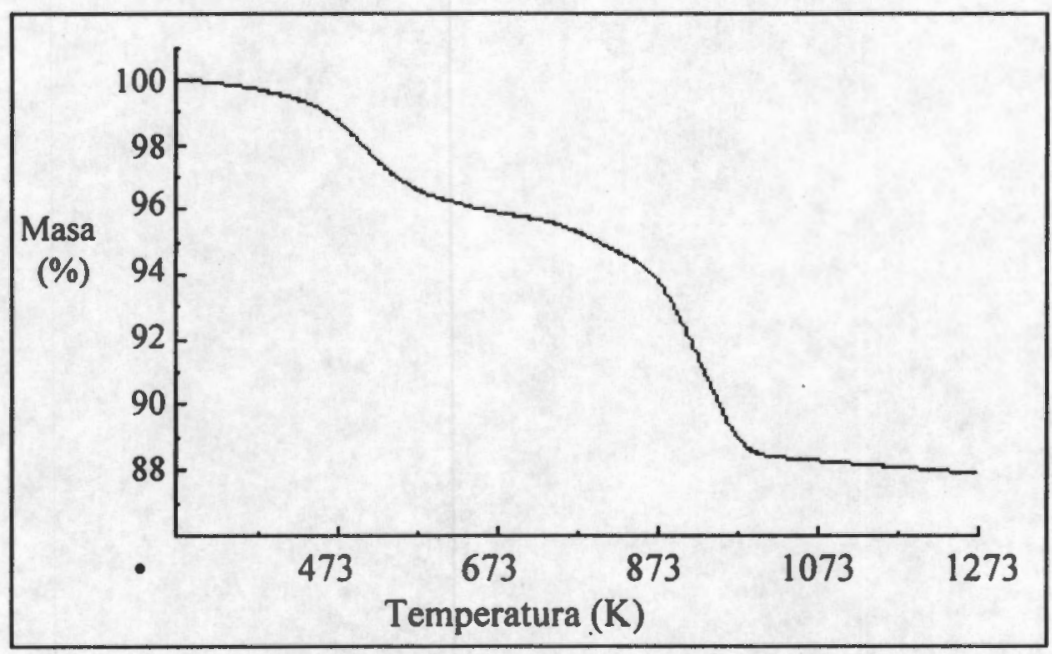

Fig. 3.22, Termograma de la muestra sintetizada con una razón molar Li:Zr:Si de 2:2:6.

\subsection{5 Área superficial (BET)}

De alguna manera era de esperarse que las muestras presentaran diferentes áreas superficiales dependiendo de su composición y de su estructura. El área superficial de las muestras aumentó a medida que el contenido de $\mathrm{ZrO}_{2}$ disminuyó, tabla 3.6. Este fenómeno se puede atribuir a que la estructura cristalina del $\mathrm{ZrO}_{2}$ no es porosa. $\mathrm{El} \mathrm{ZrO}_{2}$ presenta comúnmente un área superficial de $1 \mathrm{~m}^{2} / \mathrm{g}$ [Stiles, 1987]. Por otro lado, el área superficial crece cuando es mayor la concentración de $\mathrm{Li}_{2} \mathrm{ZrSi}_{6} \mathrm{O}_{15}$ cuya estructura es mucho más abierta.

Tabla 3.6

Área superficial calculada por el método BET.

\begin{tabular}{cc}
\hline Razón molar Li:Zr:Si & Área $\left(\mathrm{m}^{2} / \mathrm{g}\right)$ \\
\hline $1: 2: 6$ & 3.59 \\
$2: 2: 6$ & 9.20 \\
$3: 2: 6$ & 5.15 \\
\hline
\end{tabular}


Por lo tanto, el área del $\mathrm{Li}_{2} \mathrm{ZrSi}_{6} \mathrm{O}_{15}$ sintetizado en las condiciones expuestas en este trabajo, debe ser del orden del área obtenida para la muestra con una razón molar Li:Zr:Si de 2:2:6 ( $89 \%$ de abundancia de $\left.\mathrm{Li}_{2} \mathrm{ZrSi}_{6} \mathrm{O}_{15}\right)$, que es de $9 \mathrm{~m}^{2} / \mathrm{g}$.

\subsubsection{Morfología de los cristales (SEM)}

Para determinar la forma, el tamaño y la homogeneidad de las partículas del $\mathrm{Li}_{2} \mathrm{ZrSi}_{6} \mathrm{O}_{15}$, que son factores que pueden facilitar la difusión y la extracción del tritio, se llevó a cabo un estudio de microscopía electrónica de barrido. La muestra de $\mathrm{Li}_{2} \mathrm{ZrSi}_{6} \mathrm{O}_{15}$ presentó partículas de morfología esférica, unidas entre sí, formando anillos (Fig. 3.23). El tamaño de las partículas, el cual fue estimado después de analizar diferentes campos en el microscopio no fue único, varió entre 3 y $12 \times 10^{4} \AA$. Esta distribución de tamaños de partícula, así como la presencia de otros compuestos, pueden ser factores en contra de una adecuada difusión y extracción de tritio.

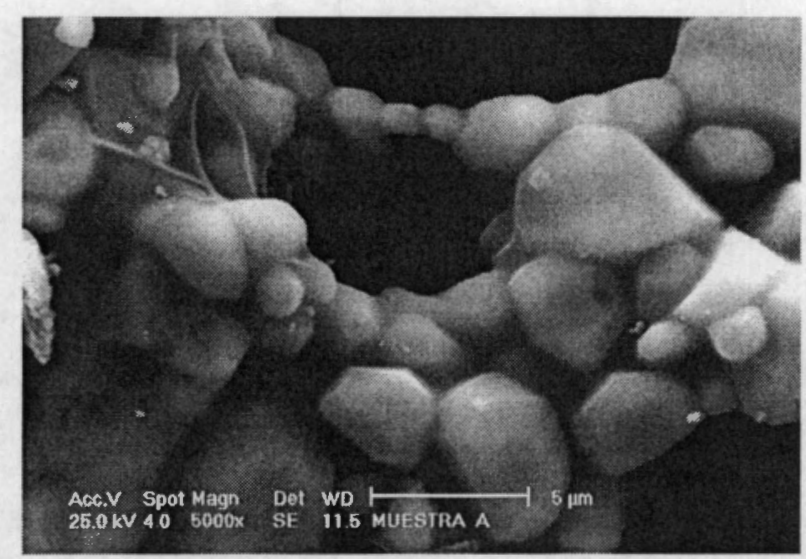

Fig. 3.23, Análisis SEM de la muestra de $\mathrm{Li}_{2} \mathrm{ZrSi}_{6} \mathrm{O}_{15}$.

En algunas imágenes se logró apreciar otro tipo de partículas, estas eran de morfología hexagonal típicas del $\mathrm{ZrO}_{2}$. Su composición se corroboró al realizar un microanálisis. En la figura 3.24 se presenta una micrografia en donde se localizó claramente el $\mathrm{ZrO}_{2}$. Finalmente las figuras 3.25 y 3.26 presentan los microanálisis hechos tanto a las partículas esféricas de $\mathrm{Li}_{2} \mathrm{ZrSi}_{6} \mathrm{O}_{15}$ como a las partículas de $\mathrm{ZrO}_{2}$. Las relaciones estequiométricas correspondientes fueron las siguientes. En el caso del $\mathrm{Li}_{2} \mathrm{ZrSi}_{6} \mathrm{O}_{15}$ vale la 
pena recordar que mediante esta técnica no es posible detectar litio, por lo tanto, la relación $\mathrm{Zr}$ :Si:O obtenida fue de 0.89:6:15.1 mientras que en caso de las partículas de $\mathrm{ZrO}_{2}$ la relación $\mathrm{Zr}: \mathrm{O}$ fue igual a 1:2.2. Tomando en cuenta el error experimental el cual varia entre el 3 y el $8 \%$, estos resultados concuerdan con las fórmulas de cada uno de los compuestos.

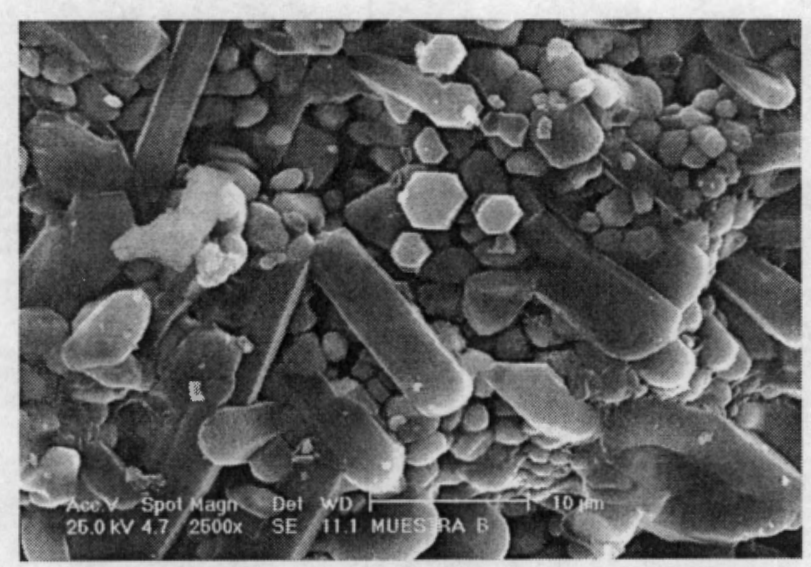

Fig. 3.24, $\mathrm{SEM}$ de la muestra de $\mathrm{Li}_{2} \mathrm{ZrSi}_{6} \mathrm{O}_{15}$,

en esta micrografía se presentan partículas de

$\mathrm{ZrO}_{2}$ (partículas de morfología hexagonal).

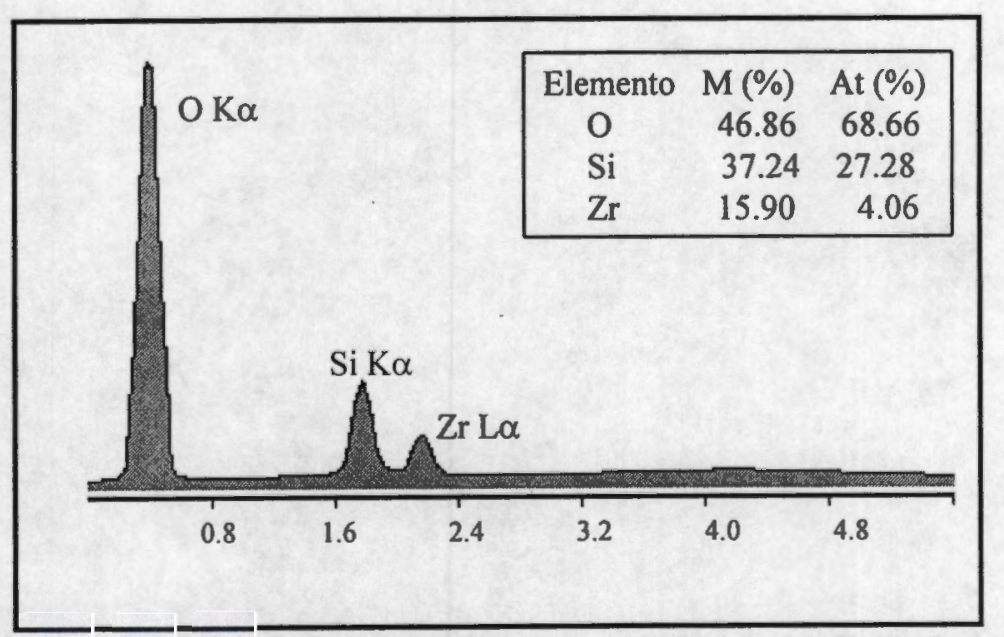

Fig. 3.25, Microanálisis de las partículas de $\mathrm{Li}_{2} \mathrm{ZrSi}_{6} \mathrm{O}_{15}$. 


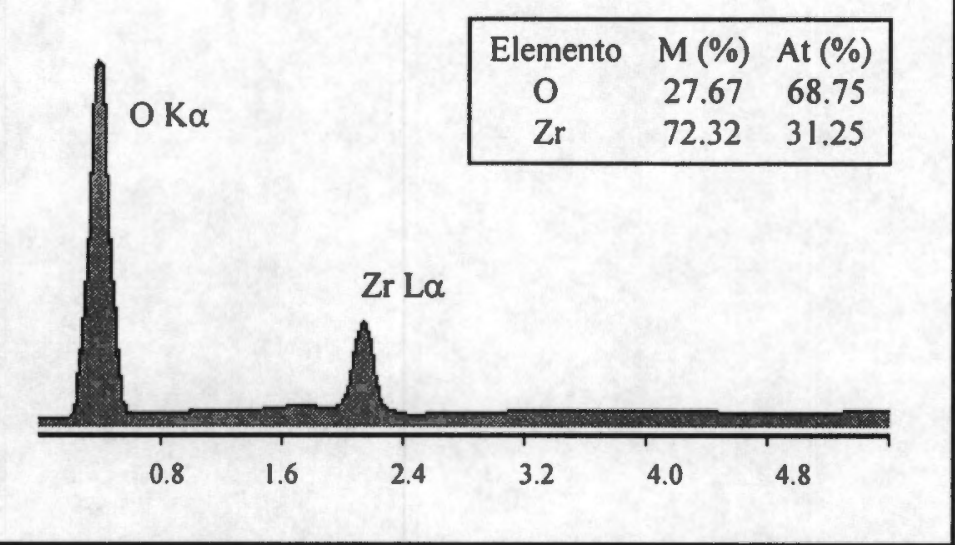

Fig. 3.26, Microanálisis de las partículas de $\mathrm{ZrO}_{2}$.

Quintana [Quintana et al. , 1981], en sus trabajos sobre $\mathrm{Li}_{2} \mathrm{ZrSi}_{6} \mathrm{O}_{15}$ no informan los porcentajes de $\mathrm{Li}_{2} \mathrm{ZrSi}_{6} \mathrm{O}_{15}$, ni de ninguno de los compuestos obtenidos: $\mathrm{ZrO}_{2}, \mathrm{ZrSiO}_{4}$, $\mathrm{Li}_{2} \mathrm{SiO}_{3}, \mathrm{Li}_{2} \mathrm{Si}_{2} \mathrm{O}_{5}$ y vidrio. En el presente trabajo no obtuvimos $\mathrm{ZrSiO}_{4}$ ni vidrio, pero siempre aparecieron los siguientes productos: $\mathrm{ZrO}_{2}, \mathrm{SiO}_{2}, \mathrm{Li}_{2} \mathrm{SiO}_{3}$ y Li2 $\mathrm{ZrO}_{3}$. Quintana et al. emplearon en sus síntesis silicio en exceso, lo cual explica la aparición de grandes cantidades de vidrio. En nuestro caso, la técnica sol-gel promueve la síntesis de productos homogéneos y al emplear menores cantidades de silicio se pudo eliminar la formación de vidrio.

En el método de síntesis sol-gel los procesos de polimerización de los alcóxidos son variados. Los primeros productos de la hidrólisis de $\mathrm{Si}\left(\mathrm{OC}_{2} \mathrm{H}_{5}\right)_{4}$ y $\mathrm{Zr}\left(\mathrm{OC}_{2} \mathrm{H}_{5}\right)_{4}$ son $\mathrm{Si}(\mathrm{OH})\left(\mathrm{OC}_{2} \mathrm{H}_{5}\right)_{3}$ y $\mathrm{Zr}(\mathrm{OH})\left(\mathrm{OC}_{2} \mathrm{H}_{5}\right)_{3}$ respectivamente. Después, probablemente los productos de la hidrólisis se vuelven a hidrolizar en más de una ocasión obteniẻndose los siguientes productos: $\mathrm{Si}(\mathrm{OH})_{x}\left(\mathrm{OC}_{2} \mathrm{H}_{5}\right)_{4-x}$ y $\mathrm{Zr}(\mathrm{OH})_{x}\left(\mathrm{OC}_{2} \mathrm{H}_{5}\right)_{4-x}$. En la figura 3.27 se esquematizan estas reacciones. Finalmente, las reacciones de autocondensación y de heterocondensación entre los alcóxidos de silicio y de zirconio se detienen por una reacción de heterocondensación con el $\mathrm{LiOCH}_{3}$ (Fig. 3.28). $\mathrm{El} \mathrm{Zr}\left(\mathrm{OC}_{2} \mathrm{H}_{5}\right)_{4}$ posee una velocidad de polimerización mayor que la del $\mathrm{Si}\left(\mathrm{OC}_{2} \mathrm{H}_{5}\right)_{4}$ [Boilot et al., 1988]. Por lo tanto, es necesario adicionar más alcóxido de zirconio en la razón molar $\mathrm{Li}: \mathrm{Zr}: \mathrm{Si}$, y así una parte polimeriza consigo mismo y la otra parte reacciona con el alcóxido de silicio y se produce el 
$\mathrm{Li}_{2} \mathrm{ZrSi}_{6} \mathrm{O}_{15}$. Aquí vale la pena mencionar que existen otros procedimientos para el manejo de alcóxidos de zirconio. Una manera de estabilizar a este tipo de alcóxidos en un sol, es mediante el empleo de quelantes [Brinker and Scherer, 1990].

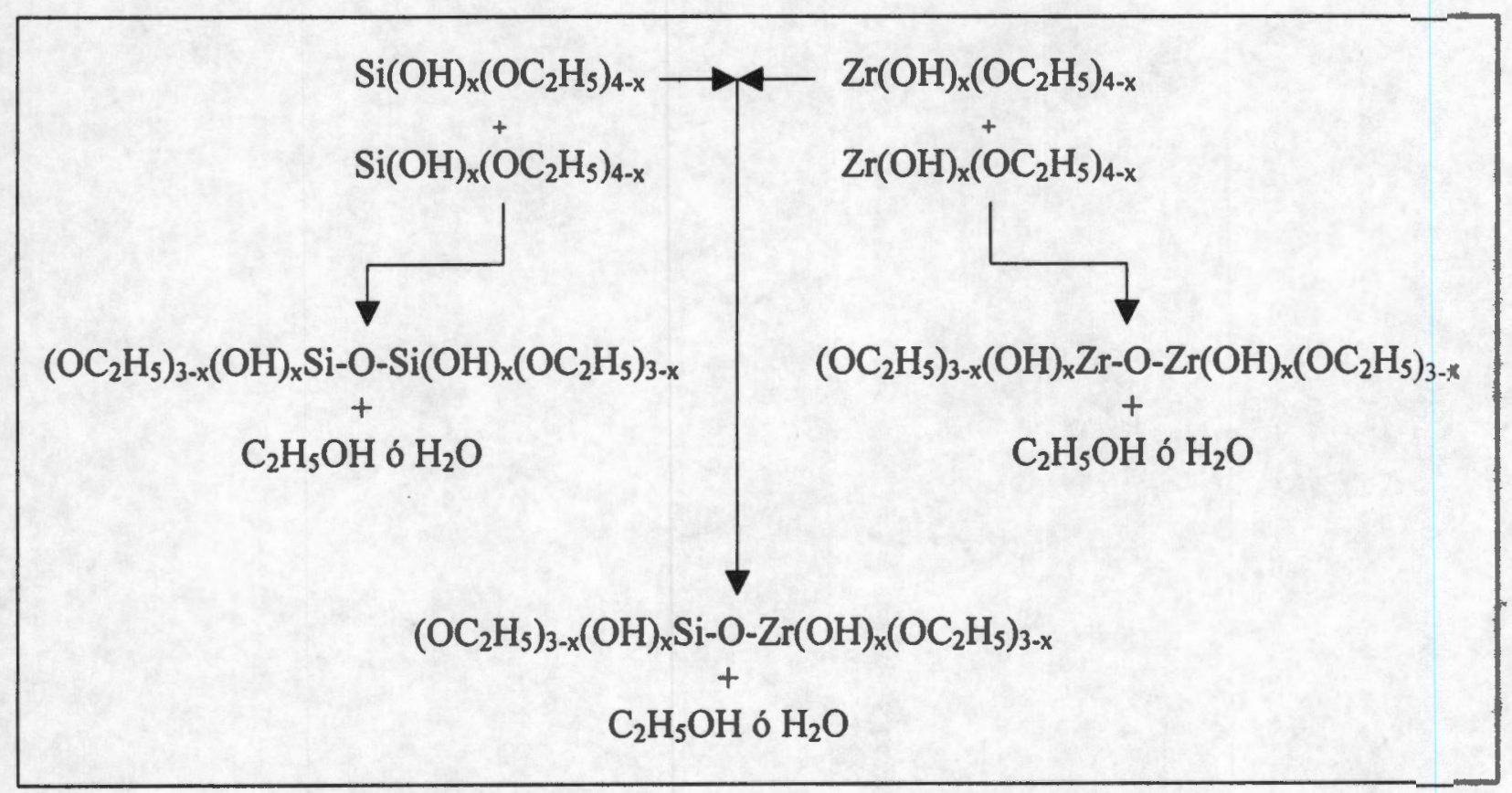

Fig. 3.27, Esquema de las posibles rutas de polimerización entre $\mathrm{Si}\left(\mathrm{OC}_{2} \mathrm{H}_{5}\right)_{4}$ y $\mathrm{Zr}\left(\mathrm{OC}_{2} \mathrm{H}_{5}\right)_{4}$.

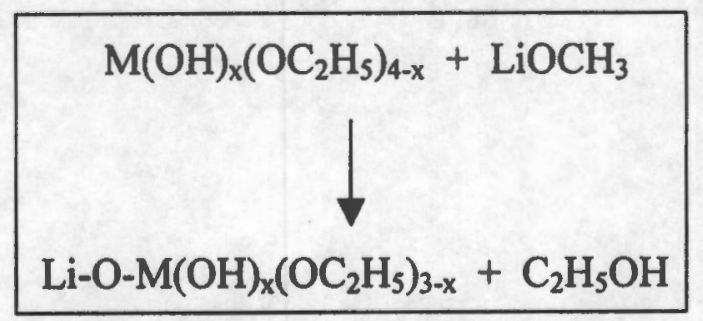

Fig. 3.28, Mecanismo de incorporación del litio en la red de polimerización, donde $-\mathrm{M}$ puede ser $-\mathrm{Si} \mathrm{o}-\mathrm{Zr}$. 


\subsection{Dinámica molecular del $\mathrm{Li}_{2} \mathrm{O}$}

En esta sección se presentan los resultados del estudio teórico del óxido de litio $\left(\mathrm{Li}_{2} \mathrm{O}\right)$ por dinámica molecular [Pfeiffer $\left.(3), 2000\right]$. Se decidió iniciar los estudios de dinámica molecular con el $\mathrm{Li}_{2} \mathrm{O}$, debido a que es un cristal iónico (estructura cúbica, con un parámetro de red $a_{0}$ igual a $4.61 \AA$ ). En la figura 3.29 se presenta la celda unidad del $\mathrm{Li}_{2} \mathrm{O}$, de acuerdo con De-Vita et al. [De-Vita, 1992]. El carácter iónico del $\mathrm{Li}_{2} \mathrm{O}$ permite el empleo de un potencial como el de Pauling, siempre y cuando se tomen en cuenta las interacciones de largo alcance mediante las sumas de Ewald (ver capítulo II). Además, el $\mathrm{Li}_{2} \mathrm{O}$ es un cerámico de litio que ha sido ampliamente estudiado como posible generador de tritio [Nagai, 1993; Tanaka, 1997; Shah, 1996].

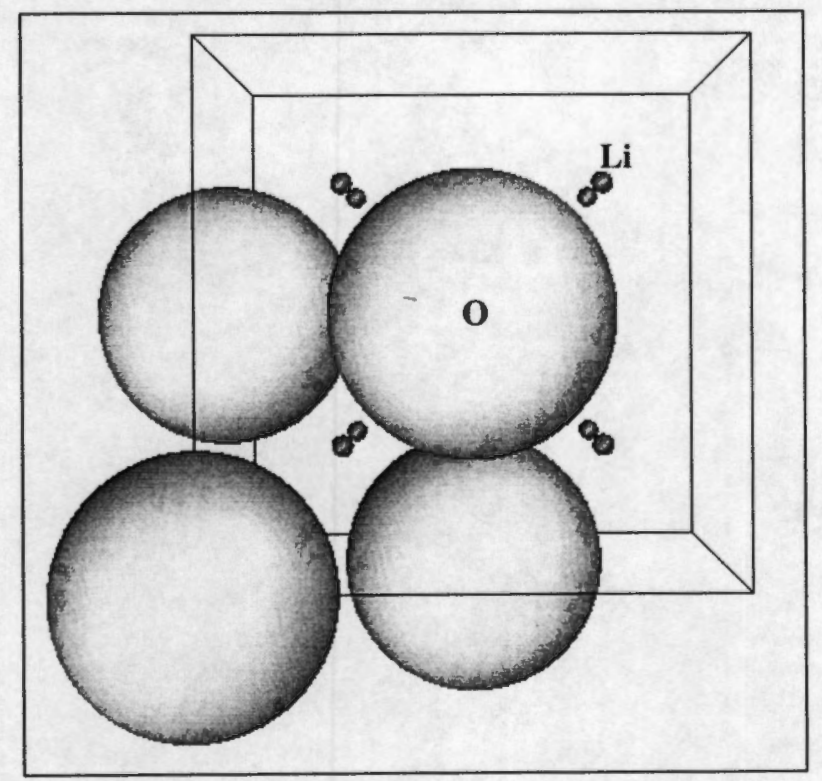

Fig. 3.29, Celda unidad del $\mathrm{Li}_{2} \mathrm{O}$.

Aunque los resultados reportados en la bibliografía difieren entre ellos todos concuerdan en que el mejor rendimiento de tritio se obtiene cuando la extracción de tritio se hace en un intervalo de temperaturas de 500 a $700 \mathrm{~K}$. Presentamos, aquí, un estudio de dinámica molecular del $\mathrm{Li}_{2} \mathrm{O}$, para determinar el papel que juega la no estequiometría y para proponer la composición del cerámico entre 300 y $1200 \mathrm{~K}$. Se presenta, además, la 
simulación de una partícula de tritio dentro de la red de $\mathrm{Li}_{2} \mathrm{O}$, en el mismo intervalo de temperaturas.

\subsubsection{Potencial Li-O}

El potencial Li-O se ajustó utilizando las cargas efectivas del litio y del oxígeno, y se obtuvo entonces el calor de formación $\left(\Delta \mathrm{H}^{0}\right)$ del $\mathrm{Li}_{2} \mathrm{O}$. El valor experimental del $\Delta \mathrm{H}^{0}$ de $-142.4 \mathrm{kcal} / \mathrm{mol}$ [Weast et al., 1982] concuerda con el valor obtenido por dinámica molecular de $-142.9 \mathrm{Kcal} / \mathrm{mol}$. Para dicho cálculo se usó un sistema con 758 partículas, de las cuales 512 correspondían a átomos de litio y 246 a átomos de oxígeno, es decir un sistemá no estequiométrico, $\mathrm{Li}_{2} \mathrm{O}_{0.96}$. Este sistema tiene una deficiencia de oxígenos del $2 \%$ en masa. En la naturaleza, cualquier óxido que se caliente hasta fundirlo, pierde alrededor de $2 \%$ en masa de oxígeno, debido a las fuertes vibraciones de los átomos de la superficie causadas por el incremento en la temperatura del sistema [Krishnan et al., 1998]. La figura 3.30 presenta la gráfica del comportamiento del $\Delta \mathrm{H}^{0}$ calculado en función de la temperatura.

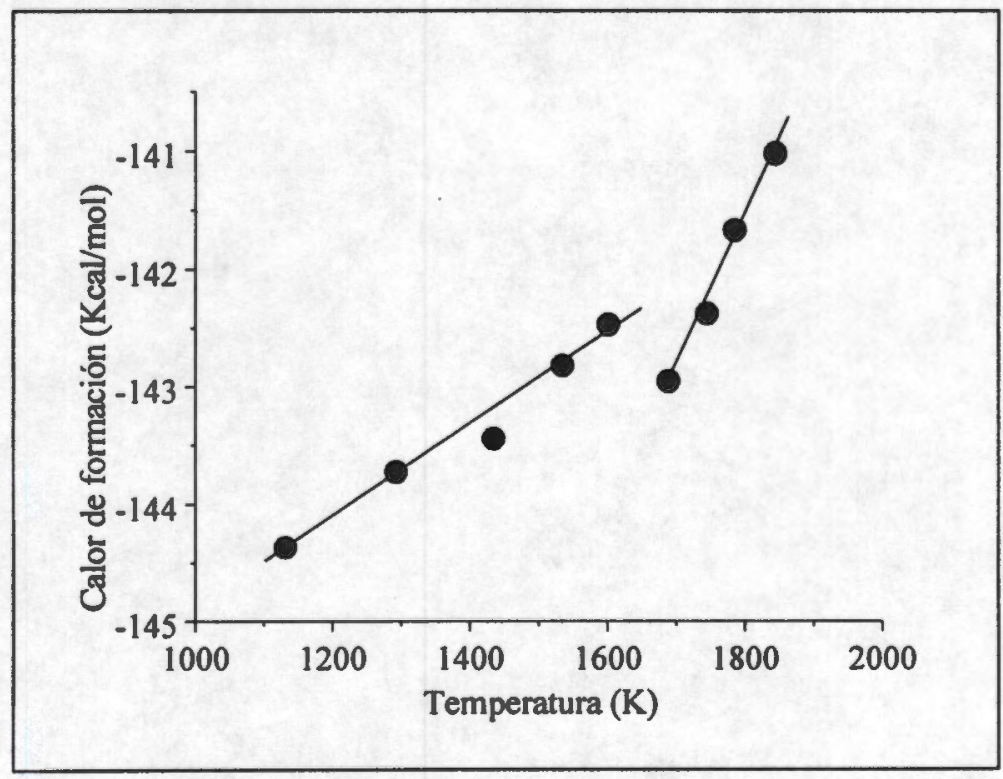

Fig. 3.30, Variación del $\Delta \mathrm{H}^{0}$ en función de la temperatura para el sistema $\mathrm{Li}_{2} \mathrm{O}_{0.96}$. 
En la figura 3.30 se aprecia una discontinuidad de la curva entre 1669 y $1715 \mathrm{~K}$, que indica una transición de fase que corresponde al punto de fusión. Este intervalo de temperaturas concuerda con el punto de fusión experimental, $1700 \mathrm{~K}$ [Weast et al., 1982]. La discontinuidad en la curva se puede asociar a dos rectas de pendiente diferente, lo que indica una variación en el comportamiento fisicoquímico, el cual se puede asociar con un cambio de fase, que efectivamente es lo que ocurre en la fusión de los materiales. Este mismo comportamiento se ha encontrado en otros sistemas iónicos [San-Miguel et al., 1998; Alvarez et al., 1999].

Se trabajó con tres sistemas para poder determinar la composición real de un cristal de $\mathrm{Li}_{2} \mathrm{O}$ a varias temperaturas. $\mathrm{El}$ primer sistema corresponde al de un cristal perfecto, $\mathrm{Li}_{2} \mathrm{O}$. El segundo sistema, presenta una deficiencia del $2 \%$ en masa de átomos de litio, $\mathrm{Li}_{1.9} \mathrm{O}$. Finalmente, el tercer sistema sufre una deficiencia de $2 \%$ en masa de átomos de oxígeno $\mathrm{Li}_{2} \mathrm{O}_{0.96}$. La tabla 3.7 presenta los potenciales y los radios iónicos empleados para los tres sistemas, $\mathrm{Li}_{2} \mathrm{O}_{0.96}, \mathrm{Li}_{2} \mathrm{O}$ y Li $\mathrm{Li}_{1.9} \mathrm{O}$.

Tabla 3.7

Radios iónicos y cargas efectivas empleadas en los tres sistemas.

\begin{tabular}{ccccc}
\hline \multirow{2}{*}{ Sistema } & \multicolumn{2}{c}{ Litio } & \multicolumn{2}{c}{ Oxígeno } \\
\cline { 2 - 5 } & $\sigma(\AA)$ & $q(\mathrm{e})$ & $\sigma(\AA)$ & $q(\mathrm{e})$ \\
\hline $\mathrm{Li}_{2} \mathrm{O}_{0.96}$ & 0.73 & 0.86 & 1.24 & -1.789 \\
$\mathrm{Li}_{2} \mathrm{O}$ & 0.73 & 0.86 & 1.24 & -1.720 \\
$\mathrm{Li}_{1.9} \mathrm{O}$ & 0.73 & 0.86 & 1.24 & -1.634 \\
\hline \hline
\end{tabular}

Los radios iónicos utilizados son los de Shannon [Huheey, 1981].

Fijando la carga del litio y ajustando la carga del oxígeno de manera que se mantuviera la electroneutralidad del sistema, se determinó la carga efectiva de los sistemas no estequiométricos. Hubo después que suponer que al eliminar átomos de litio o de oxígeno, el exceso de carga resultante se había repartido entre los átomos de oxígeno.

Las simulaciones se hicieron a $300,600,900$ y $1200 \mathrm{~K}$, bajo condiciones periódicas. Durante los primeros 5 picosegundos (ps) de las corridas, se reescalaron las velocidades de 
todas las partículas en cada paso de la iteración para termalizar la corrida. En los siguientes $2.5 \mathrm{ps}$, ya sin un control de la temperatura, se dejó que el sistema se relajara para asegurarse de llegar a un equilibrio termodinámico. Finalmente, la acumulación de datos se hizo en los siguientes 7.5 ps.

\subsubsection{Estructura}

La figura 3.31 presenta las funciones de distribución radial parciales $\mathrm{g}\left(\mathrm{r}_{\mathrm{Li}-\mathrm{Li}}\right), \mathrm{g}\left(\mathrm{r}_{\mathrm{Li}-\mathrm{O}}\right)$ y $\mathrm{g}\left(\mathrm{r}_{\mathrm{O}-\mathrm{o}}\right)$ de los tres sistemas a una temperatura de $1200 \mathrm{~K}$.

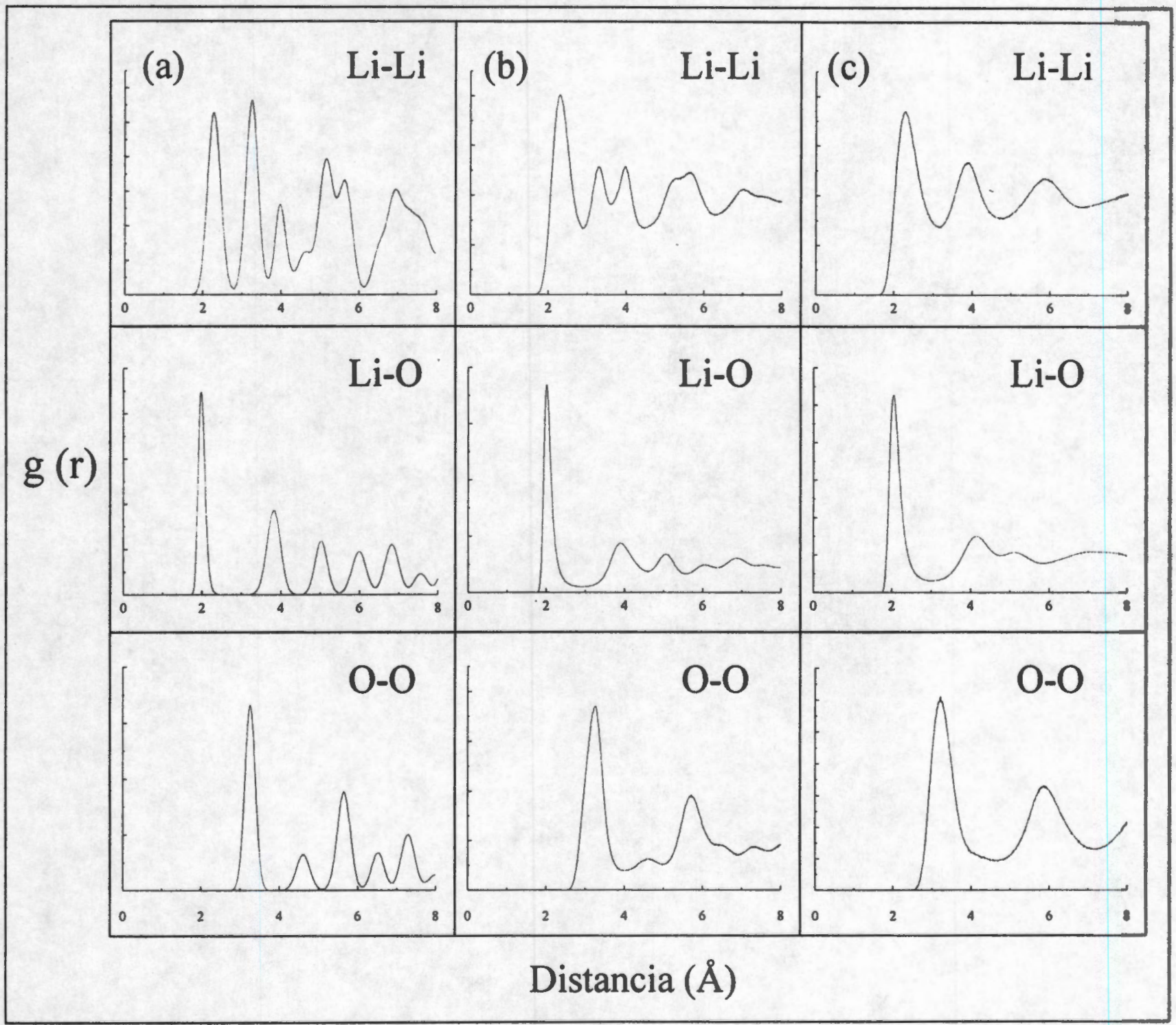

Fig. 3.31, Funciones de distribución radial parciales a $1200 \mathrm{~K}$ para los sistemas (a) $\mathrm{Li}_{2} \mathrm{O}$, (b)

$$
\mathrm{Li}_{1.9} \mathrm{O} \text { y (c) } \mathrm{Li}_{2} \mathrm{O}_{1.96} \text {. }
$$


En esta figura se puede apreciar que en los sistemas $\mathrm{Li}_{1.9} \mathrm{O}$ y $\mathrm{Li}_{2} \mathrm{O}$ los átomos están perfectamente localizados. Son arreglos de una estructura cristalina clara, mientras que el sistema $\mathrm{Li}_{2} \mathrm{O}_{0.96}$ pierde el orden a largo alcance. El sistema real a esta temperatura es, en efecto, cristalino. Por otro lado, la temperatura a la cual se calcularon las funciones de distribución radial es de $1200 \mathrm{~K}$, o sea, $500 \mathrm{~K}$ por debajo de la temperatura de fusión,es decir que el sistema $\mathrm{Li}_{1.9} \mathrm{O}$ presenta un comportamiento más cercano al real que el sistema $\mathrm{Li}_{2} \mathrm{O}_{0.96}$.

La figura 3.32 presenta imágenes de las tres configuraciones después de calentar a $1200 \mathrm{~K}$. Las figuras $3.32 \mathrm{a}$ y $3.32 \mathrm{~b}$ presentan la configuracion ideal sin calentar y calentada. Se pueden apreciar algunos detalles diferentes entre estos dos sistemas, debidos a los movimentos de los átomos y a las condiciones periódicas impuestas al sistema. Sin embargo, se puede afirmar que ambas configuraciones son prácticamente iguales.

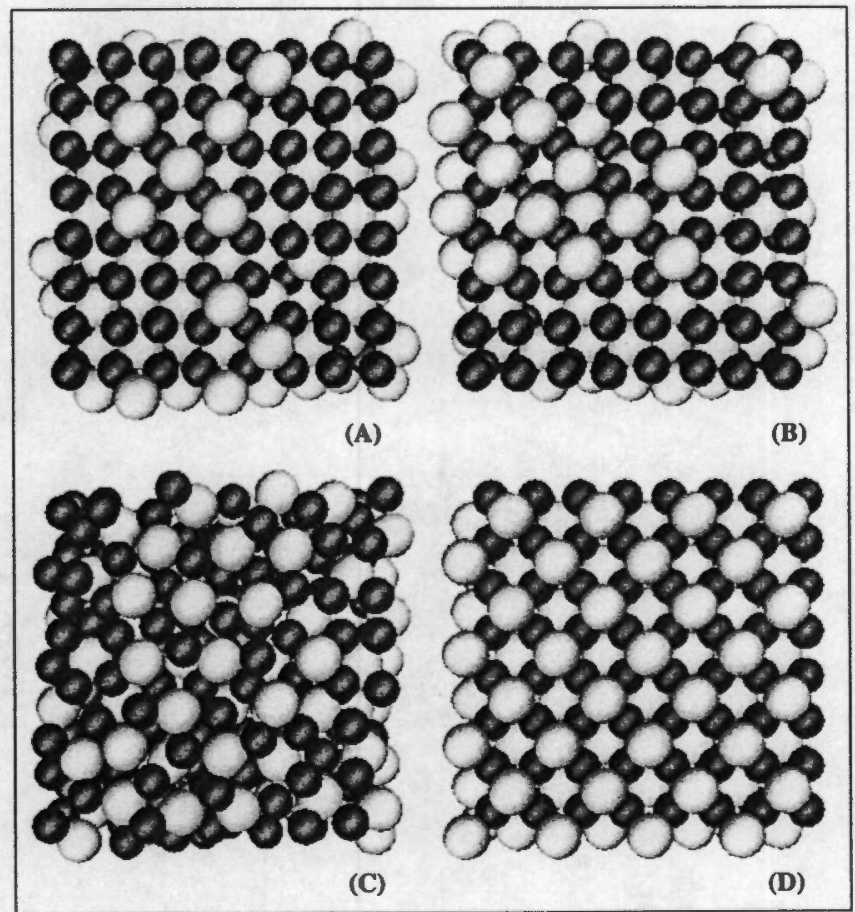

Fig. 3.32, Imágenes de las configuraciones finales de los tres sistemas a $1200 \mathrm{~K}$, (a) $\mathrm{Li}_{2} \mathrm{O}$, (b) $\mathrm{Li}_{1.9} \mathrm{O}$, (c) $\mathrm{Li}_{2} \mathrm{O}_{0.96}$ y (d) configuración inicial. Las esferas grandes y claras representan a los átomos de oxígeno, mientras que las esferas pequeñas y obscuras representan a los átomos de litio. 
La figura $3.32 \mathrm{c}$ correspondiente al sistema $\mathrm{Li}_{2} \mathrm{O}_{0.96}$ presenta un grado de desorden bastante evidente. Finalmente la figura $3.32 \mathrm{~b}$ muestra la configuración final del sistema $\mathrm{Li}_{1.9} \mathrm{O}$, el orden se mantiene y además se logra detectar algunas vacancias de litio. La presencia de estas vacancias genera un cierto grado de desorden en los primeros vecinos de la vacancia. Este efecto produce un alargamiento de las distancias $\mathrm{Li}-\mathrm{O}$ y $\mathrm{O}-\mathrm{O}$, tabla 3.8.

Tabla 3.8

Posiciones de los tres primeros picos de las funciones de distribución radial.

\begin{tabular}{cccc}
\hline $\mathrm{g}(\mathrm{r})$ & $\mathrm{Li}_{2} \mathrm{O}(\AA)$ & $\mathrm{Li}_{2} \mathrm{O}_{0.96}(\AA)$ & $\mathrm{Li}_{1.9} \mathrm{O}(\AA)$ \\
\hline $\mathrm{Li}-\mathrm{O}$ & 1.98 & 2.06 & 2.06 \\
$\mathrm{O}-\mathrm{O}$ & 3.29 & 3.14 & 3.32 \\
$\mathrm{Li}-\mathrm{Li}$ & 2.32 & 2.36 & 2.32 \\
\hline
\end{tabular}

\subsubsection{Difusión de litio y de oxígeno}

La relación de Einstein que proporciona el desplazamiento cuadrático medio como una función del tiempo $\mathrm{m}(\mathrm{t})$ entre el coeficiente de difusión medio, permite hacer el cálculo del coeficiente de difusión $\mathrm{D}$, para cualquier especie del sistema:

$$
2 t D=1 / 3\left\langle/ r_{i}(t)-r_{i}(0)||^{2}\right\rangle
$$

donde, $\mathrm{r}$ es la posición de la especie a difundir y $\mathrm{t}$ es el tiempo. Esta relación indica que ocurre un proceso de difusión cuando la pendiente a lo largo del tiempo del desplazamiento cuadrático medio de las especies es diferente de cero.

La figura 3.33 muestra el desplazamiento cuadrático medio del litio y del oxígeno en las muestras calentadas a $300,600,900$ y $1200 \mathrm{~K}$. En el cristal perfecto $\left(\mathrm{Li}_{2} \mathrm{O}\right)$, ninguna especie se difunde a ninguna temperatura, en efecto, no existiendo vacancias, el arreglo de los átomos es el de un empaquetamiento denso de esferas. 


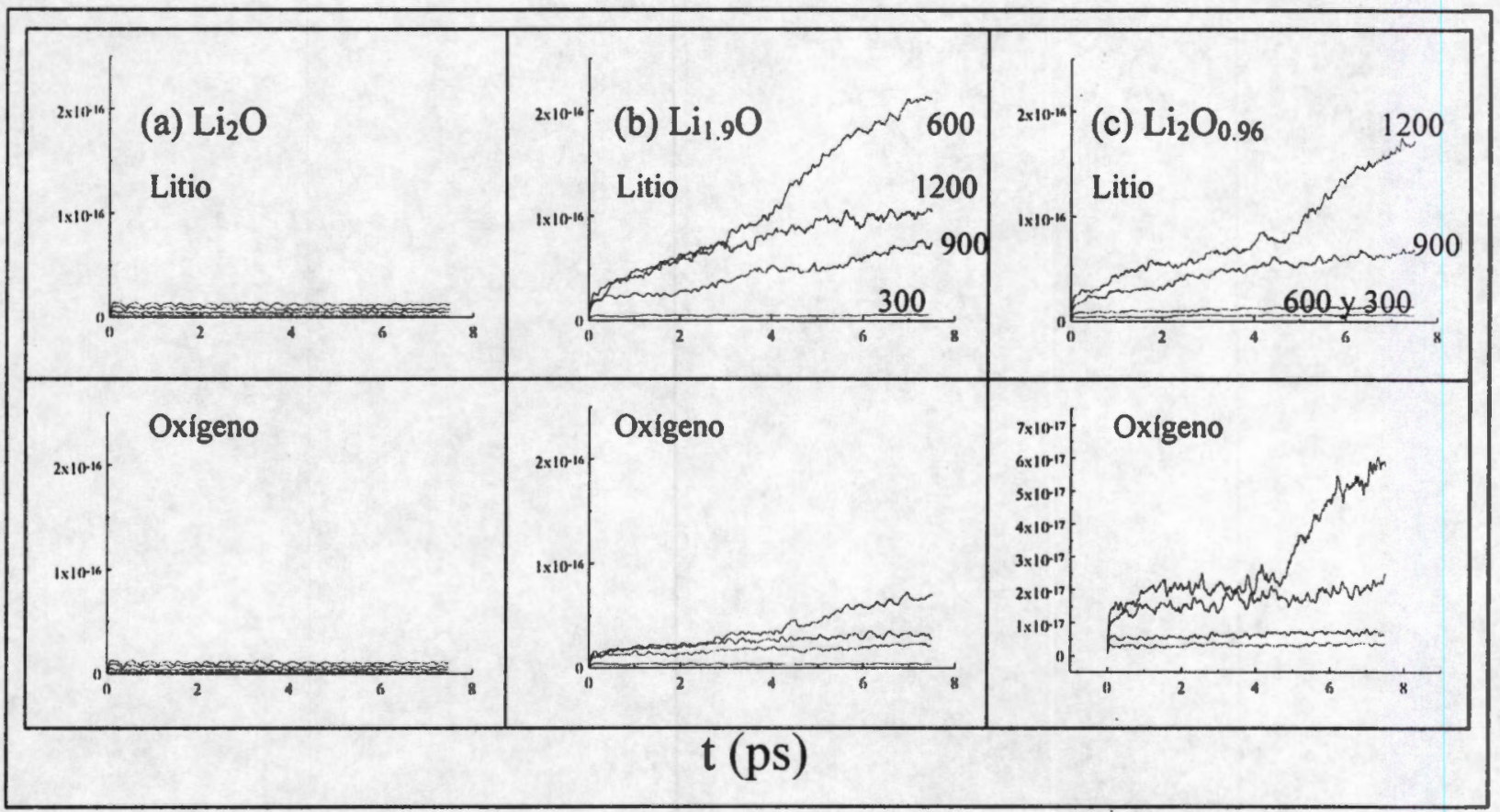

Fig. 3.33, Desplazamiento cuadrático medio del litio y del oxígeno a 300, 600, 900 y $1200 \mathrm{~K}$ en los sistemas (a) $\mathrm{Li}_{2} \mathrm{O}$, (b) $\mathrm{Li}_{1.9} \mathrm{O}$ y (c) $\mathrm{Li}_{2} \mathrm{O}_{0.96}$. En las curvas correspondientes al oxígeno, el comportamiento térmico es igual al mostrado para las curvas de litio.

En el sistema $\mathrm{Li}_{2} \mathrm{O}_{0.96}$ los átomos de oxígeno no se desplazan ni a $300 \mathrm{ni}$ a $600 \mathrm{~K}$. A $900 \mathrm{~K}$ se comprueba una ligera difusión de los átomos de litio. Finalmente, a $1200 \mathrm{~K}$ la pendiente de la curva cambia a los 5 ps tanto para el litio como para el oxígeno, poniéndose de manifiesto un movimiento generalizado del sistema, figura 3.33. Este cambio en la pendiente indica la pérdida de cristalinidad del sistema.

Los resultados de difusión para el sistema $\mathrm{Li}_{1.9} \mathrm{O}$ son muy claros. A 300,900 y 1200 $\mathrm{K}$ el coeficiente de difusión medio de ambas especies es muy lento en comparación con el mismo a $600 \mathrm{~K}$. A esta temperatura la pendiente de la distribución cuadrática media para el desplazamiento del litio es aproximadamente tres veces mayor que la del oxígeno, quizá por problemas estéricos. Estos resultados están de acuerdo con los datos experimentales ya que la temperatura adecuada para la difusión del tritio se encuentra entre 500 y $700 \mathrm{~K}$. 
En la figura 3.34 se grafican los coeficientes de difusión (D) del litio y del oxígeno de los dos sistemas no estequiométricos en función de la temperatura. En el sistema $\mathrm{Li}_{1.9} \mathrm{O}$, ambas especies mostraron una $\mathrm{D}$ máxima a $600 \mathrm{~K}$, mientras que en el sistema $\mathrm{Li}_{2} \mathrm{O}_{0.96}$ la $\mathrm{D}$ aumentó al incrementar la temperatura. De estos resultados, queda claro que el sistema que se parece más al sistema real es el $\mathrm{Li}_{1.9} \mathrm{O}$. Por lo tanto, sólo estudiaremos a partir de ahora el sistema $\mathrm{Li}_{1.9} \mathrm{O}$.

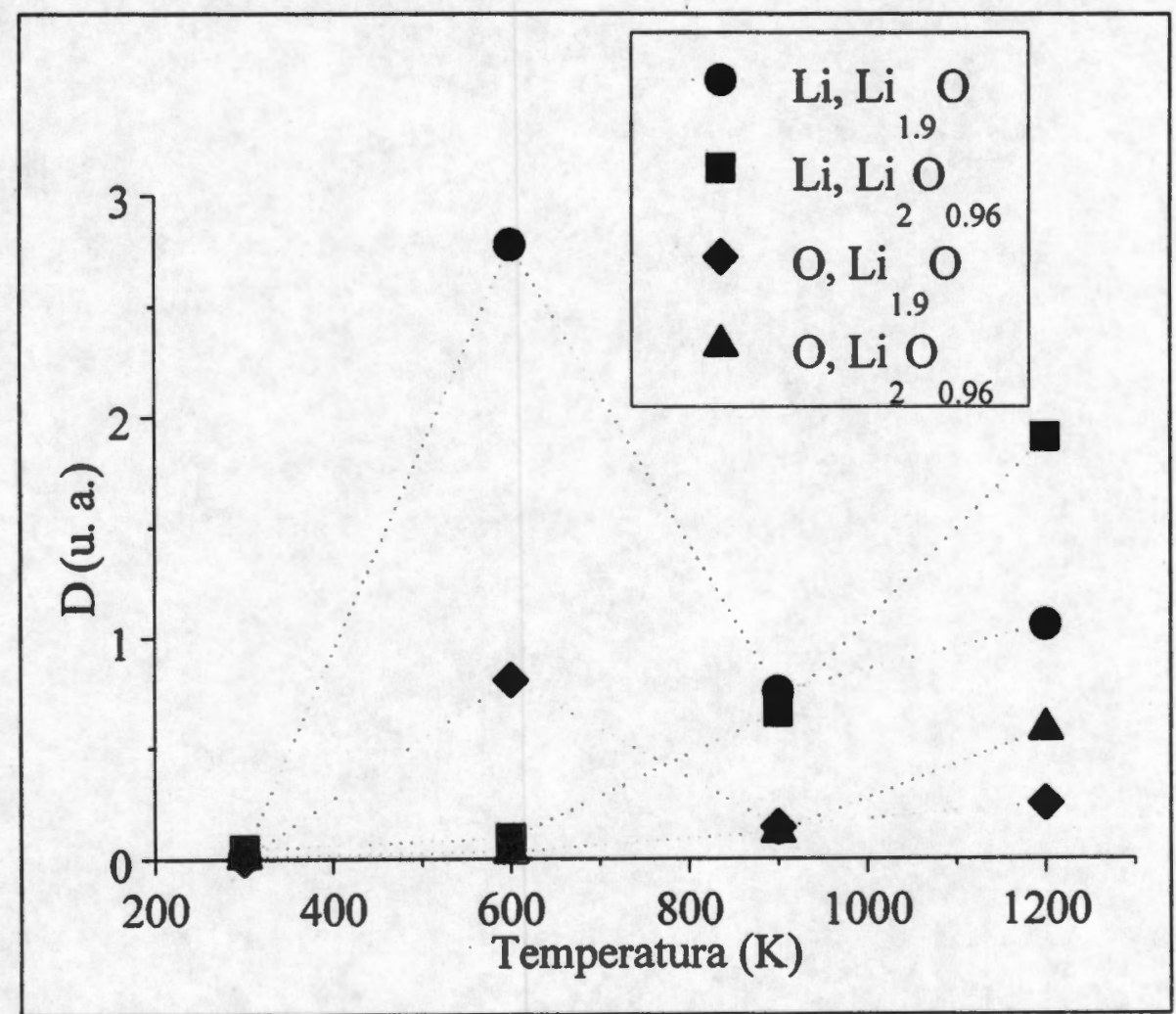

Fig. 3.34, Coeficientes de difusión media del litio y del oxígeno en los sistemas $\mathrm{Li}_{1.9} \mathrm{O}$ y $\mathrm{Li}_{2} \mathrm{O}_{0.96}$ como una función de la temperatura.

Para entender el mecanismo de difusión como una función de la temperatura se hizo un análisis detallado de la coordinación de los átomos. En la figura 3.35 se grafica el porcentaje de litio y de oxígeno con diferentes números de coordinación. La coordinación promedio de los átomos de litio a 300 y $600 \mathrm{~K}$ es de 4.05 y de 4.14 respectivamente. Cuando la temperatura se incrementó a 900 a $1200 \mathrm{~K}$ las coordinaciones promedio del litio aumentaron a 4.86 y a 4.83 respectivamente. Además la coordinación promedio del oxígeno 
creció de 8 a 9 cuando la temperatura resulto ser mayor de $600 \mathrm{~K}$. Los sistemas a 300 y 600 $\mathrm{K}$ presentaron coordinaciones parecidas a los datos experimentales, ya que las coordinaciones experimentales de litio y de oxígeno reportadas son 4 y 8 respectivamente [De-Vita et al., 1992].

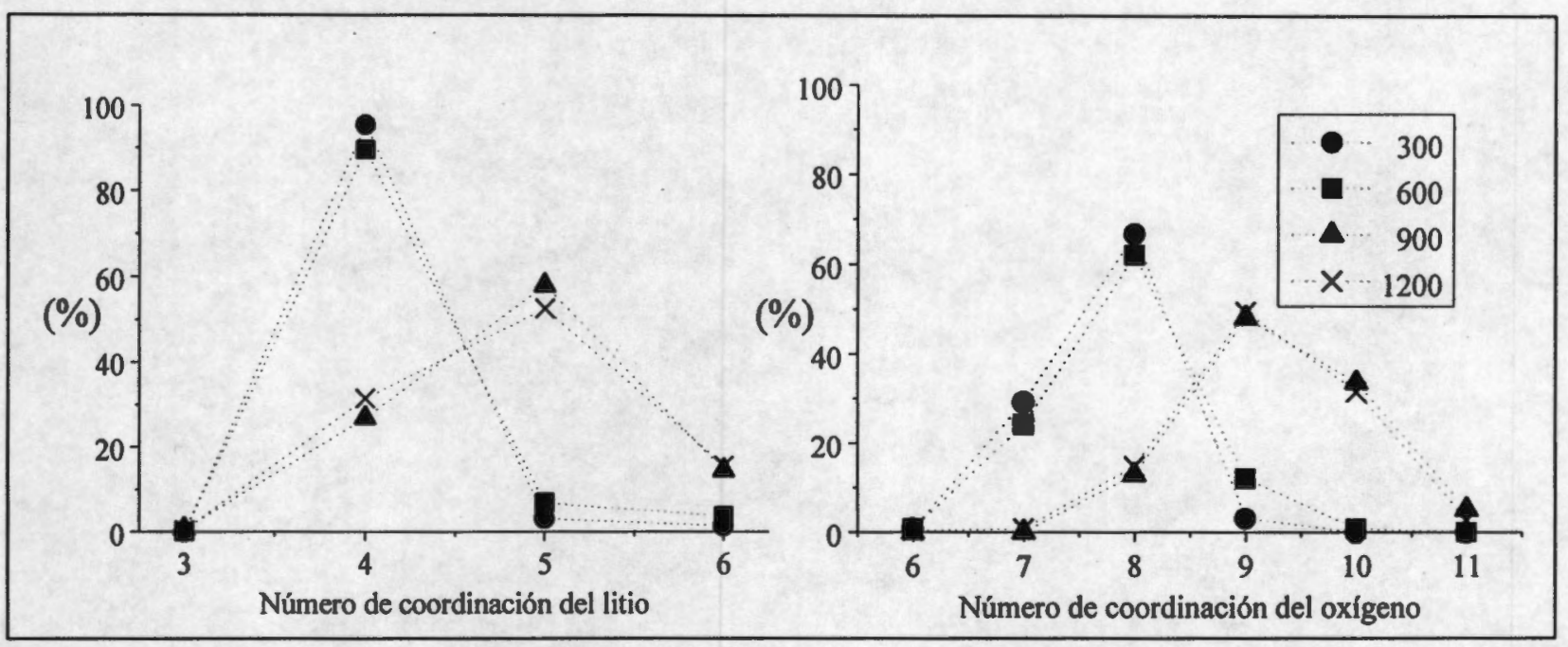

Fig. 3.35, Coordinación del litio y del oxígeno a las diferentes temperaturas, para el sistema $\mathrm{Li}_{1.9} \mathrm{O}$.

Los resultados del cálculo del desplazamiento cuadrático medio y las coordinaciones según la temperatura, además del hecho de que la estructura original tiene defectos tetraédricos del tipo Schottky [West, 1990], sugieren que los átomos de litio con coordinación cuatro son los que se difunden preferentemente de una vacancia tetraédrica a otra. Por otro lado, la energía de activación para la difusión del litio se debe alcanzar a 600 $\mathrm{K}$, y por ello, no hay difusión a temperaturas inferiores a $600 \mathrm{~K}$. A temperaturas mayores de $600 \mathrm{~K}$ la difusión del litio vuelve a ser menor debido a una transformación estructural del sistema, claramente puesta de manifiesto por el incremento en el número de coordinación, es decir que se inhibe la difusión por el aumento en la energía de enlace de ambas especies. La población de átomos de litio con coordinación cuatro es de 465 y de 436 a 300 y a $600 \mathrm{~K}$ respectivamente, mientras que a 900 y a $1200 \mathrm{~K}$ la población decrece a 131 y a 153 . Por otro lado, la población de átomos de litio con coordinación cinco a 300 y a $600 \mathrm{~K}$ es de 15 y. 
de 33 , mientras que a 900 y a $1200 \mathrm{~K}$ existe una población de 283 y de 256 respectivamente, tabla 3.9 .

\section{Tabla 3.9}

Población de la coordinación del litio en el $\mathrm{Li}_{1.9} \mathrm{O}$ en función de la temperatura.

\begin{tabular}{ccccc}
\hline \multirow{2}{*}{$\begin{array}{c}\text { Numero de } \\
\text { coordinación }\end{array}$} & \multicolumn{4}{c}{ Temperatura (K) } \\
\cline { 2 - 5 } & 300 & 600 & 900 & 1200 \\
\hline 3 & -- & -- & 3 & 2 \\
4 & 465 & 436 & 131 & 153 \\
5 & 15 & 33 & 283 & 256 \\
6 & 7 & 18 & 70 & 76 \\
Coord. promedio & 4.05 & 4.14 & 4.86 & 4.83 \\
\hline
\end{tabular}

La figura 3.36 compara las funciones de distribución radial Li-O obtenidas a las diferentes temperaturas. A $600 \mathrm{~K}$ todavía se observa un orden de largo alcance, mientras que a 900 y a $1200 \mathrm{~K}$ tan sólo se observa un orden de corto alcance. Se confirma así que a $600 \mathrm{~K} \mathrm{el} \mathrm{sistema} \mathrm{presenta} \mathrm{una} \mathrm{estructura} \mathrm{parcialmente} \mathrm{cristalina.}$

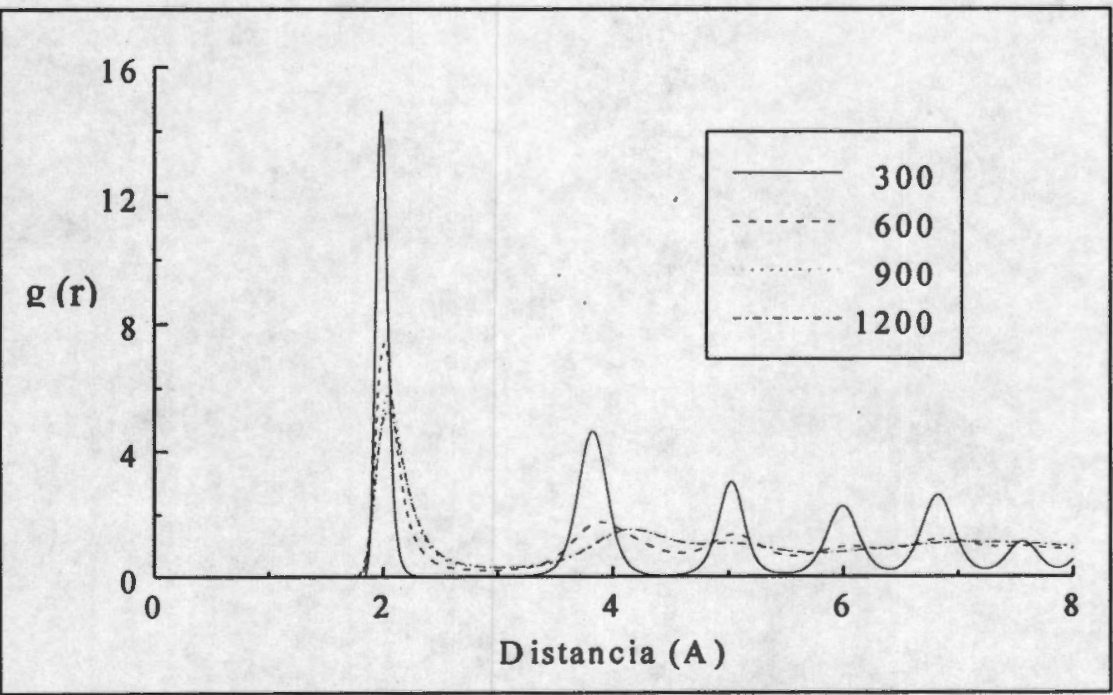

Fig. 3.36, Funciones de distribución radial Li-O en el sistema $\mathrm{Li}_{1.9} \mathrm{O}$, a las temperaturas de estudio. 


\subsubsection{Difusión del tritio}

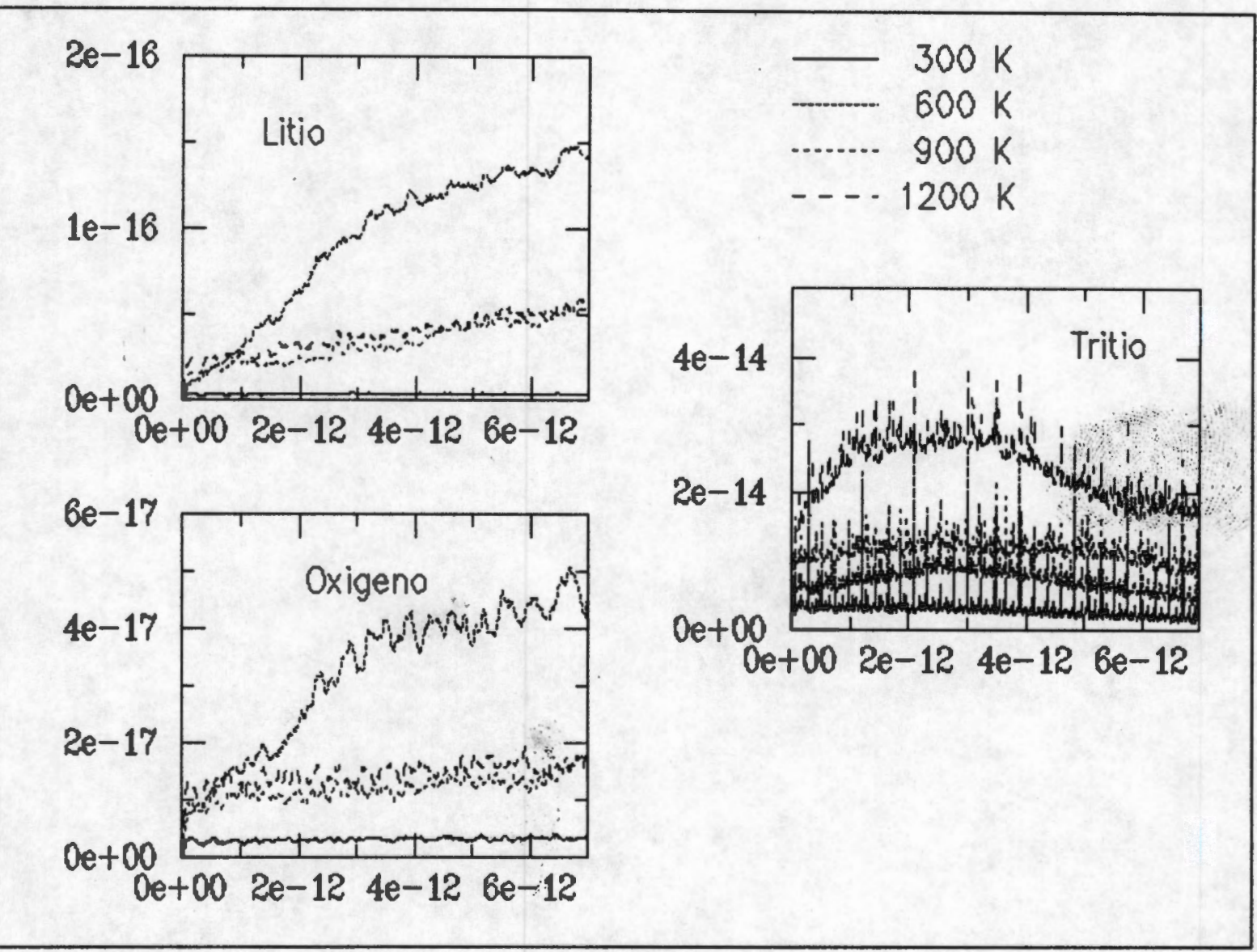

Fig. 3.37, Desplazamiento cuadrático medio $(\mathrm{m}(\mathrm{t}))$ de las especies del sistema $\mathrm{Li}_{1.9} \mathrm{O}$ con un átomo de tritio, a 300, 600, 900 y $1200 \mathrm{~K}$.

Para estudiar el comportamiento del tritio dentro de la red de $\mathrm{Li}_{1.9} \mathrm{O}$, se introdujo en una posición al azar una partícula de 3.006 unidades de masa atómica, con una carga de 1 electrón y un radio de $0.048 \mathrm{~nm}$ representando un átomo de tritio. El potencial de interacción para el tritio fue del mismo tipo que para el resto de las especies. La figura 3.37 muestra el desplazamiento cuadrático medio en función del tiempo para las tres especies, litio, oxígeno y tritio. El litio y el oxígeno presentan el mismo comportamiento que el sistema sin tritio (Fig. 3.33), en el cual la máxima difusión se presenta a una temperatura de $600 \mathrm{~K}$. Sin embargo el coeficiente de difusión del litio es 
aproximadamente $30 \%$ menor que en el sistema sin tritio. Algo similar pasa con el oxígeno.

El átomo de tritio se difunde rápidamente en un tiempo muy corto (no mayor de $0.1 \mathrm{ps})$, este comportamiento se presenta a todas las temperaturas. Después de este lapso la pendiente de la curva es igual a cero entre 300 y $900 \mathrm{~K}$, lo que indica que el átomo de tritio no se difunde. Para $1200 \mathrm{~K}$, aparentemente, el átomo de tritio se difunde rápidamente en los primeros $2 \mathrm{ps}$, pero al final de los 7,5 ps el tritio regresa a una posición muy parecida a la inicial. Es decir que el átomo de tritio instantaneamente se encuentra atrapado en la red del $\mathrm{Li}_{1.9} \mathrm{O}$. La figura 3.38 muestra un esquema de la posición del átomo de tritio al finalizar la simulación. El átomo de tritio se encuentra en el centro de un tetraedro cuyos vértices estan ocupados por oxígenos. Evidentemente el tritio está localizado en una vacancia de litio con una distancia interatómica con los oxígenos de 2 $\AA$.

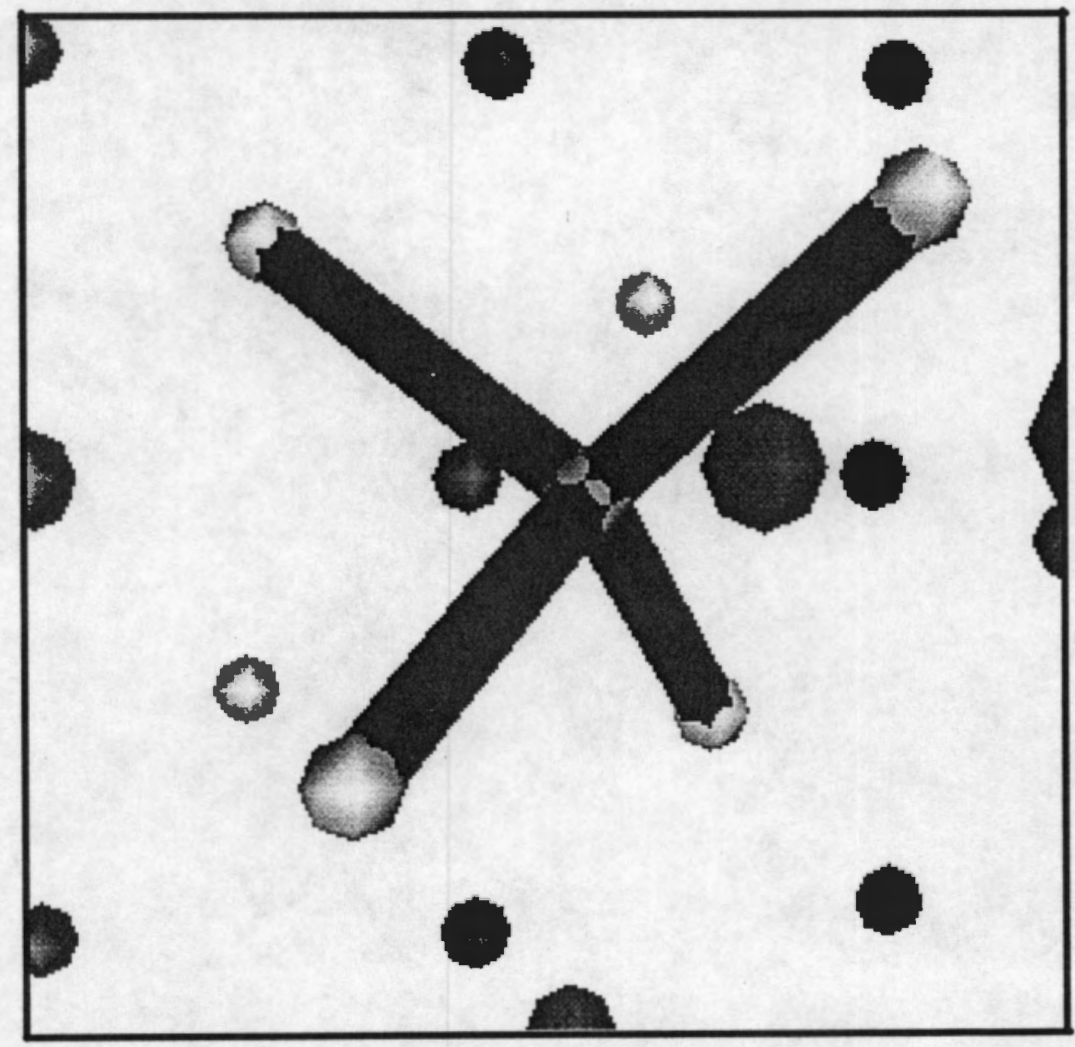

Fig. 3.38, Esquema de la localización del átomo de tritio en la estructura del $\mathrm{Li}_{1.9} \mathrm{O}$, a $1200 \mathrm{~K}$. 
Aparentemente el motivo por el que el átomo de tritio no se difunde igual que los átomos de litio es por la diferencia de carga, ya que el tritio tiene un $20 \%$ más de carga efectiva que el litio. Por otro lado, al encontrarse el átomo de tritio atrapado en el centro de una cavidad tetraédrica, esto puede explicar la necesidad de hacer pasar un flujo de gas inerte enriquecido con hidrógeno para poder extraer el tritio del cerámico de litio. La presencia de hidrógeno en la red del óxido de litio seguramente debilita la interacción T-O favoreciendo el rompimiento del enlace y por lo tanto su posterior difusión y extracción.

\subsection{Irradiación de los silicozirconatos de litio}

Las muestras de $\mathrm{Li}_{2} \mathrm{ZrSi}_{6} \mathrm{O}_{15}$ y de $\mathrm{Li}-\mathrm{ZrSiO}_{4}$ con relaciones molares $\mathrm{Li}: \mathrm{Zr}$ de $1,3,5$ y 6 se irradiaron en un campo mixto de neutrones térmicos y de radiación gamma con la finalidad, por un lado, de determinar su estabilidad ante la irradiación, y por otro, de estimar la cantidad de tritio producido por cada una de ellas.

\subsubsection{Dosis de radiación}

Tabla 3.10

Resultados obtenidos con el dosímetro secundario de ácido oxálico.

\begin{tabular}{cc}
\hline Muestra & Dosis Absorbida (MGy) \\
\hline $\mathrm{Li}_{2} \mathrm{ZrSi}_{6} \mathrm{O}_{15}$ & 1.202 \\
$\mathrm{Li}_{-}-\mathrm{rSiO}_{4}(1)$ & 1.390 \\
$\mathrm{Li}_{2} \mathrm{ZrSiO}_{4}(3)$ & 1.165 \\
$\mathrm{Li}_{-} \mathrm{ZrSiO}_{4}(5)$ & 1.390 \\
$\mathrm{Li}_{-} \mathrm{ZrSiO}_{4}(6)$ & 1.247 \\
\hline
\end{tabular}

El ácido oxálico se usó como dosímetro secundario para determinar las dosis absorbidas por las muestras [Sanchez-Ocampo et al., 1985]. Los resultados se muestran en la tabla 3.10. Las muestras absorbieron cantidades muy similares de radiación, alrededor de $1 \mathrm{MGy}$, por lo cual no fue necesario realizar un ajuste por dosis absorbida. Aquí cabe hacer mención que la muestra irradiada de $\mathrm{Li}_{2} \mathrm{ZrSi}_{6} \mathrm{O}_{15}$ fue la que contenía $89 \%$ de $\mathrm{Li}_{2} \mathrm{ZrSi}_{6} \mathrm{O}_{15}, 5$ $\%$ de $\mathrm{SiO}_{2}$ y $6 \%$ de $\mathrm{ZrO}_{2}$. 


\subsubsection{Daños por radiación}

\subsubsection{Características físicas}

Las muestras de $\mathrm{Li}-\mathrm{ZrSiO}_{4}$ irradiardas en el campo mixto de neutrones y de radiación gamma no presentaron cambios físicos. Todas las muestras presentaron un aspecto de polvo blanco opaco tanto antes como después de la radiación. En cambio, la muestra de $\mathrm{Li}_{2} \mathrm{ZrSi}_{6} \mathrm{O}_{15}$ pasó de ser un polvo blanco opaco antes de ser irradiada a un polvo amarillento después de someterla a la irradiación.

\subsubsection{Identificación de compuestos (XRD)}

La figura 3.39 compara los difractogramas de las muestras de $\mathrm{Li}_{-} \mathrm{ZrSiO}_{4}$ con razones molares Li:Zr de 1 antes y después del proceso de irradiación. En esta figura se puede comprobar que no hubo variación alguna en la composición y/o en la estructura. Las otras tres muestras de $\mathrm{Li}_{-} \mathrm{ZrSiO}_{4}$ (razones molares de 3,5 y 6) se comportaron análogamente.

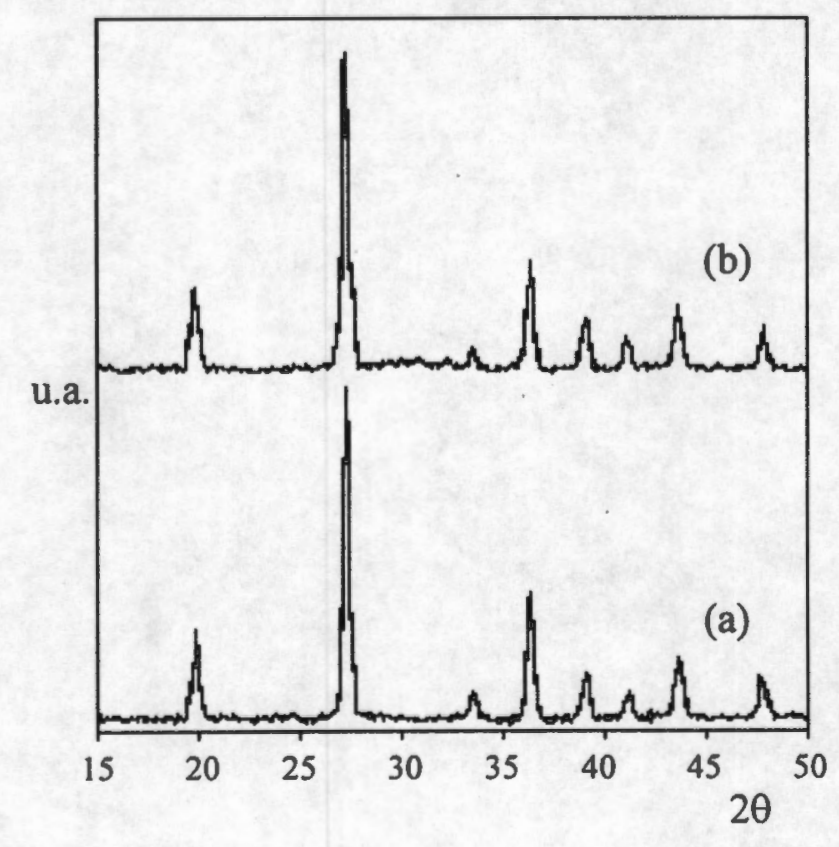

Fig. 3.39, Difractogramas de la muestra de $\mathrm{Li}-\mathrm{ZrSiO}_{4}$ con una razón molar $\mathrm{Li}: \mathrm{Zr}$ de 1, (a) antes de ser irradiada y (b) después de ser irradiada. 
En cambio, el $\mathrm{Li}_{2} \mathrm{ZrSi}_{6} \mathrm{O}_{15}$ presentó variaciones en su composición después de ser irradiado en el campo mixto. En el difractograma de la figura 3.40 se puede apreciar cómo los contenidos de $\mathrm{SiO}_{2}$ y de $\mathrm{ZrO}_{2}$ aumentaron de $5 \%$ a $12 \%$ y de $6 \%$ a $11 \%$ respectivamente. Por lo tanto, el contenido de $\mathrm{Li}_{2} \mathrm{ZrSi}_{6} \mathrm{O}_{15}$ disminuyó de 89 a $77 \%$. Los cambios en la composición de la muestra deben atribuirse a la interacción entre la muestra y el campo mixto del reactor nuclear. $\mathrm{La}$ muestra de $\mathrm{Li}_{2} \mathrm{ZrSi}_{6} \mathrm{O}_{15}$ es entonces menos estable ante un campo de radiación mixto que las muestras de $\mathrm{Li}_{-} \mathrm{ZrSiO}_{4}$.

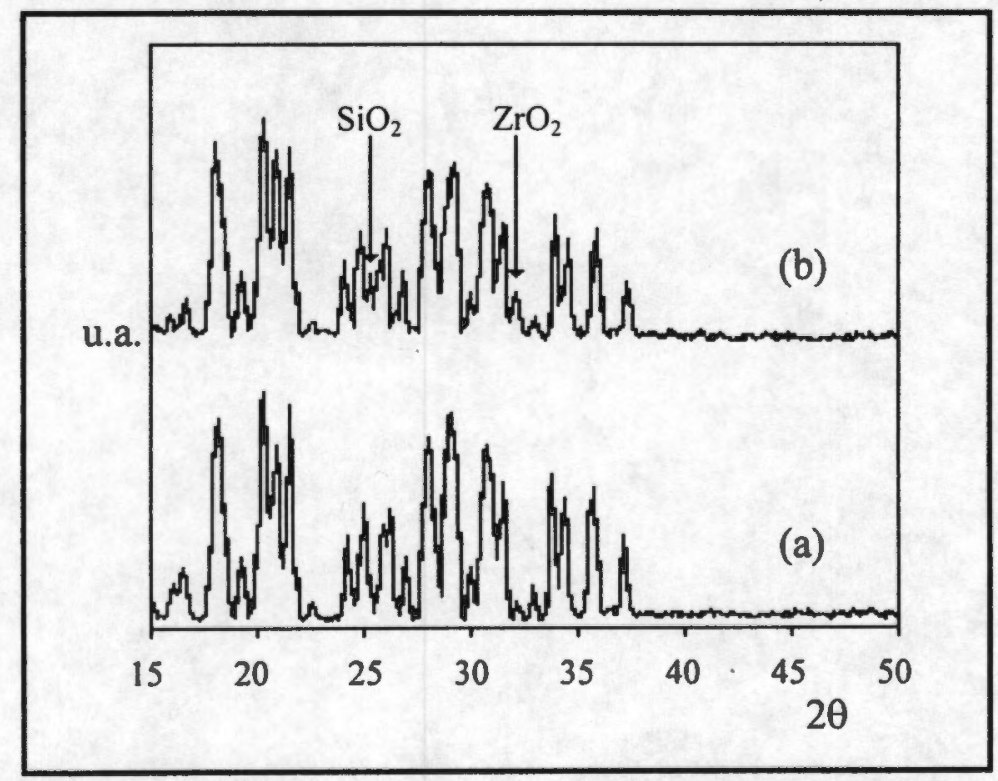

Fig. 3.40, Difractogramas de la muestra de $\mathrm{Li}_{2} \mathrm{ZrSi}_{6} \mathrm{O}_{15}$,

(a) antes de ser irradiada y (b) después de ser irradiada.

\subsubsection{3 Área superficial (BET)}

La tabla 3.11 presenta las áreas superficiales de las muestras antes y después de someterlas al proceso de irradiación. Las áreas de las muestras de $\mathrm{Li}_{-} \mathrm{ZrSiO}_{4}$ no variaron, lo cual complementa los resultados obtenidos por XRD. Podemos afirmar, entonces, que la estructura no varió pero tampoco la textura. El área superficial de la muestra de $\mathrm{Li}_{2} \mathrm{ZrSi}_{6} \mathrm{O}_{15}$ decreció de $9.2 \mathrm{~m}^{2} / \mathrm{g} \mathrm{a} 3.1 \mathrm{~m}^{2} / \mathrm{g}$. El cambio en el área superficial se debe a las variaciones de composición. 
Tabla 3.11

Área superficial de las muestras antes y después de irradiarlas.

\begin{tabular}{ccc}
\hline \multirow{2}{*}{ Muestra } & \multicolumn{2}{c}{ Área $\left(\mathrm{m}^{2} / \mathrm{g}\right)$} \\
\cline { 2 - 3 } & Antes de irradiar & Después de irradiar \\
\hline $\mathrm{Li}_{2} \mathrm{ZrSi}_{6} \mathrm{O}_{15}$ & 9.2 & 3.1 \\
$\mathrm{Li}_{-} \mathrm{ZrSiO}_{4}(1)$ & 15.0 & 14.8 \\
$\mathrm{Li}_{-\mathrm{ZrSiO}}(3)$ & 14.7 & 14.1 \\
$\mathrm{Li}_{2} \mathrm{ZrSiO}_{4}(5)$ & 15.8 & 15.0 \\
$\mathrm{Li}-\mathrm{ZrSiO}_{4}(6)$ & 14.9 & 15.2 \\
\hline \hline
\end{tabular}

\subsubsection{Morfología de los cristales (SEM)}

Las partículas de $\mathrm{Li}_{-2 r S i O}$ no presentaron cambios significativos en la morfología ni en el tamaño después de irradiarlas (Fig. 3.41). Únicamente, las partículas de $\mathrm{Li}-\mathrm{ZrSiO}_{4}$ después de la irradiación resultaron ser un poco más lisas, compárense las micrografias de las figuras 3.12 y 3.41 que corresponden a las muestras antes y después de irradiar respectivamente.

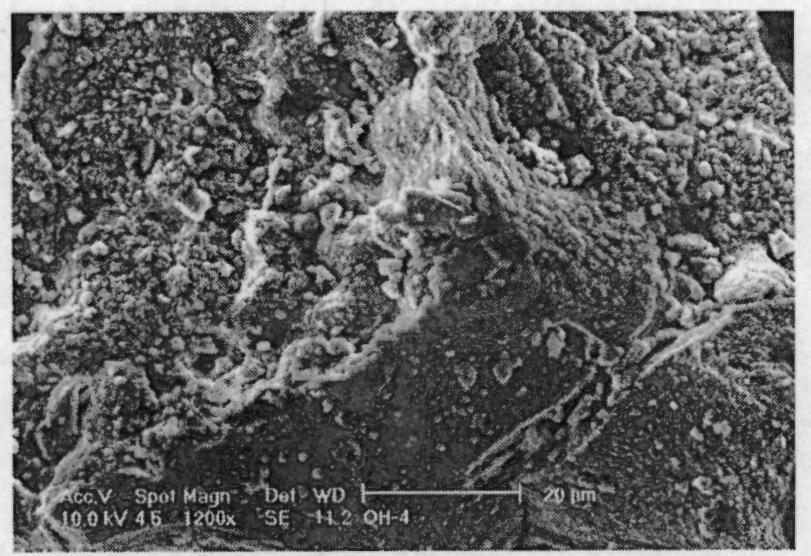

Fig. 3.41, Análisis SEM de la muestra $\mathrm{Li}_{-} \mathrm{ZrSiO}_{4}$ con una relación molar $\mathrm{Li}: \mathrm{Zr}$ de 1 , después de irradiarla.

En la figura 3.42 se puede apreciar que las partículas de $\mathrm{Li}_{2} \mathrm{ZrSi}_{6} \mathrm{O}_{15}$ conservaron después de la irradiación la geometría esférica y el arreglo de partículas encadenadas en 
forma de anillos. Sin embargo, las partículas se consolidaron tal y como lo reportaron previamente Yang. en el $\mathrm{Li}_{4} \mathrm{SiO}_{4}$ [Yang et al., 1981]. Se trata de un proceso similar al de sinterización. Lo que causa la consolidación no es un proceso térmico, sino que es un proceso causado por la radiación. Debido a este fenómeno de consolidación el tamaño de las partículas varió, formándose partículas de un mayor tamaño, $15-20 \times 10^{4} \AA$. La consolidación del material explica la disminución del área superficial.

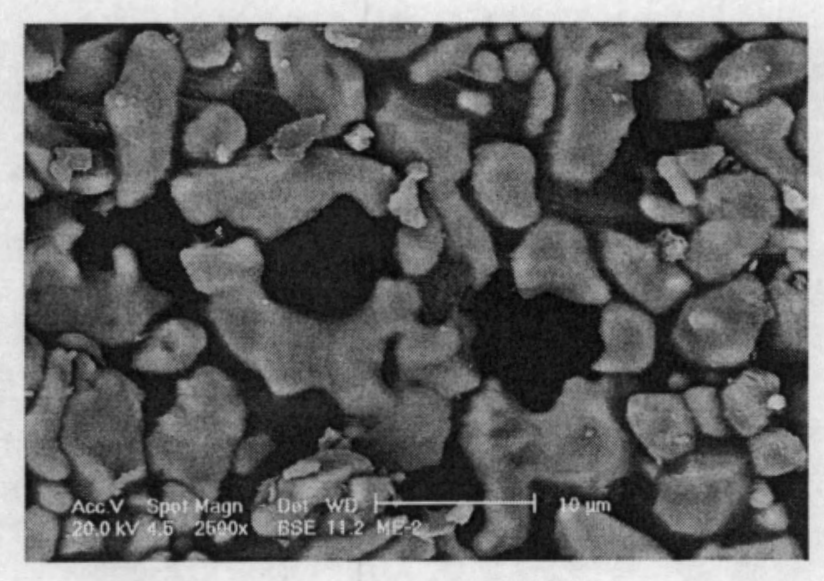

Fig. 3.42, Análisis SEM de las partículas de $\mathrm{Li}_{2} \mathrm{ZrSi}_{6} \mathrm{O}_{15}$ después de ser irradiado.

\subsubsection{Producción de tritio}

La producción y extracción de tritio del $\mathrm{Li}_{2} \mathrm{ZrSi}_{6} \mathrm{O}_{15}$ y del $\mathrm{Li}-\mathrm{ZrSiO}_{4}$ dopado con litio en diferentes razones molares de $\mathrm{Li}: \mathrm{Zr}$ se comparan en esta sección con dos de los sistemas más estudiados, el metasilicato de litio $\left(\mathrm{Li}_{2} \mathrm{SiO}_{3}\right)$ y el metazirconato de litio $\left(\mathrm{Li}_{2} \mathrm{ZrO}_{3}\right)$ [Johnson et al., 1988; Masabumi et al., 1998]. Se utilizó el $\mathrm{Li}_{2} \mathrm{ZrO}_{3}$ sintetizado por el método sol-gel, y preparado para el estudio del efecto del $\mathrm{pH}$ en la síntesis de los zirconatos de litio (ver 3.1). $\mathrm{El} \mathrm{Li}_{2} \mathrm{SiO}_{3}$ fue un silicato sintetizado anteriormente, también por el método sol-gel [Pfeiffer et al., 1998]. La figura 3.43 muestra el espectro obtenido con el equipo de centelleo líquido para el tritio. 


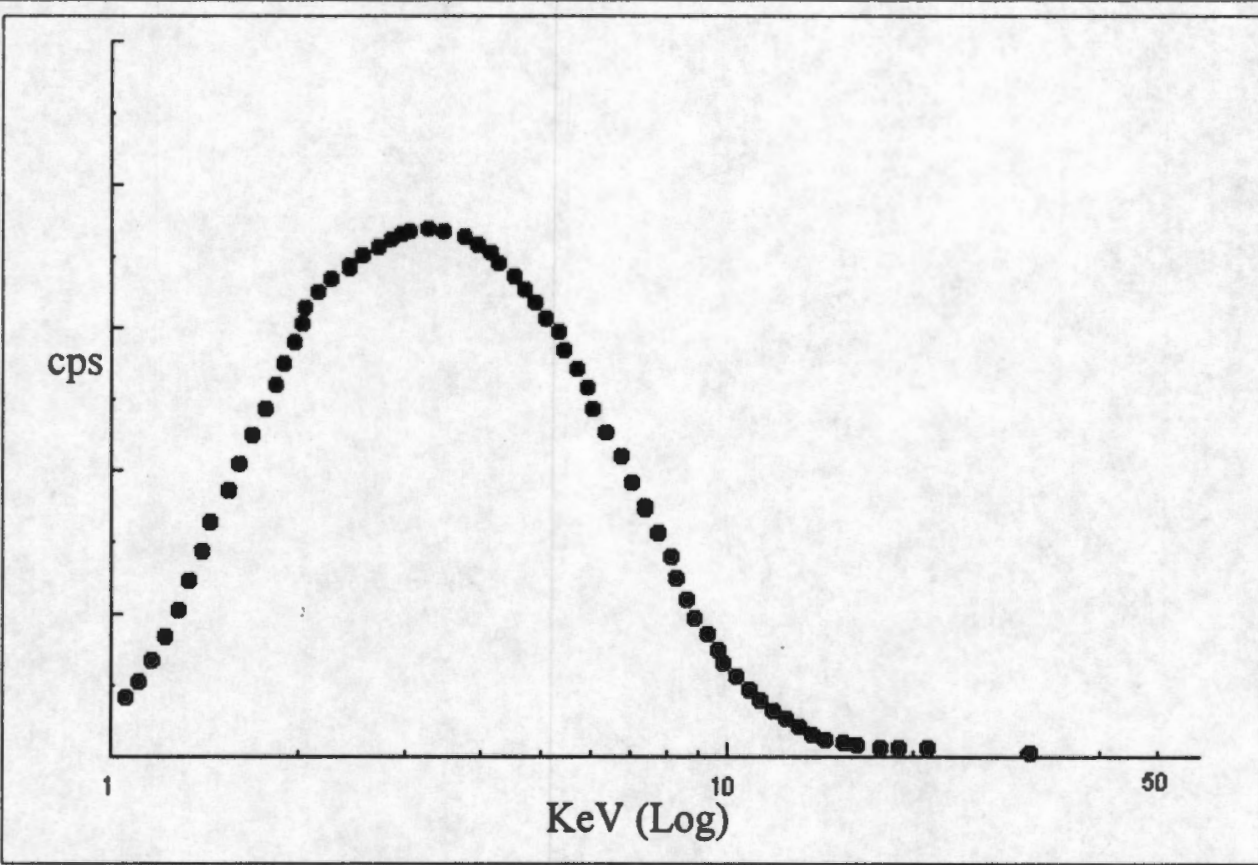

Fig. 3.43, Espectro tipo obtenido mediante el conteo

del tritio en las muestras analizadas.

Los resultados obtenidos para la extracción del tritio del $\mathrm{Li}_{2} \mathrm{ZrO}_{3}$ prueban que el sistema de extracción de tritio es adecuado, ya que son comparables con los resultados teóricos y experimentales obtenidos por Masabumi [Masabumi et al., 1998]. En la figura 3.44 se grafica el tiempo en que tarda en salir la máxima cantidad de tritio de las muestras (tiempo total de retención, $\theta$ ) en función de la temperatura.



Fig. 3.44, Comparación de los valores obtenidos para el tiempo total de retención $(\theta)$, en función del la temperatura, para el $\mathrm{Li}_{2} \mathrm{ZrO}_{3}$. 
Los puntos experimentales obtenidos en nuestro trabajo están por debajo de las curvas teóricas ( 1 y $0.1 \% \mathrm{H}_{2}$ ). Esto es debido a lo siguiente: Masabumi et al. toma en cuenta en su modelo teórico la presencia de vapor de agua que se inyecta junto con el gas de arrastre y expresa el tiempo de retención $(\theta)$ como:

$$
\theta_{T o t}=\theta_{T 2}+\theta_{T 2 O}+\theta_{H 2 O}+\theta_{\alpha}
$$

Donde, $\theta_{T 2}$ y $\theta_{T 2 O}$ son los tiempos totales de retención del tritio en forma de hidrógeno molecular y en forma de agua tritiada, respectivamente. $\theta_{H 2 O}$ es el tiempo total de retención del agua dentro del sistema y $\theta_{\alpha}$ es un factor relacionado con la estructura y la composición del cerámico. En nuestro caso, el gas de arrastre no contiene $\mathrm{H}_{2} \mathrm{O}$, por lo que este factor se podría restar del modelo teórico, de tal manera que, los puntos estarían más cerca de dicha curva.

La figura 3.45 presenta los resultados de la extracción de tritio en función del tiempo para las muestras de $\mathrm{Li}_{-} \mathrm{ZrSiO}_{4}$. De todas las muestras, al llegar al equilibrio, se extrajo entre el 60 y el $76 \%$ del tritio total producido. La extracción de tritio aumentó cuando la relación molar de $\mathrm{Li}: \mathrm{Zr}$ en el $\mathrm{Li}-\mathrm{ZrSiO}_{4}$ se incrementó también. Aparentemente las vacancias y las posiciones intersticiales dentro de la red del $\mathrm{ZrSiO}_{4}$ inhiben la difusión y la posterior extracción del tritio. En efecto, los átomos de tritio seguramente quedan atrapados en dichas posiciones, tal y como se probó en el estudio de dinámica molecular del $\mathrm{Li}_{2} \mathrm{O}$ (ver sección 3.4). Por lo tanto, cuando la red del $\mathrm{ZrSiO}_{4}$ está saturada con átomos de litio, no existen o hay menos vacancias disponibles para el tritio, el tritio entonces se difunde a través de la red hasta ser extraído. 


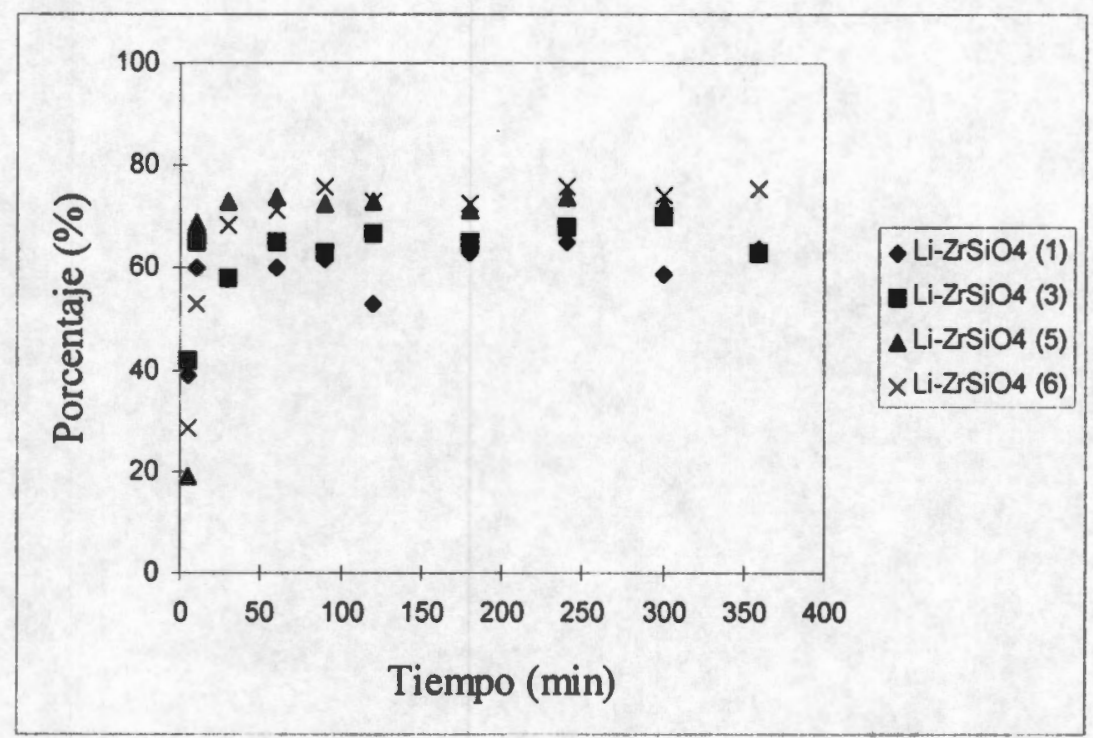

Fig. 3.45, Curvas de extracción de tritio en función del tiempo, para las diferentes muestras de $\mathrm{Li}-\mathrm{ZrSiO}_{4}$.

La figura 3.46 compara la extracción de tritio en función del tiempo para los compuestos $\mathrm{Li}_{2} \mathrm{ZrSi}_{6} \mathrm{O}_{15}, \mathrm{Li}-\mathrm{ZrSiO}_{4}$ con relación molar $\mathrm{Li}: \mathrm{Zr}$ de $6, \mathrm{Li}_{2} \mathrm{SiO}_{3}$ y $\mathrm{Li}_{2} \mathrm{ZrO}_{3}$. $\mathrm{La}$ curva de extracción de tritio del sistema $\mathrm{Li}-\mathrm{ZrSiO}_{4}$ con relación molar $\mathrm{Li}: \mathrm{Zr}$ de 6 se incluye en este gráfico ya que representa el mejor rendimiento. Las muestras en el equilibrio presentaron variaciones sustanciales en la cantidad de tritio extraído, pues varía entre el 78 y el $45 \%$.

Las muestras de $\mathrm{Li}_{2} \mathrm{SiO}_{3}$ y $\mathrm{Li}_{2} \mathrm{ZrO}_{3}$ presentaron comportamientos similares a los que se mencionan en la bibliografia [Johnson et al., 1981; Johnson et al., 1988; Charpin et al., 1989; Masabumi et al., 1998]. El $\mathrm{Li}_{2} \mathrm{SiO}_{3}$ presentó un buen rendimiento en la extracción de tritio, en efecto, se extrajo $78 \%$ del tritio total. Por otro lado, el $\mathrm{Li}_{2} \mathrm{ZrO}_{3}$ presentó un rendimiento moderado (45\%). Además, la velocidad de extracción del tritio del $\mathrm{Li}_{2} \mathrm{ZrO}_{3}$ fue diferente en comparación con el resto de los compuestos, puesto que todos los compuestos llegaron al equilibrio en aproximadamente 30 minutos, mientras que el $\mathrm{Li}_{2} \mathrm{ZrO}_{3}$ llegó al equilibrio en $300 \mathrm{~min}$. Este comportamiento se explica debido a la densa estructura que posee el $\mathrm{Li}_{2} \mathrm{ZrO}_{3}$ en comparación con el resto de los sistemas en estudio. Además, la 
densidad de litio en este compuesto es pobre (ver tabla 1.1). Se explica así que el tritio no se difunda libremente dentro del $\mathrm{Li}_{2} \mathrm{ZrO}_{3}$.

El $\mathrm{Li}_{2} \mathrm{ZrSi}_{6} \mathrm{O}_{15}$ presentó un buen rendimiento de extracción de tritio (60\%), pero el compuesto se daña con el campo de irradiación mixto, lo cual no es recomendable en un cerámico de recubrimiento dentro de un reactor de fusión termonuclear.



Fig. 3.46, Curvas de extracción de tritio en función del tiempo de calentamiento, para las muestras de $\mathrm{Li}_{2} \mathrm{ZrSi}_{6} \mathrm{O}_{15}, \mathrm{Li}-\mathrm{ZrSiO}_{4}(6)$, $\mathrm{Li}_{2} \mathrm{SiO}_{3}$ y $\mathrm{Li}_{2} \mathrm{ZrO}_{3}$.

Bajo estas condiciones de trabajo, el mejor rendimiento de extracción de tritio se obtuvo con las muestras de $\mathrm{Li}_{2} \mathrm{SiO}_{3}$ y de $\mathrm{Li}-\mathrm{ZrSiO}_{4}$ con relación molar $\mathrm{Li}: \mathrm{Zr}$ de 6 , de las que se extrajo hasta el $78 \%$ del tritio total producido. El rendimiento de extracción de tritio fue prácticamente idéntico para el $\mathrm{Li}_{-}-\mathrm{ZrSiO}_{4}(76 \%)$ y para el $\mathrm{Li}_{2} \mathrm{SiO}_{3}(78 \%)$, donde este ultimo se considera como uno de los mejores productores de tritio [Clemmer et al., 1985]. $\mathrm{El} \mathrm{ZrSiO}_{4}$ también es un material estable a altas temperaturas, incluso mejor que los zirconatos de litio que figuran entre los cerámicos de litio más estables a altas temperaturas. Por lo tanto, el sistema $\mathrm{Li}_{-} \mathrm{ZrSiO}_{4}$ debe considerarse un buen candidato para emplearlo como cerámico de litio dentro de los reactores de fusión. En la figura 3.47 se grafica el 
porcentaje de tritio extraído en función del cerámico correspondiente. La localización, en este gráfico, del $\mathrm{Li}_{-} \mathrm{ZrSiO}_{4}$ revela su inmejorable rendimiento en la extracción de tritio, así como su estabilidad térmica.

Tabla 3.12

Datos de la estabilidad térmica y el porcentaje de extracción de tritio, para los cerámicos estudiados.

\begin{tabular}{ccc}
\hline Cerámico de litio & $\begin{array}{c}\text { Temperatura de estabilidad } \\
\text { térmica }(\mathrm{K})\end{array}$ & $\begin{array}{c}\text { Porcentaje de extracción } \\
\text { de tritio (\%) }\end{array}$ \\
\hline $\mathrm{Li}^{-} \mathrm{ZrSiO}_{4}$ & 2773 & 76 \\
$\mathrm{Li}_{2} \mathrm{SiO}_{3}$ & 1473 & 78 \\
$\mathrm{Li}_{2} \mathrm{ZrO}_{3}$ & 1888 & 45 \\
$\mathrm{Li}_{2} \mathrm{ZrSi}_{6} \mathrm{O}_{15}$ & 1820 & 60 \\
\hline
\end{tabular}




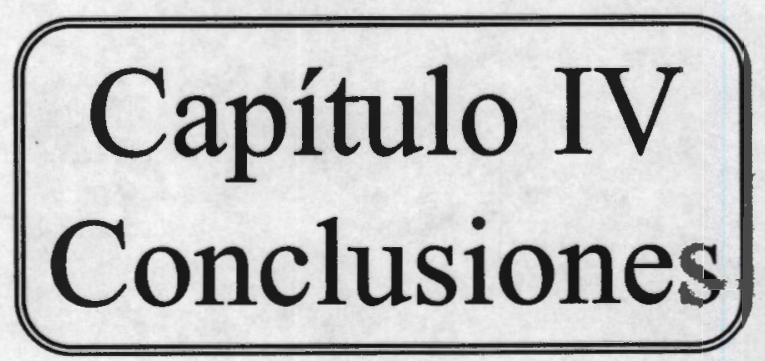




\section{Capítulo IV Conclusiones}

A continuación se presentan las conclusiones particulares de este trabajo:

Al variar el $\mathrm{pH}$ en la sintesis sol-gel del $\mathrm{Li}_{2} \mathrm{ZrO}_{3}$ se lograron establecer las condiciones para obtener el $\mathrm{Li}_{2} \mathrm{ZrO}_{3}$ puro, esto fue mediante el empleo de etóxido de zirconio y metóxido de litio en un medio ácido. Estas mismas condiciones fueron adecuadas para la síntesis sol-gel del $\mathrm{Li}_{2} \mathrm{ZrSi}_{6} \mathrm{O}_{15}$ y del $\mathrm{Li}_{-} \mathrm{ZrSiO}_{4}$.

Se logró preparar tanto el $\mathrm{Li}_{2} \mathrm{ZrSi}_{6} \mathrm{O}_{15}$ como el $\mathrm{Li}_{-}-\mathrm{ZrSiO}_{4}$ por el método de sol-gel [Pfeiffer (1) et al., 2000; Pfeiffer (2) et al., 2000]. En el caso de la síntesis del $\mathrm{Li}_{2} \mathrm{ZrSi}_{6} \mathrm{O}_{15}$ se obtuvieron mejores resultados que los resultados obtenidos por Quintana et al. [Quintana (2) et al., 1981], quienes sintetizaron el $\mathrm{Li}_{2} \mathrm{ZrSi}_{6} \mathrm{O}_{15}$ mediante una reacción por estado sólido.

Los estudios de dinámica molecular sugieren 'que para llevar a cabo la difusión de las diferentes especies presentes en el sistema (litio, oxígeno y tritio), el intervalo de temperaturas más adecuados se encuentra entre 500 y $700 \mathrm{~K}$ [Pfeiffer (3) et al., 2000].

Después de irradiar el $\mathrm{Li}_{2} \mathrm{ZrSi}_{6} \mathrm{O}_{15}$ en un campo mixto de radiación se encontraron cambios en su estructura y composición, así como en la morfología de las partículas. Por lo tanto, el $\mathrm{Li}_{2} \mathrm{ZrSi}_{6} \mathrm{O}_{15}$ es un material poco estable ante un campo mixto de radiación. Por otro lado, las muestras de $\mathrm{Li}_{-} \mathrm{ZrSiO}_{4}$ no presentaron ningún tipo de cambio al ser sometidos a un campo mixto de radiación, por lo que se puede concluir que el $\mathrm{Li}_{-}-\mathrm{ZrSiO}_{4}$ posee una gran estabilidad ante la radiación.

Las muestras de $\mathrm{Li}-\mathrm{ZrSiO}_{4}$ presentaron buenos rendimientos de extracción de tritio. La extracción de tritio aumentó cuando se incrementó la razón molar de Li:Zr. Las vacancias en el $\mathrm{ZrSiO}_{4}$ inhiben la difusión y la posterior extracción de tritio. Si estas 
vacancias están saturadas con litio, el tritio se difunden más fácilmente obteniéndose mejores rendimientos en su extracción.

Finalmente, de una manera general se puede concluir que el $\mathrm{Li}_{2} \mathrm{ZrSi}_{6} \mathrm{O}_{15}$ no es estable ante la radiación y es un generador moderado de tritio. En cambio, el $\mathrm{Li}_{-}-\mathrm{ZrSiO}_{4}$ es altamente estable ante la radiación y es un buen generador de tritio, además de su gran estabilidad térmica. Por lo tanto, el $\mathrm{Li}_{-} \mathrm{ZrSiO}_{4}$ podría utilizarse con grandes ventajas en los reactores de fusión termonuclear. 


\section{Bibliografía}




\section{Bibliografía}

Abdou M., Hollenberg G. W. and Johnson C. E., J. Nucl. Mater., 84 (1984) 137.

Aboites V., Fusión Nuclear por Medio de Láser, Fondo de Cultura Económica, La Ciencia desde México, México, 135 (1993).

Ackland G. J., Phys. Rev. Lett., 80 (1998) 2333.

Adams D. J. and Mc Donald Y. R., Physica B, 79 (1975) 159.

Allen M. P. and Tildesley D. J., Computer Simulations of Liquids, Clarendon Press-Oxford, 1987.

Alvani C., Carconi P. L., Casadio S. and Moauro A., J. Nucl. Mater., 208 (1994) 259.

Alvarez L. J., León L. E., Fernandez-Sanz J., Capitán M. J. and Odriozola J. A., Phys. Rev. B, 50 (1994) 2561.

Alvarez L. J., San-Miguel M. A. and Odriozola J. A., Phys. Rev. B, 59 (1999) 11303.

Anderson J. S. and Ogden J. S., J. Chem Phys., 51 (1969) 142.

Arons R. M. and Poeppel R. B., J. Nucl. Mater., 103-104 (1981) 573.

Auvray-Gély M. H., Dunlop A. and Hobbs R., J. Nucl. Mater., 133-134 (1985) 230.

Baldwin D., J. Nucl. Mater., 122-123 (1984) 871.

Boilot J. P. and Colomban P., Superionic Conductors from the Sol-Gel Process, Sol-Gel Technology for Thin Films, Fibres, Preforms, Electronics and Specialty Shapes, L. Klein Editor, Notes Publications, Park Ridge, New Jersey, USA, 1988, p 303.

Bonal J. P., Measures Post-irradiation des Quantites Residuelles de tritium et d'helium 4 dans l'aluminate de lithium, Commissariat a l'Energie Atomique, France (1987).

Breitung W., Elbel H., Lebkücher J., Schumacher G. and Werle H., J. Nucl. Mater., 155157 (1988) 507.

Brinker C. J. and Scherer G. W., Sol-Gel Science, The Physics and Chemistry of Sol-Gel Processing, (Academic Press, USA, 1990).

Brown M. E. Introduction to Thermal Analisys, (Chapman and Hall, USA, 1988).

Carconi P. L., Casadio S. and Moauro A., Fus. Tech., 21 (1992) 775.

Cerius $^{2}$, Quantum Mechanics-Physics of Molecular Simulation Inc. (San Diego, Cal., USA, 1997). 
Charpin J., Botter F., Briec M., Rasneur B., Roth E., Roux N. and Sannier J., Fusion Eng. Des., 8 (1989) 407.

Clemmer R. G., Finn P. A., Misra B., Billone M. C., Fischer A. K., Tam S. W., Johnson C. E. and Scandora A. E., J. Nucl. Mater., 133-134 (1985) 171.

Connolly T. J., Fundámentos de Energía Nuclear, Limusa, México (1983).

D’Haeseleer W. D., Plasma Phys. Control Fusion, 41 (1999) B25.

Demontis P. and Suffritti G. B., Modelling of Structure and Reactivity in Zeolites, Molecular Dynamics Studies on Zeolites, Edited by Catlow C. R. A., USA, (1992).

De-Vita A., Gillan M. J., Lin J: S., Payne M. C., Stich Y. and Clarke L. J., Phys. Rev. Lett., 68 (1992) 3319.

Dai-Kai S., Fusion Power Program, 26 (1994) 1061.

Dunn P. J., Rouse R. C., Cannon B. and Nelen J. A., Am. Mineral., 62 (1977) 416.

Flipot A. J., Diels P. and Lecocq R., J. Nucl. Mater., 133-134 (1985) 1226.

Haile J. M., Molecular Dynamics Simulation Elementary Methods, John Wiley \& Sons 1997.

Hardy A. B. and Rhine W. E., Chem. Proc. Adv. Mater., 577 (1992).

Hollenberg G. W. and Baldwin D., J. Nucl. Mater., 133-134 (1985) 242.

Huheey J. E., Química Inorgánica Principios de Estructura y Reactividad, Segunda edición, Harla, México D. F., México (1981).

Hyde B. G. and Anderson S., Inorganic Crystal Structures, J. Wiley \& Sons, USA; (1989) 272.

Jacobs J. P., San-Miguel M. A., Álvarez.L. J. and P. Bosch, J. Nucl. Mater., 232 (1996) 131.

Jimenez-Becerril J., Bosch P. and Bulbulian S., J. Nucl. Mater., 185 (1991) 304.

Johnson C. E. and Hollenberg G. W., J. Nucl. Mater., 103-104 (1981) 547.

Johnson C. E., Kummerer K. R. and Roth E., J. Nucl. Mater., 155-157 (1988) 188.

Johnson C. E., Kopasz J. P. and Tam S. W., J. Nucl. Mater., 248 (1997) 91.

Johnson C. E., J. Nucl. Mater., 270 (1999) 212.

Khon W. and Sham L. J., Phys. Rev. A-140 (1965) 1133.

Kopasz J. P., Seils C. A. and Johnson C. E., J. Nucl. Mater., 191-194 (1992) 231. 
Krishnan S., Ansell S. and Price D. L., J. Am. Ceram. Soc., 81 (1998) 1967.

Kummerer K. R. and Ritzhaupt-Kleissl, J. Nucl. Mater., 179-181 (1991) 831.

Lederer C. M., Hollander J. M. and Perlman Y., Table of Isotopes, John Wiley \& Sons, USA, 1978.

Livage J., J. Solid State Chem., 64 (1986) 322.

Llorens M., Menzell A. y Villarubia M., Física y Tecnología del Reactor de Fusión, Investigación y Ciencia, Edición en Español de Scientific American, 51 (1980).

Martinell B. J., Los Prometeos Modernos o el Esfuerzo para Controlar la Fusión Nuclear, Fondo de Cultura Económica, La Ciencia desde México, México, 106 (1993).

Masabumi N. and Baba A., J. Nucl. Mater., 257 (1998) 162.

Montanaro L. and Lecompte J. P., J. Mater. Sci., 27 (1992) 3763.

Mori T., Yamamura H., Kobayashi H. and Mitamura T., J. Mater. Sci., 28 (1993) 4970.

Muller O. and Roy R., Chem. non-Metal. Mater., 4 (1974) 83.

Murray R. L., Nuclear Energy, Introduction to the Concepts, Systems and Applications of Nuclear Processes, Pergamon Press, Canada (1988).

Nagai M., Hibino M., Nishino T. and Noda K., J. Nucl. Mater., 12 (1993) 107.

Nakamoto K., Infra-red and raman Spectra of Inorganic and Coordination Compounds, (Wiley \& Sons, USA, 1986).

Noda K., Ishii Y., Ohno H. and Watanabe H., Adv. Ceram., 27 (1990) 173.

Nuñez Y., Poré J. V., Cordoncillo E., Escribano P., Kozhukharov V. y Carda J. B., Bol.

Soc. Esp. Ceram. y Vidrio, 37 (1998) 291.

O'kula K. and Vogelsang W., Fus. Tech., 8 (1985) 2054.

Ohno H., Konishi K., Nagasaki T., Kurasawa T., Katsuta H. and Natanabe H., J. Nucl. Mater., 133-134 (1985) 181.

Pfeiffer H., Bosch P. and Bulbulian S., J. Nucl. Mater., 257 (1998) 309.

Pfeiffer H. (1), P. Bosch, J. A. Odriozola, A. López, J. A. Ascencio and S. Bulbulian, J. Mater. Res., 15 (2000) 1490.

Pfeiffer H. (2), P. Bosch and S. Bulbulian, J. Mater. Chem., 10 (2000) 1255.

Pfeiffer H. (3), J. Sánchez-Sánchez and L. J. Álvarez, J. Nucl. Mater., 280 (2000) 295.

Porter D. L. and Krsul J. R., ANL/FPP/TM167 (1992). 
Quintana P (1). and West A. R., Mineral. Mag., 44 (1981) 361.

Quintana P. (2) and West A. R., Trans. Br. Ceram. Soc., 80 (1981) 91.

Rasneur B., Adv. Ceram., 27 (1990) 63.

Robinson J. W., C. R. C. Handbook of Spectroscopy, Vol. II (C. R. C. Press, USA, 1994).

Ross S. D., Inorganic Infra-red and Ramaan Spectra, (Mc Graw Hill, USA, 1972).

Roth E., Botter J. J., Briec F., Chenebault M., Masson P., Rasneur B. and Roux N.., J. Nucl. Mater., 133-134 (1985) 275.

Ṙoux N., Johnson C. E. and Noda K., J. Nucl. Mater., 191-194 (1992) 15.

Sanchez-Ocampo A. and Jimenez-Reyes M., Rev. Mex. Fis., 2 (1985) 329.

San-Miguel M. A., Fernandez-Sanz J. and Odriozola J. A., Phys. Rev. B, 57 (1998) 741.

Schiller P., J. Nucl. Mater., 206 (1993) 113.

Shah R., De-Vita A., Heine V. and Payne M. C., Phys. Rev. B, 52 (1996) 1274.

Smaihi M., Boilot J. P., Botter F., Mougin J. and Boncoeur M. J., J. Nucl. Mater., 185 (1991) 19.

Stiles A. B., Catalyst Supports and Supported Catalyts (Butterworth Publications, Stoneham, USA, 1987).

Szu S. P., Greenblatt M. and Klein L. C., J. Non-Cryst. Sol., 124 (1990) 91.

Tanaka S. and Tanigushi M., J. Nucl. Mater., 248 (1997) 101.

Vollath D., Wedemeyer H. and Günther E., J. Nucl. Mater., 133-134 (1985) 2221.

Valenzuela M. A., Bosch P., Jimenez-Becerril J. and Bulbulian S., J. Am. Ceram. Soc., 79 (1996) 455 .

West A. R., Solid State Chemistry and its Applications, John Wiley \& Sons, USA, (1990).

Weast R. C. and Astle M. J. editors; "C. R. C. Handbook of Chemistry and Physics", $63^{\text {rd }}$ edition, USA, 1982.

Yang L., Medico R., Baugh W. and Schultz K., J. Nucl. Mater., 103 \& 104 (1981) 585. 


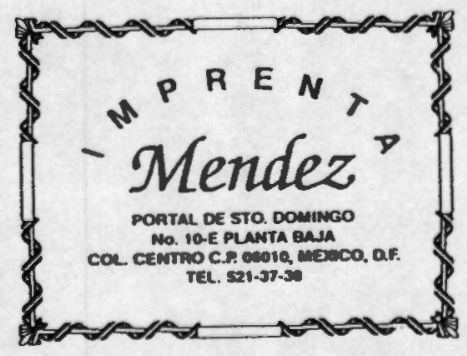


